For mul at i on for Shear For ce- Rel at i ve Di spl acement Rel at i onshi p of L- shape Shear Connect or in St eel - Concr et e Composi te Struct ures

\begin{tabular}{|l|l|}
\hline 著者 & ROS Sot y \\
\hline year & 2011- 09 \\
\hline その他のタイトル & $\begin{array}{l}\text { 鋼コンクリート合成構造におけつるL形鋼シアコネク } \\
\text { タのせん断力- 相対変位関係の定式化 }\end{array}$ \\
\hline 学位授与番号 & 26402甲第210号 \\
\hline URL & $\mathrm{ht} \mathrm{t} \mathrm{p:} \mathrm{//hdl} \mathrm{.} \mathrm{handl} \mathrm{e.} \mathrm{net} / 10173 / 779$ \\
\hline
\end{tabular}




\title{
Formulation for Shear Force-Relative Displacement Relationship of L-shape Shear Connector in Steel-Concrete Composite Structures
}

\author{
ROS Soty
}

\author{
A dissertation submitted to \\ Kochi University of Technology \\ in partial fulfillment of the requirements for the degree of \\ Doctor of Engineering
}

Department of Infrastructure Systems Engineering

Graduate School of Engineering

Kochi University of Technology

Kochi, Japan

August 2011 


\section{ACKNOLEDGEMENTS}

I would like to express my deepest gratitude with full respect to my supervisor, Professor Doctor Hiroshi Shima for his endorsement giving me numerous of creative suggestions and guidance on my research work. I am greatly indebted to him that cannot be described in words for his enduring patience and continuous encouragement throughout my study. Without him this research work would have not yet been achieved.

My grateful thanks also go to all members of my thesis supervising committee, Prof. Nobumitsu Fujisawa, Prof. Yoshiro Kai, Prof. Masataka Takagi, and Assoc. Prof. Masahiro Ouchi for their valuable comments on my thesis. By means of their comments the scope of my work has been enhanced.

My gratitude goes to Mr. Hideo Miyazi for his helpful technical instructions during my experimental work. My gratitude also extends the members of concrete laboratory of Infrastructure Systems Engineering Department for their helpful assistances during the experimental work.

Special thanks are due to all members of IRC, International Relationship Center for their helpful support for all administration works during my study. With their helps I feel like home living and working here.

Finally, I would like to dedicate this thesis to my wife, NUON Puthearene for her full support and encouragement for every day life, and to my first son, ROS Sotypiseth born on $3^{\text {rd }}$ August, 2011. The dedications also go to my family for their guidance and supports through all difficult times. 


\begin{abstract}
Partial interaction between steel and concrete has become a challenge in more rational design and more economical construction of steel-concrete composite structures. According to the design specifications for hybrid structures of JSCE 2009, the formulation of shear force and slip relationship of headed stud, plate shape, and block dowel shear connectors have already been proposed. However, that of L-shape shear connector has not yet been identified. Therefore, this study was conducted to formulate the relationship between shear force and relative displacement relationship of L-shape shear connector in steel-concrete composite structures.

The investigation has been made through the experiments and compared with the FEM analyses. Beam type specimens in which the shear connectors were installed to be subjected to strut compressive force were constructed and tested. Concrete strength, size of shear connector, and strut angle are the main parameters which were typically selected by means FEM analyses conducted during the experimental planning.
\end{abstract}

Consequently, different failure modes of L-shape shear connectors, split failure, shear failure/concrete crush were identified. The possibility of split failure mode and shear failure/concrete crush mode were found to be controlled by the strut angle and the thickness to height ratio of the shear connector. Moreover, there exists a critical strut angle separating the two different failure modes. Accordingly, an equation to predict the critical strut angle was developed and it was a function of thickness to height ratio of the shear connector.

Furthermore, the ultimate shear force of L-shape shear connector calculated by means of the design specifications for hybrid structures of JSCE 2009 was found to be too conservative when the strut angles were small. Accordingly, the formulas to predict the ultimate shear capacity of Lshape shear connector at split failure and at shear failure/concrete crush were developed and proposed. The equations were found to be functions of thickness to height ratio of the shear connector, the height and with width of the shear connector, the concrete strength, and the strut angle. The applicable ranges of the formulas were proposed for the strut angle between 20 to 45 degrees.

More importantly, the relationships between shear force and relative displacement of L-shape shear connector can be represented by a unique enveloped curve by normalizing shear force by the ultimate shear force and the relative displacement by the height of the shear connector. The 
unique enveloped curve was observed regardless of concrete strengths, sizes of shear connectors and strut angles. Hence, a unique formula to predict the shear force-relative displacement relationship of L-shape shear connector subjected to strut compressive force was developed and proposed. Meanwhile, the ultimate relative displacements of L-shape shear connectors were found approximately 0.02 times the height of the shear connector. 


\section{TABLE OF CONTENTS}

Page No.

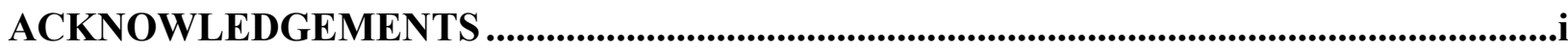

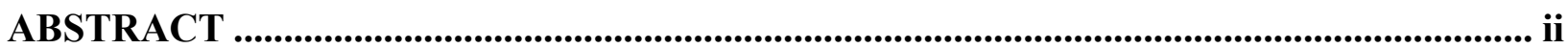

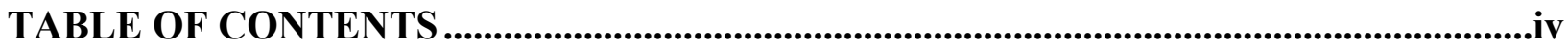

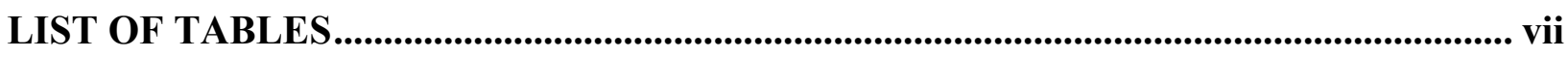

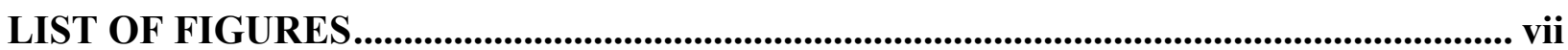

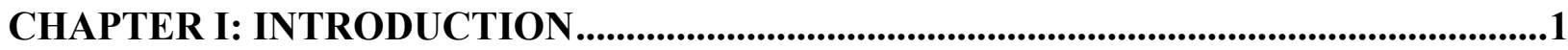

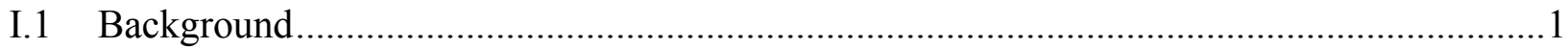

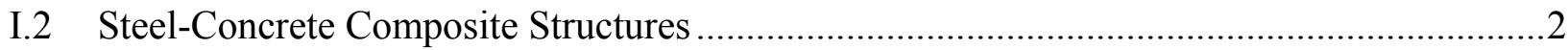

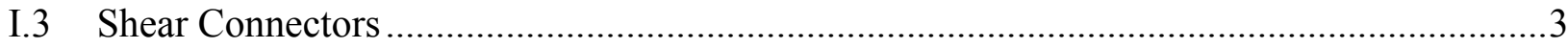

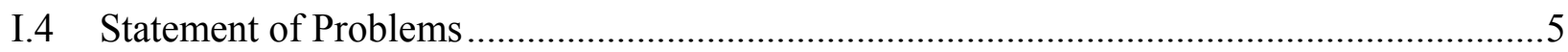

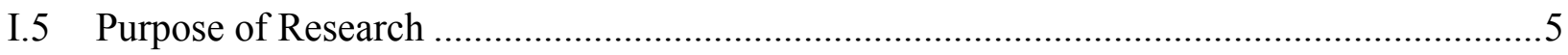

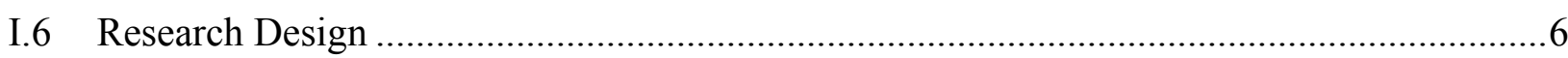

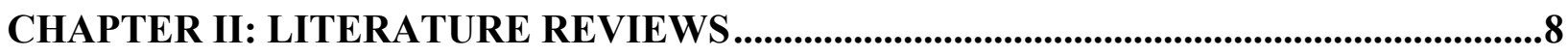

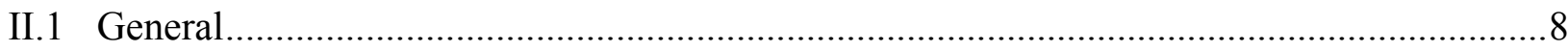

II.2 Existing Test Methods for Shear Connectors ........................................................ 8

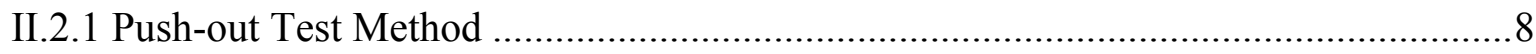

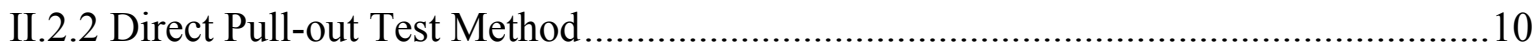

II.2.3 Steel-Concrete Sandwich Beam Test Method........................................................ 13

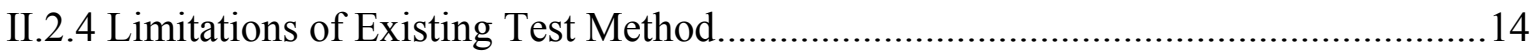

II.3 Existing Formulas of Shear Force-Slip Relationship of Shear Connectors........................15

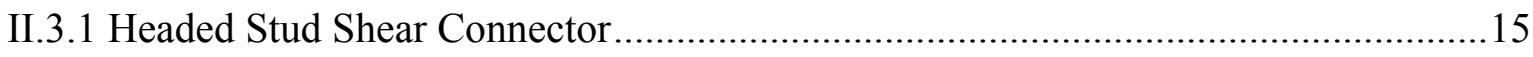

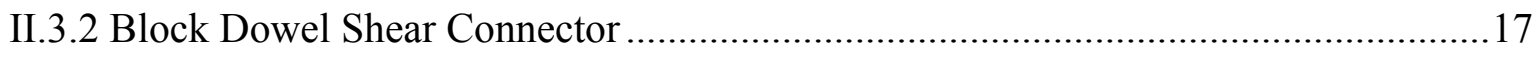


III.1 General

III.2 Beam Type Test Method

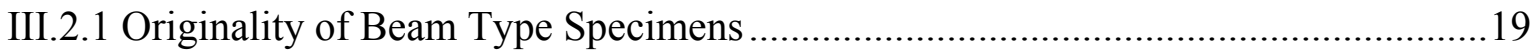

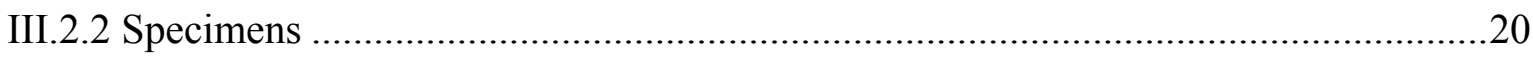

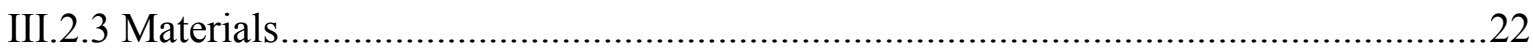

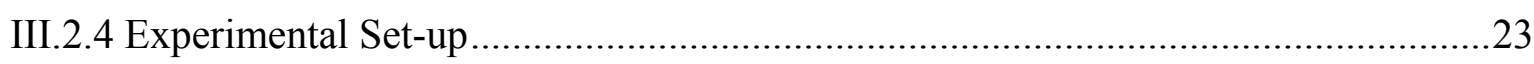

CHAPTER IV: EXPERIMENTAL RESULTS, ANALYSES, AND DISCUSSIONS .26

IV.1 L-Shape Shear Connector under Strut Compressive Force with Strut Angle of

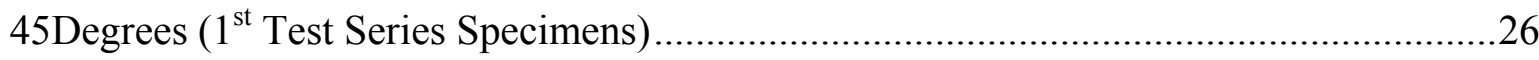

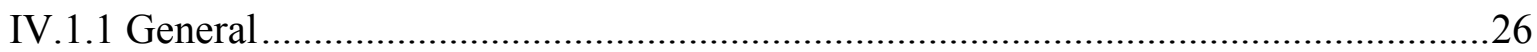

IV.1.2 Failure Mode of L-Shape Shear Connectors $\left(\theta=45^{\circ}\right)$........................................26

IV.1.3 Ultimate Shear Force of Shear Connector Failed in Split Failure Mode $\left(\theta=45^{\circ}\right) \ldots 28$

IV.1.4 Shear Force-Slip Relationship of L-shape Shear Connector ..................................34

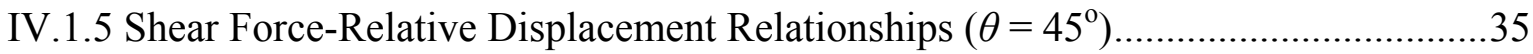

IV.1.6 FEM Analyses for Shear Force-Relative Displacement Relationships $\left(\theta=45^{\circ}\right) \ldots . .37$

IV.1.7 FEM Analyses for Eq.IV.4 Verification ...........................................................41

IV.1.8 Formulation for Shear Force-Relative Displacement Relationships $\left(\theta=45^{\circ}\right)$.......44

IV.2 L-Shape Shear Connector under Strut Compressive Force with Strut Angle

Smaller Than 45 Degrees $\left(2^{\text {nd }}\right.$ Test Series Specimens) .................................................52

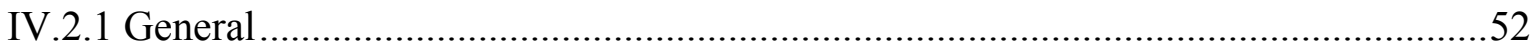

IV.2.2 FEM Analyses for Parameter Selection for 2nd Test Series Specimens ..................52

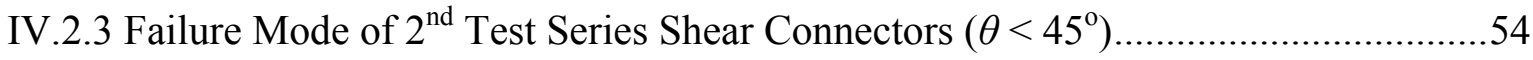

IV.2.4 Ultimate Shear Force of L-shape Shear Connector $\left(\theta \leq 45^{\circ}\right) \ldots \ldots \ldots \ldots \ldots \ldots \ldots \ldots \ldots \ldots \ldots . . .61$

IV.2.5 Ultimate Shear Force of Shear Connector, Split Failure Mode $\left(\theta_{0}<\theta \leq 45^{\circ}\right) \ldots \ldots \ldots .62$

IV.2.6 Ultimate Shear Force of Shear Connector in Concrete Crush/Shear 
Failure Mode. .65

IV.2.7 Shear Force-Slip Relationship of L-shape Shear Connector $\left(\theta \leq 45^{\circ}\right)$ 69

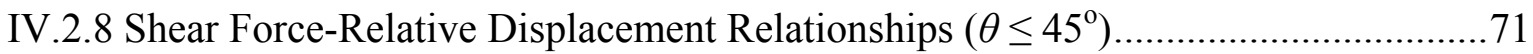

IV.2.9 Formulation for Shear Force-Relative Displacement Relationships $\left(\theta \leq 45^{\circ}\right) \ldots \ldots . . .73$

IV.2.10 Modification of Shear Capacity Formula ….......................................................

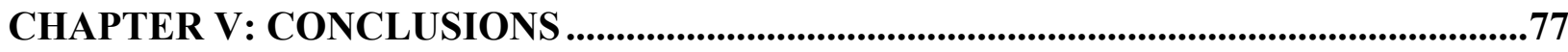

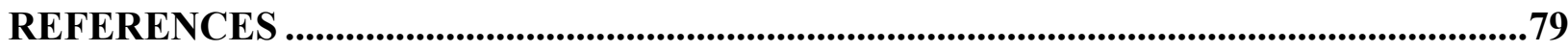

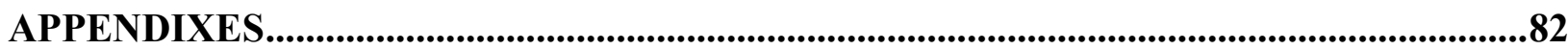




\section{LIST OF TABLES}

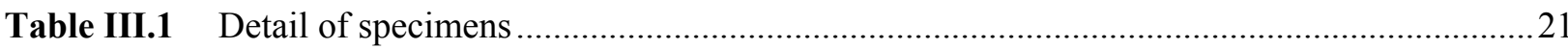

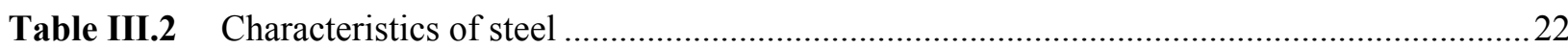

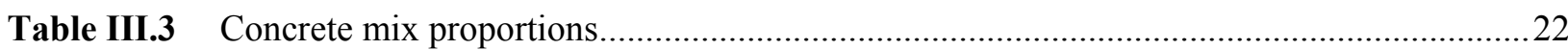

Table IV.1.1 Ultimate shear forces and k1 values obtained from experimental results ...........................32

Table IV.1.2 Ultimate Shear force of shear connector from experiments and calculations ......................34

Table IV.1.3 Ultimate shear forces from FEM analyses and calculation by means of Eq.IV.4 ...............42

Table IV.1.4 FEM analyses and calculations for size of surrounding concrete effects............................43

Table IV.2.1 Ultimate shear force of shear connector obtained from experiment and calculation results.62

Table IV.2.2 Ultimate shear forces obtained from experiments and calculations by means of Eq.IV.4 and Eq.IV.7. 62

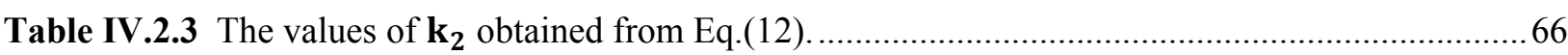

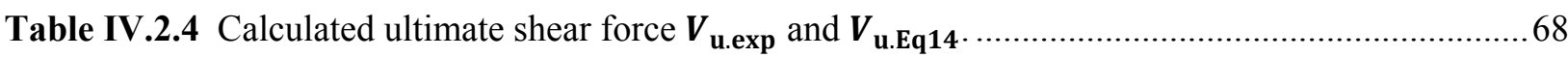

\section{LIST OF FIGURES}

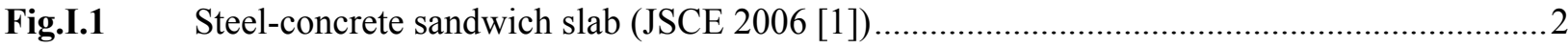

Fig.I.2 Various sectional types of composite column (JSCE 2006 [1]) ............................................ 3

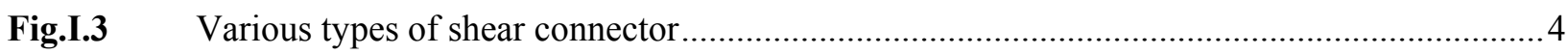

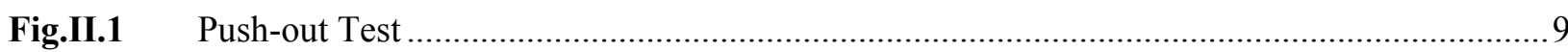

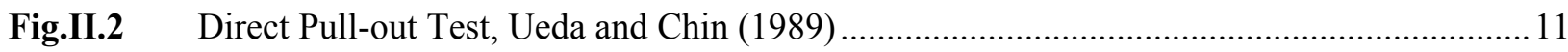

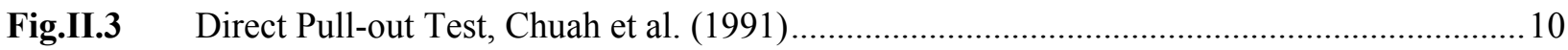

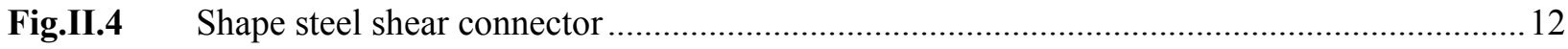

Fig.II.5 Layout of steel-concrete sandwich beam test ................................................................... 13

Fig.II.6 Shear force-slip relationship of headed stud shear connector................................................ 16

Fig.II.7 Shear force-slip relationship of plate shape shear connector............................................... 17

Fig.II.8 Shear force-slip relationship of block dowel shear connector .............................................. 17

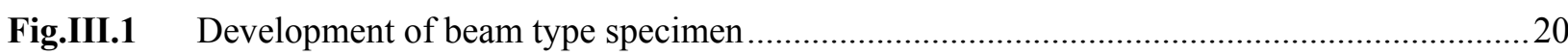

Fig.III.2 Detail of beam type specimen and shear connector............................................................21

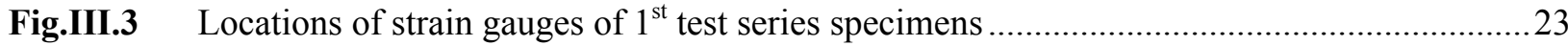

Fig.III.4 Detail of relative displacement measurement ...................................................................24

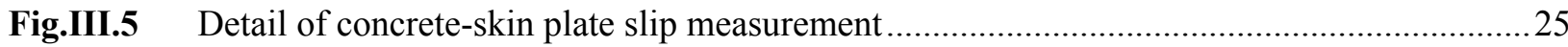

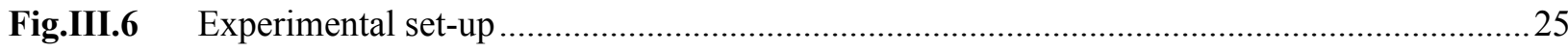

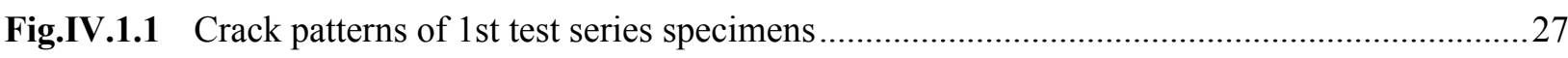

Fig.IV.1.2 Load-mid span deflection relationships of 1 st test series specimens....................................28

Fig.IV.1.3 Shear force and principal tensile strain relationship ........................................................29 
Fig.IV.1.4 L-shape shear connector before and at split failure

Fig.IV.1.5 Model of L-shape shear connector subjected to strut compressive force $\left(\boldsymbol{\theta}=\mathbf{4 5}^{\mathbf{0}}\right)$............31

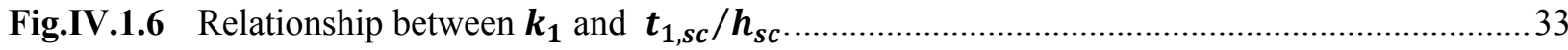

Fig.IV.1.7 The comparison between ultimate shear force from experiments and calculations ...............33

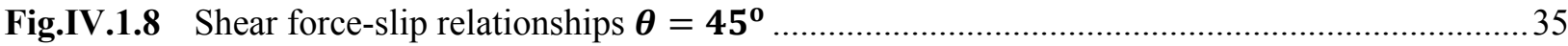

Fig.IV.1.9 Shear force-relative displacement relationship before the occurrence of crack from the

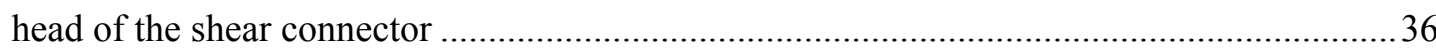

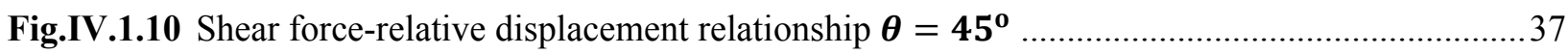

Fig.IV.1.11 Development of FEM Mesh of beam type specimen …........................................................38

Fig.IV.1.12 Failure mode of shear connector in FEM analysis and beam type specimen .........................39

Fig.IV.1.13 Experimental Results and FEM analyses results S-600-200-9-25.3-45 ...............................40

Fig.IV.1.14 Experimental Results and FEM analyses results S-300-100-9-25.1-45 ..............................40

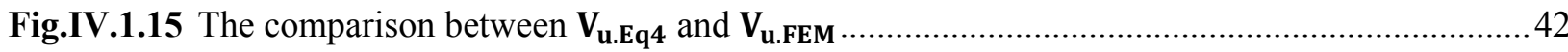

Fig.IV.1.16 Shear force-relative displacement relationship observed in FEM analyses..........................43

Fig.IV.1.17 $\boldsymbol{V}-\boldsymbol{\delta}$ relationships for the same size proportion shear connectors......................................4 44

Fig.IV.1.18 $\boldsymbol{V} / \boldsymbol{V}_{\boldsymbol{u}}-\boldsymbol{\delta} / \boldsymbol{h}_{\boldsymbol{s} \boldsymbol{c}}$ relationships for the same size proportion shear connectors ....................... 45

Fig.IV.1.19 $\boldsymbol{V}-\boldsymbol{\delta}$ relationships for different thickness of shear connectors .......................................... 46

Fig.IV.1.20 $\boldsymbol{V} / \boldsymbol{V}_{\boldsymbol{u}}-\boldsymbol{\delta} / \boldsymbol{h}_{\boldsymbol{s c}}$ relationships for different thickness of shear connectors ............................ 47

Fig.IV.1.21 $\boldsymbol{V}-\boldsymbol{\delta}$ relationships for different concrete strength ........................................................... 48

Fig.IV.1.22 $\boldsymbol{V} / \boldsymbol{V}_{\boldsymbol{u}}-\boldsymbol{\delta} / \boldsymbol{h}_{\boldsymbol{s} \boldsymbol{c}}$ relationships for different concrete strength ............................................... 48

Fig.IV.1.23 $\boldsymbol{V}-\boldsymbol{\delta}$ relationships for different height of shear connectors ..............................................49

Fig.IV.1.24 $\boldsymbol{V} / \boldsymbol{V}_{\boldsymbol{u}}-\boldsymbol{\delta} / \boldsymbol{h}_{\boldsymbol{s c}}$ relationships for different height of shear connector..................................50

Fig.IV.1.25 $\boldsymbol{V} / \boldsymbol{V}_{\boldsymbol{u}}-\boldsymbol{\delta} / \boldsymbol{h}_{\boldsymbol{s} \boldsymbol{c}}$ relationships from experimental results and Eq.IV.5 …...........................51

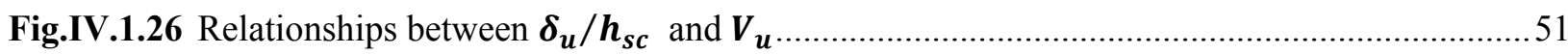

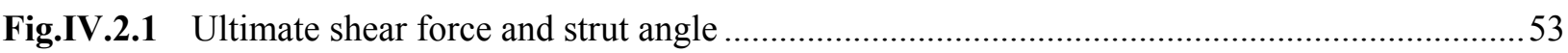

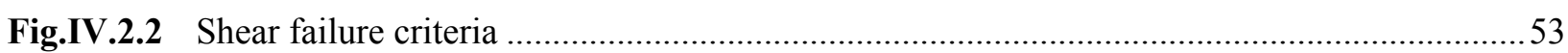

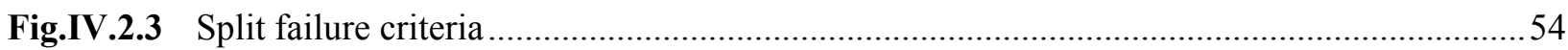

Fig.IV.2.4 Different failure modes of shear connectors in 2nd test series specimens. .........................55

Fig.IV.2.5 Crack patterns of specimens failed in split failure mode....................................................56

Fig.IV.2.6 Crack patterns of specimens failed in concrete crush and shear failure mode. .....................56

Fig.IV.2.7 Relationships between shear force and strain in the vertical part of the shear connectors

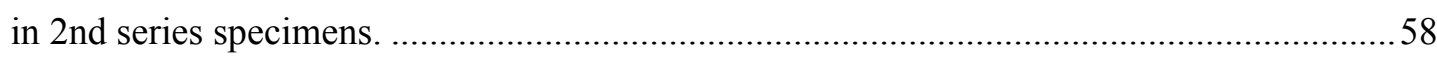

Fig.IV.2.8 Relationships between shear force and strain in the vertical ...............................................59

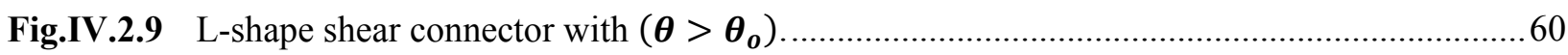

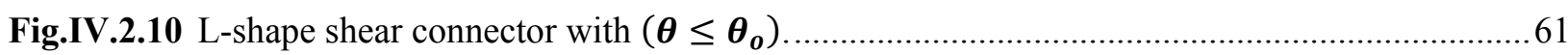

Fig.IV.2.11 Model of L-shape shear connector failed in split failure mode. ….......................................... 64 
Fig.IV.2.12 Ultimate shear force of shear connectors in split failure mode 64

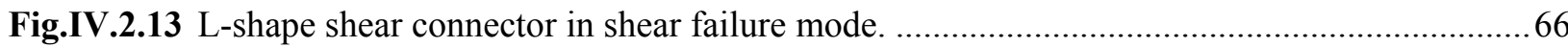

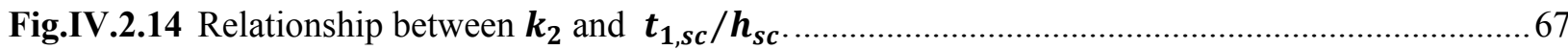

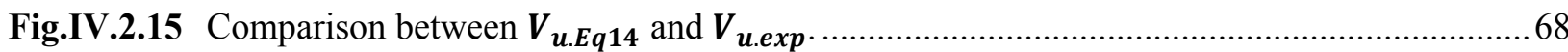

Fig.IV.2.16 Shear force-slip relationships of 1 st and 2nd test series shear connectors. ...........................70

Fig.IV.2.17 Shear force-slip relationships of shear connectors. ............................................................ 71

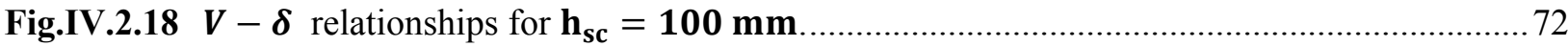

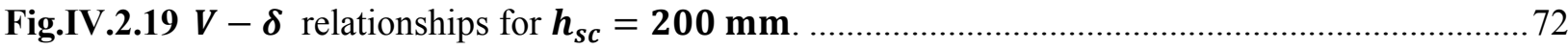

Fig.IV.2.20 $\boldsymbol{V}-\boldsymbol{\delta}$ relationships of 1st and 2nd test series shear connectors.....................................73

Fig.IV.2.21 $\boldsymbol{V} / \boldsymbol{V}_{\mathbf{u}}-\boldsymbol{\delta} / \boldsymbol{h}_{\mathbf{s c}}$ relationships of shear connectors failed in split failure modes....................... 74

Fig.IV.2.22 $\boldsymbol{V} / \boldsymbol{V}_{\boldsymbol{u}}-\boldsymbol{\delta} / \boldsymbol{h}_{\boldsymbol{s c}}$ relationships of shear connectors failed in concrete crush or shear

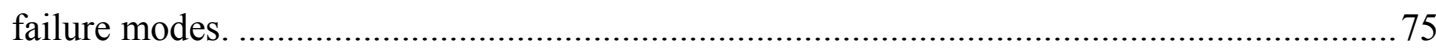

Fig.IV.2.23 $\boldsymbol{V}_{\boldsymbol{u}}-\boldsymbol{\delta}_{\boldsymbol{u}} / \boldsymbol{h}_{\boldsymbol{s c}}$ relationships of 1 st and 2nd test series shear connectors.................................. 75 


\section{CHAPTER I}

\section{INTRODUCTION}

\section{I.1Background}

Steel-concrete composite structure has been popular in advance concrete construction technology in these recent years. This kind of structure has been widely used instead of the conventional reinforced concrete structure in many purposes including buildings, bridges, retaining walls, as well as underground structures. It has been becoming under high demand for civil engineer societies due to its high durability and constructability.

One of the most important components in steel-concrete composite structure is the shear connector. It has been known to be a structure component used to mechanically connect steel with concrete and it plays a vital role in the composite structure. It prevents the separation at steelconcrete interface and transfers shear force, delamination force, and bearing force from steel to concrete and vice versa [1]. The monolithic behavior of steel-concrete composite structure is highly influenced by the performance of the shear connector. Accordingly, several researches have been conducted to examine the mechanical properties of the shear connector to fulfill the needs of civil engineers in the designing work. Most recently, in 2006, Japanese Society of Civil Engineers has developed a guideline for performance verification of steel-concrete composite structures in which the equations to design the shear capacity of the shear connectors were introduced.

However, the focuses of civil engineers' point of view are not only the stability and the constructability, but also the economy and the rationality. Therefore, many researchers have been trying to develop a design method which meets the present demands. Similarly, this research was conducted to propose a rational design model for L-shape shear connector which is recently used in the steel-concrete composite structures. Not only the shear resisting capacity of the shear connector itself, but also its partial interaction mechanisms represented by shear force-slip relationships are included in this study. The propose equations were developed by means of experimentations and FEM analyses. Moreover, the applicable ranges of the proposed equations were also introduced. 
Prior to the experimental program, the properties of steel-concrete composite structures and the existing shear connectors used in practices are briefly described in the following subchapters.

\section{I.2 Steel-Concrete Composite Structures}

Steel-concrete composite structure is a structural member, which is composed of steel and concrete behaving as a monolithic member. The components of the structure generally consist of steel, concrete, stiffener, shear connector, shear reinforcing steel plate and diaphragm. The definitions and the functions of these components in the structure are available in the Guidelines for Performance Verification for Hybrid Structures of JSCE 2006 [1]. According to the guidelines, the performance of the structure is highly influenced by the presence of these components. For instant, it has been confirmed that the monolithic behavior of steel-concrete composite structure is highly influenced by the performance of the shear connector.

Fig.I.1 illustrates a typical steel-concrete sandwich slab given by JSCE 2006 [1]. The core concrete was sandwiched by the steel skin plate, while the steel and concrete were connected each other by shear connectors. Steel-concrete composite members could be used as slab, beam, and column. Meanwhile, the typical sections of composite columns are given in Fig.I.2.

The design shear capacity of steel-concrete composite beam, slap, column, and shear connectors are available in the Design Specifications for Steel-Concrete Composite Structure of JSCE 2009[2] as well as in the Design Code for Steel-Concrete Sandwich Structures, JSCE 1992[3].

In the design of steel-concrete composite structures, the mechanical properties of the shear connectors are always concerned. The following subchapter presents the details of the shear connectors most recently used in practice.

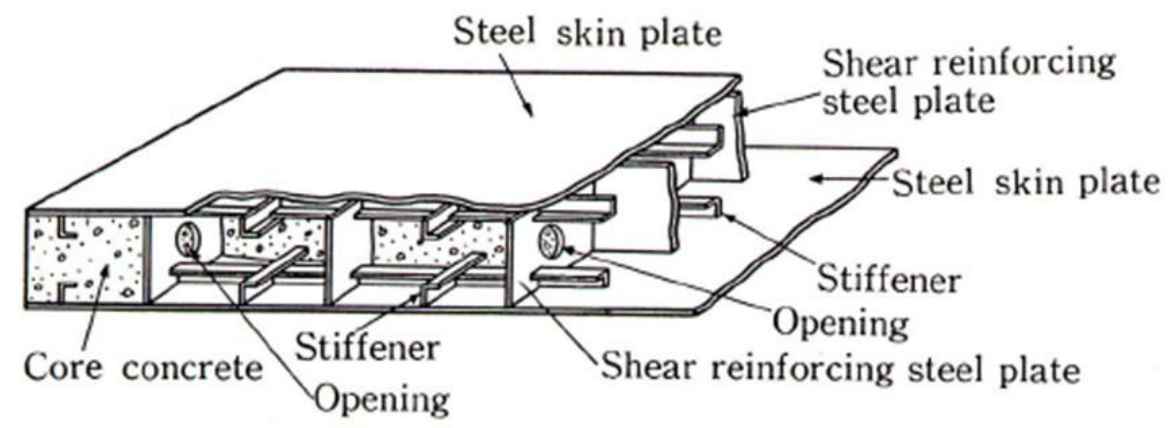

Figure I.1 Steel-concrete sandwich slab (JSCE 2006 [1]) 

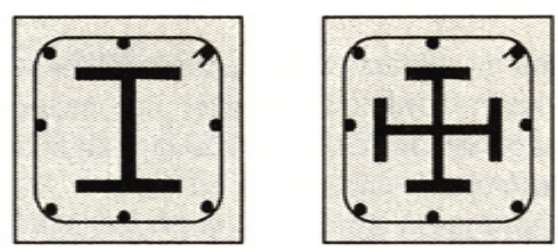

Full web steel-frame column
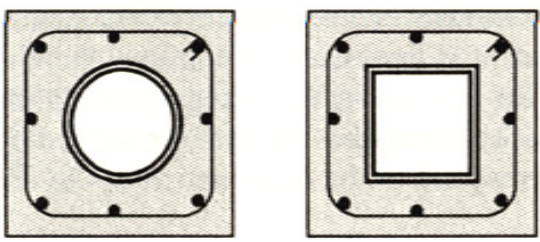

Column with steel pipe encased with reinforced concrete

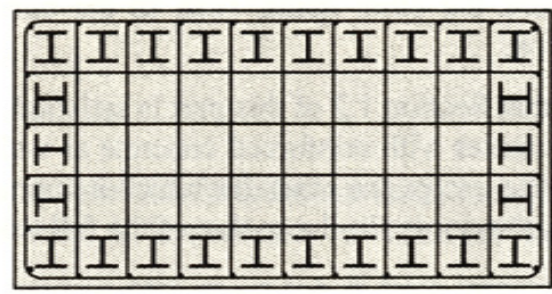

Structural steel reinforcing bar composite column
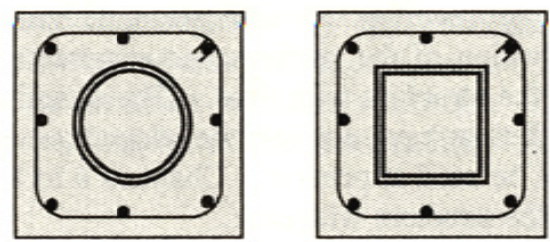

Column with in-filled concrete steel pipe encased with reinforced concrete

Figure I.2 Various sectional types of composite column (JSCE 2006 [1])

\section{I.3 Shear Connectors}

There are several types of shear connector used in the composite structures such as headed stud shear connector, plate shape shear connector, block dowel shear connector, channel shear connector, and L-shape shear connector. The illustrations of these shear connectors are given in

\section{Fig.I.3.}

Headed stud shear connector is widely used to connector the shape steel (I-shape or H-shape steel) with the concrete slab forming the composite beam. It has been also used to connect steel plate and concrete for road bridges. Moreover, in bridge structures, if the space between the main girders is large, the shear connectors located at the slab-girder connector are subjected to pull-out force due to the rotational deformation of the floor slab. Meanwhile, the level of pull-out force depends on the locations and the weight of the wheels. According to Sakai et al [4][5], the shear capacity of the head stud shear connector decreased approximately $25 \%$ with the presence of pull-out out force. Furthermore, with the presence of repeated loads of the vehicle wheels, shear connectors will be also subjected to fatigue loads and it is ineligible in the design for road bridge structures. 


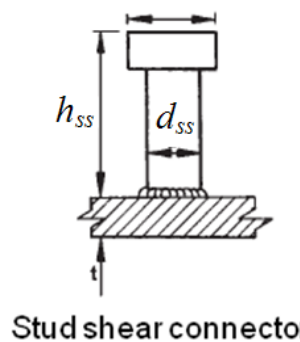

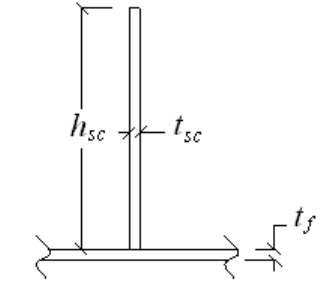

Plate shape shear connector

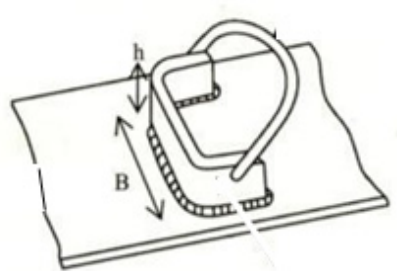

Block dowel shear connector

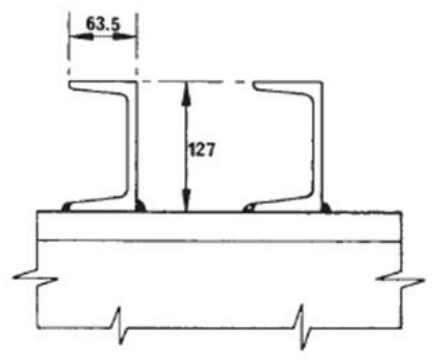

Channel shear connector

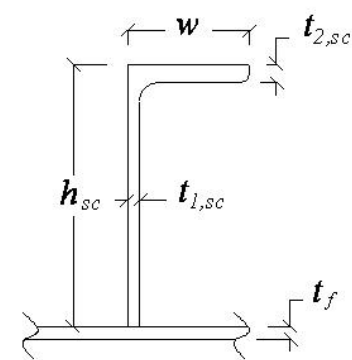

L-shape shear connector

Figure I.3 Various types of shear connector

Additionally, other types of shear connector including plate shape shear connector, L-shape shear connector, and channel shear connector are usually used in the steel-concrete sandwich slab for tunneling constructions, floor slab for bridge constructions, dam wall constructions, and so on. They became popular due to their high strength durability and easy-installing process. The shear connectors are used not only to transfer shear in steel-concrete interface, but also to prevent the buckling of the steel skin plate during service life. On the other hand, the block dowel shear connector is usually used in railway bridges.

According to the design code of steel-concrete sandwich structure of JSCE 1992 [3], in order to assure the full interaction between steel and concrete, the numbers of shear connector used can be determined by dividing the total shear force by the individual shear capacity of the shear connector as given in Eq.I.1.

$$
\gamma_{i} \frac{H_{d}}{\sum_{i=1}^{N_{s c}} V_{s c d i}} \leq 1.0
$$

Where:

$H_{d}$ : design value for shear force per unit width transferred between skin plate and core concrete at portion $L=t_{f} \sigma_{\mathrm{f}}$; 
$\gamma_{\mathrm{i}}$ : structure factor;

$V_{\text {scdi }}$ : design value for shear transfer capacity of individual shear connector per unit width;

$N_{s c}$ : total number of shear connectors per unit width at portion $L$;

$L \quad$ : portion between maximum flexural moment and zero flexural moment section;

$t_{\mathrm{f}} \quad$ : thickness of steel skin plate at maximum flexural moment;

$\sigma_{\mathrm{f}}$ : tensile stress in steel skin plate at maximum flexural moment section $\left(=f_{y d}\left(M_{d} / M_{u d}\right)\right)$;

$M_{\mathrm{d}}$ : Design value for flexural moment at maximum flexural moment section;

$M_{\mathrm{ud}}$ : Design value for flexural capacity of maximum flexural moment section.

\section{I.4 Statement of Problems}

Usually, in design of steel-concrete composite structures, plane remain plane assumption has been applied for conservative purpose. However, partial interaction between steel and concrete has been becoming highly demanded due to more rational and more economical respectively in the design and in the construction. The partial interaction mechanisms of the shear connector are explained by the relationships between shear force and slip. Consequently, several types of test methods for shear connectors were developed and the existing research results are summarized in the following subchapter. It has been observed that the formulas for shear force-slip relationship of some types of shear connectors namely Plate shape, Headed Stud, and Block Dowel shear connectors have been formulated and proposed. However, the study of L-shape shear connector is quite limited and the formula to predict its shear force-slip displacement relationship has not yet been identified.

\section{I.5 Purpose of Research}

This study was conducted to examine the partial interaction mechanisms of L-shape shear connector in steel-concrete composite structure by taking into account the effects of concrete strength, size of shear connector, and direction of the applied shear force. Again, the purpose of this study is to "Formulate the relationship between shear force and slip of L-shape shear connector subjected to strut compressive force in steel-concrete composite structures".

At the same time, the ultimate shear capacity and the ultimate slip of the shear connector are also required to fully understand the partial interaction mechanisms of the shear connector. 


\section{I.6 Research Design}

In this study, L-shape shear connectors were examined by means of experimentation and FEM Analysis. A new beam type test method was developed and used for the experiment. Two series of beam type specimens were constructed and tested. The $1^{\text {st }}$ test series consists of four specimens in which the shear connectors were designed to be subjected to strut compressive force with 45 degrees of strut direction. Concrete strength and size of shear connector are the main focus parameters. The equations to predict the shear force-relative displacement relationship and the ultimate shear force of the shear connector were formulated for the case that the strut angle is equal to 45 degrees. Subsequently, the $2^{\text {nd }}$ test series specimens were tested to confirm the applicable ranges of the proposed equations found from the $1^{\text {st }}$ test series. The selection of the main parameters was made with the help from the FEM analysis during the experimental planning which are the strut angle and the size of the shear connector. The results calculated by means of the proposed equations were compared with those of the $2^{\text {nd }}$ test series specimens.

There are five chapters in this thesis which orderly introduced as followings:

Chapter I: This chapter introduces the steel-concrete composite structure and its components especially the shear connector. The usage and importance of the shear connector in the structure were explained. The purpose of research and the research design were described in this chapter.

Chapter II: This chapter describes the literature reviews which are related to the purpose this research. In this chapter, the existing test methods including push-out test method, direct pull-out test method, and steel-concrete sandwich beam test methods were described and their limitations were introduced. Moreover, the existing research results of shear force-slip relationship of the Headed stud, and Block dowel shear connector were also summarized and discussed. Accordingly, the absence and the importance of the study on L-shape shear connector were introduced.

Chapter III: This chapter describes in details about the experiments. Properties of steel, concrete, and shear connector were introduced. The originality and the details of beam type specimens are illustrated while the measurement and the equipment installations were also illustrated.

Chapter IV: This chapter shows, analyzes, and discusses all experimental results of both $1^{\text {st }}$ and $2^{\text {nd }}$ test series specimens. In this chapter, the shear resisting mechanisms of L-shape shear connector were identified. The formula for shear force-relative displacement relationship of L- 


\section{CHAPTER II}

\section{LITERATURE REVIEWS}

\section{II.1General}

Partial interaction mechanisms of shear connector have been becoming high demand due to more rational in the design and more economical in the construction. That was the reason why several test methods for examining both the shear capacity and the partial interaction mechanisms of the shear connectors have been developed. Consequently, the mechanical properties of the shear connectors including shear resisting capacity and shear force-slip relationship have been identified. The following subchapters described the existing test methods as well as the existing research results of different types of shear connectors.

\section{II.2 Existing Test Methods for Shear Connectors}

\section{II.2.1 Push-out Test Method}

Push-out test is a popular test method to study the performances of shear connectors. The illustration of this test method is given in Fig.II.1(a). The shear connectors are perpendicularly welded with the H-shape steel and connect the concrete with the steel as shown in the figure. When the load is applied by the hydraulic jack, the relative displacement between the steel and concrete can be measured by the displacement transducer, while the load magnitudes are detected by the load cell. More details illustration and explanation of this test method are available in the Euro-code II. This test method is applicable to study the partial interaction mechanisms of the shear connectors which are expressed by the shear force and slip relationships.

For instant, in 1986, Kiyomiya et al. [6] studied the behavior the shape steel shear connector by means of push-out test method and found that the relative slip between the steel and the concrete appeared even under load level. Meanwhile, the cracking loads were found approximately half of the maximum applied load. The failure mode of the specimens was shown in Fig.II.1(b). Tensile fracture of shear connector, concrete crush, and shear failure of concrete were observed in their study. Consequently an equation to predict the load-carrying capacity of the angle, T-shape steel, 

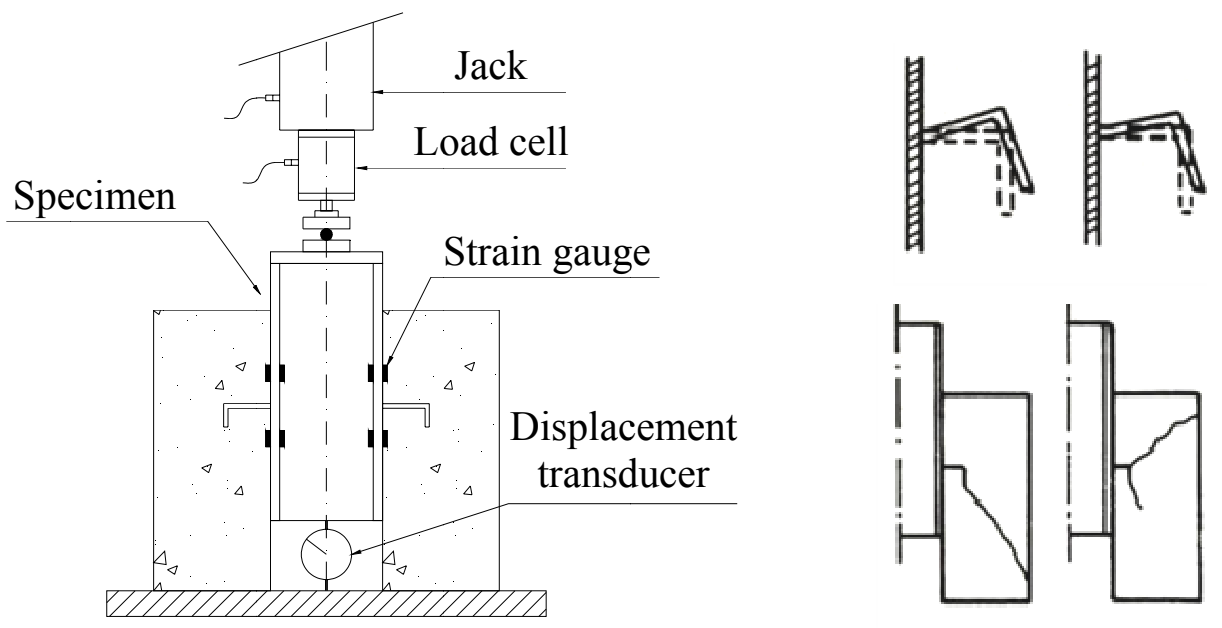

(a) Test Set-up

(b) Failure mode, Kiyomiya et al. (1986)

Figure II.1 Push-out Test

and channel shear connector was developed by selecting the lower limit of the maximum shear force obtained from experimental results. Their equation is expressed as followings:

$$
P=75 \times \sqrt{t} \times w \times \sqrt{f_{c}^{\prime}}
$$

Where:

$t \quad$ : Thickness of the shear connector (inches)

$w \quad$ : Length of channel (inches)

$f_{c}^{\prime}$ : Concrete compressive strength (psi)

Moreover, in 1993 Kimura et al. [7] presented the effects of test method on the ultimate strength of shape steel shear connector by means of the modified push-out test method. The core concrete was sandwiched by the two steel plates. The load was applied by pulling and pushing as shown in the figure. As a result, the shear capacity of the shear connector was found relatively low as compared to the results found by Kiyomiya et al. [6] due to large deformation of the steel plate found in the modified test method. 


\section{II.2.2 Direct Pull-out Test Method}

The illustrations of direct pull-out test method are given in both Fig.II.2(a), a single shear connector test and Fig.II.3(a), a multiple shear connectors test. As shown in the figures, the concrete specimens are connected with the skin plate by the shear connectors. During the test, the pulling load was applied and the reacting load accordingly reacted. This test method is also applicable for examining the shear force and slip relationship of the shear connector that slip can be easily obtained from the relative displacement between the steel and the concrete.

In 1989, Ueda and Chin [8] used this test method to examine the shear resisting capacity of a single plate shape shear connector as illustrated in Fig.II.2(a). The specimens were found to failed by the occurrence of crack in the concrete from the head of the shear connector as shown in Fig.II.2(b). Also, punching shear was also found at failure of the shear connector. Consequently, a formula for predicting the shear capacity of the plate shape shear connector was developed by assuming that the punching shear strength of the concrete in front of the shear connector is equal to the bearing strength of the concrete block on which the load was applied through the steel plate. Meanwhile, the bearing strength of the concrete affected by thickness to height ratio of the shear connector and the ratio between the shear connector's thickness to that of the steel plate. However, the effect of shear connector spacing was not included.

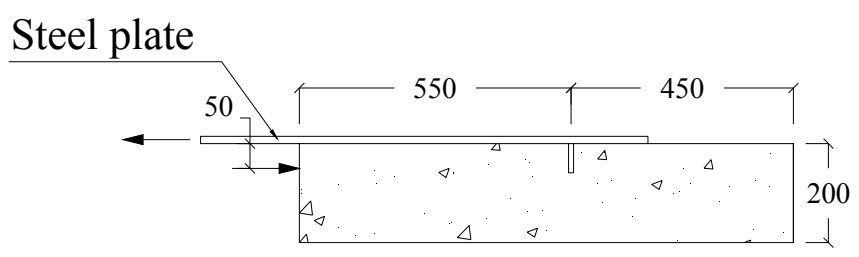

(a) Test Set-up

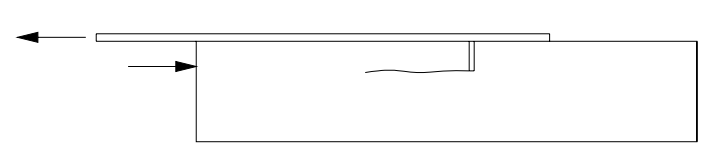

(b) Failure mode

Figure II.2 Direct Pull-out Test, Ueda and Chin (1989) 


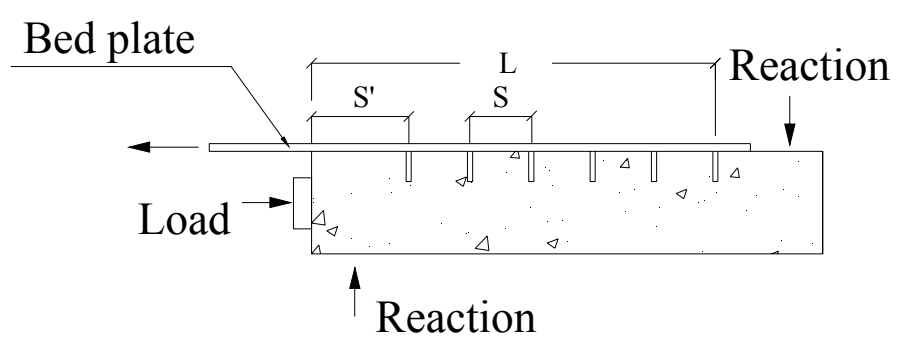

(a) Test Set-up

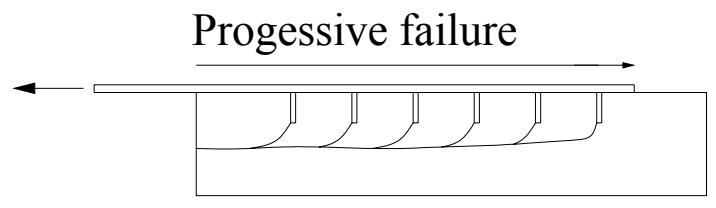

(b) Failure mode

Figure II.3 Direct Pull-out Test, Chuah et al. (1991)

Two years later, in 1991, Chuah et al. [9] examining the load-slip relationship of the plate shape shear connector by the direct pull-out test method with multiple shear connectors as illustrated in Fig.II.3(a). Consequently progressive failure was observed which cracks appeared from the heads of the shear connectors and continuously propagated as shown in Fig.II.3(b). Moreover, they found that the shear resisting capacity of the shear connector gradually reduced after the occurrence of crack in the concrete from the head of the shear connector. By means of their experimental results, the effect of shear connector spacing on the shear capacity of the shear connector was identified.

As a results, by combining the research results of both Ueda and Chin (1992) [10] and Chuah et al. (1991) [9], the formula to predict the shear capacity of plate shape shear connector was available in the Design Code of Steel-Concrete Sandwich Structure of JSCE in 1992 [3] and also in the Guidelines for performances verifications of steel-concrete hybrid structures in 2006 [1] and lately in the Design specifications for hybrid structures in 2009 [2]. The equation was also proposed to be applicable for the angle shape shear connector with the configurations illustrated in Fig.II.4. 


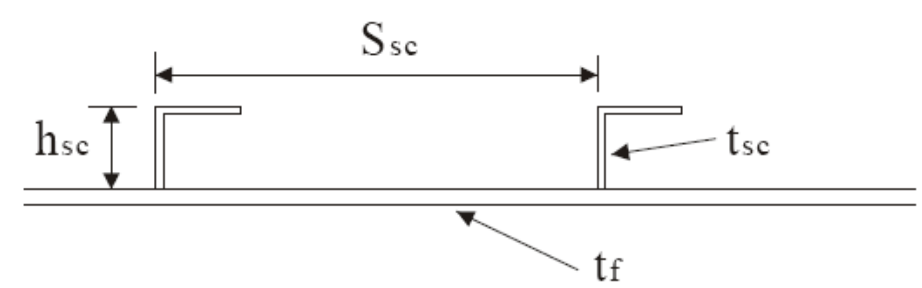

Figure II.4 Shape steel shear connector

The equation is expressed as followings:

$$
V_{s c d 1}=\left(0.56 h_{s c} w_{s c}\left(f_{c d}^{\prime}\right)^{1 / 2} k_{1} k_{2} k_{3}\right)
$$

But not greater than the tensile yield strength of the shear connector $V_{s c d 2}$.

$$
V_{s c d 2}=0.1 t_{s c o} w_{s c}\left(f_{s c y d} / \sqrt{3}\right) / \gamma_{b 2}
$$

Where:

$k_{1}=2.2\left(t_{s c} / h_{s c}\right)^{2 / 3} \leq 1$

$k_{2}=0.4\left(t_{f} / t_{s c}\right)^{1 / 2}+0.43 \leq 1$

$k_{2}=\left(\left(S_{s c} / h_{s c}\right) / 10\right)^{1 / 2} \leq 1$

$f_{c d}^{\prime} \quad:$ design value for compressive strength of concrete $\left(\mathrm{N} / \mathrm{mm}^{2}\right)$;

$h_{\text {sc }}:$ height of shear connector $(\mathrm{cm})$;

$w_{\mathrm{sc}}:$ width in the direction normal to shear force of shear connector $(\mathrm{cm})$;

$t_{\text {sco }}:$ a lesser of thickness of shear connector considering welded part and thickness of shear connector itself $(\mathrm{cm})$;

$f_{\text {scyd }}$ : design value for tensile yield strength of shear connector $(\mathrm{N} / \mathrm{mm} 2)$;

$t_{\mathrm{sc}} \quad:$ thickness of shear connector $(\mathrm{cm})$;

$S_{\mathrm{sc}} \quad$ : spacing in the direction of shear force of shear connectors $(\mathrm{cm})$;

$\gamma_{\mathrm{b} 1}:$ member factor which may be 1.3 generally;

$\gamma_{\mathrm{b} 2}:$ member factor which may be 1.15 generally; 
$\gamma_{c}:$ material factor for calculation of $\mathrm{f}_{\mathrm{c}}^{\prime}$ which maybe 1.3 general;

$\gamma_{\mathrm{s}} \quad$ : material factor for calculation of $\mathrm{f}_{\text {scyd }}$ which maybe 1.05 generally;

\section{II.2.3 Steel-Concrete Sandwich Beam Test Method}

Steel-concrete sandwich beam test has also been used to study the mechanical properties of the shear connector. The layout of steel-concrete sandwich beam is given in Fig.II.5. The concrete core is sandwiched by the steel skin plates, while the steel and the concrete were connected by the shear connector.

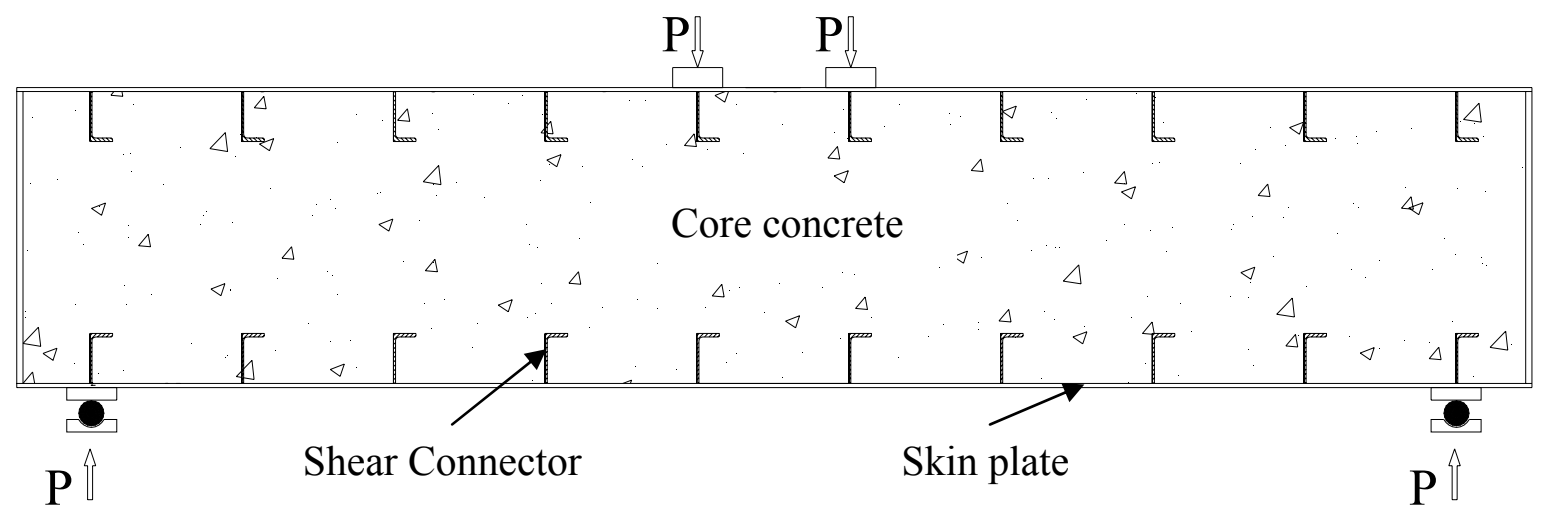

Figure II.5 Layout of steel-concrete sandwich beam test

In 1992, Makabe et al. [11] studied the mechanical properties of steel and concrete sandwich beam in which L-shape shear connectors were used. The behaviors of the L-shape shear connector in steel-concrete sandwich beam were also identified. By examining the strain distributions on the vertical part of the shear connector, the curvature was observed. Meanwhile, the head of the shear connector was found to have forward movement (opposite to the direction of shear force) under low load levels $(0-100 \mathrm{kN})$ and have backward movement (the same the direction of shear force) under higher load levels (greater than $100 \mathrm{kN}$ ).

The same test method was used by Saidi et al. [12][13][14] to study the transferred shear force and relative displacement relationship of the shear connector including L-shape, T-shape and Ishape shear connector. A formula to predict the transferred shear force at a sudden decrease of the equivalent stiffness of the shear connector $\left(Q_{c}\right)$ was proposed as expressed in Eq.II.4. 


$$
Q_{c}=\left(0.000216 F_{c o m}^{\prime}+0.00542\right) f_{c}^{\prime 0.5} \frac{b_{s c} t_{c} t_{s c}}{h_{s c}^{0.8}}
$$

Where:

$F_{\text {com }}^{\prime}$ : compressive force on the shear connector $(\mathrm{kN})$;

$f_{c}^{\prime} \quad$ : compressive strength of concrete $\left(\mathrm{N} / \mathrm{mm}^{2}\right)$;

$h_{\mathrm{sc}} \quad$ : height of shear connector $(\mathrm{mm})$;

$b_{\mathrm{sc}} \quad$ : width in the direction normal to shear force of shear connector $(\mathrm{mm})$;

$t_{\mathrm{c}} \quad$ : effective thickness of concrete surrounding the shear connector $(\mathrm{mm})$;

$t_{\mathrm{sc}} \quad$ : thickness of shear connector $(\mathrm{mm})$

Moreover, Saidi et al. [14] also proposed an equation, Eq.II.4 to predict the transferred shear force-relative displacement relationship in which the stiffness of the shear connector $(E I)$, the slope $\left(\theta_{0}\right)$ and the modulus of the assumed foundation $(k)$ were considered.

\section{II.2.4 Limitations of Existing Test Method}

\section{a) Limitations of Push-out Test Method}

The limitations can be derived from the configurations of the both push-out test method and the experimental results found in previous studies. Three considerable limitations were observed as followings:

(1) The thickness of the H-shape steel is too thick which may affect on both behaviors of the shear connectors as well as their shear resisting capacity. It has been clarified by Kimura et al. [7] that the shear capacity of the shear connectors reduces with the deformation of the attached steel plates.

(2) The direction of stress upon the shear connectors are only perpendicular $\left(\theta=0^{\circ}\right)$ which is different from the real structure that the stress direction changes according to the location of the applied load; for instant, the locations of the vehicles on the bridge deck.

(3) The ultimate state of the shear connectors cannot be observed. Based on previous studied, the shear resisting capacity of the shear connector can be obtained only until crack in the 
concrete reached surface of the specimen [9] \& [10]. It means that both the ultimate shear capacity and the ultimate slip of the shear connector cannot be identified.

\section{b) Limitations of Direct Pull-out Test Method}

Three limitations were also observed in this test method:

(1) The first limitation is similar to that of the Push-out test method that the directions of stress upon the shear connectors are only perpendicular $\left(\theta=0^{\circ}\right)$.

(2) Progressive failure would occur in case of multiple shear connectors are tested and the shear resisting ability of the shear connector gradually reduces after the occurrence of first crack from the head of the shear connector [9]. It means that the ultimate state of the shear connectors cannot be obtained.

\section{c) Limitations of Steel-Concrete Sandwich Beam Test Method}

Steel-concrete sandwich beam test method was also found to have some limitations that cannot be avoided.

(1) Steel-concrete sandwich beam was found to fail before the shear connector that the ultimate shear capacity and the ultimate slip of the shear connector cannot be obtained [12][13][14].

(2) The specimen will be too large in case of large size shear connector need to be tested. It would mean that this kind of test method seems to be inapplicable for large size shear connector. Additionally, the maximum size of L-shape shear connector used to be investigated by this test method was L $140 \times 40 \times 5 \mathrm{~mm}[14]$.

\section{II.3 Existing Formulas of Shear Force-Slip Relationship of Shear Connectors}

\section{II.3.1 Headed Stud Shear Connector}

The equation of shear force-slip relationship of headed stud shear connector with diameter of 19 $\mathrm{mm}$ and $9.5 \mathrm{~mm}$ were previously proposed by Ollgaard et al [15] and Chuah et al [9], respectively. Moreover, the most recent formula of shear force-slip relationship of headed stud shear connector was given by Shima and Watanabe in 2009 [16] and again was recommended by JSCE 2009 [2]. Fig.II.6 gives the shear force-slip relationship of headed stud shear connector. 

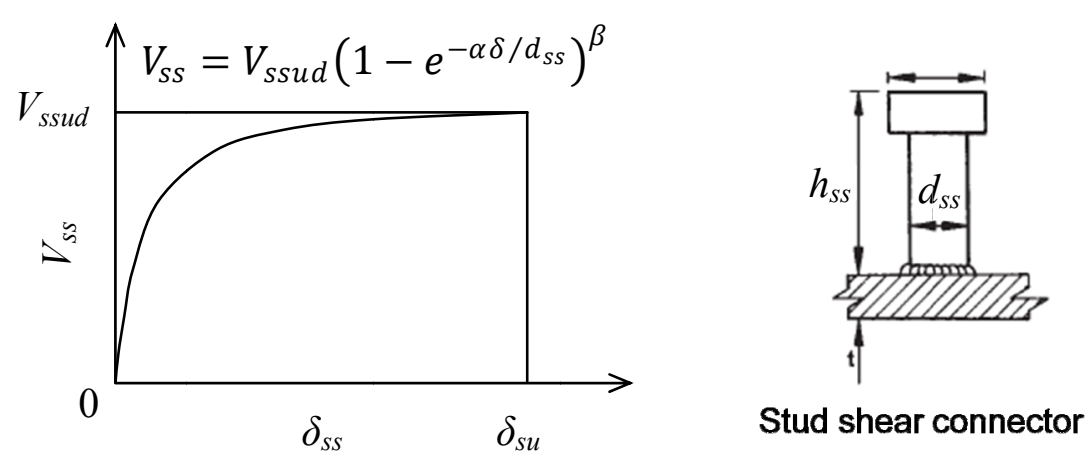

Figure II.6 Shear force-slip relationship of headed stud shear connector

It was confirmed that the relationship between shear force and slip of headed stud shear connector can be represented by the normalized curve in which the shear force was normalized by the ultimate shear capacity of the shear connector and the slip was normalized by the diameter of the stud. The equation was expressed as followings:

$$
\begin{aligned}
& V_{s s}=V_{\text {ssud }}\left(1-e^{-\alpha \delta / d_{s s}}\right)^{\beta} \\
& \alpha=11.5\left\{1.1(\gamma-1)^{2}+1\right\} f_{c}^{\prime} / f_{c o}^{\prime}
\end{aligned}
$$

And $V_{\text {ssud }}$ is the ultimate shear capacity of the headed stud shear connector which is the lower value between Eq.II.7 and Eq.II.8.

$$
\begin{aligned}
& V_{u}=31 A_{s s} \sqrt{\frac{h_{s s}}{d_{s s}}} f_{c}^{\prime}+1000 \\
& V_{u}=31 A_{s s} f_{s s}
\end{aligned}
$$

Where:

$$
\begin{aligned}
& A_{s S}: \text { cross sectional area of stud }\left(\mathrm{mm}^{2}\right) \\
& f_{c}^{\prime} \quad \text { : compressive strength of concrete }\left(\mathrm{N} / \mathrm{mm}^{2}\right) \\
& f_{y} \quad: \text { tensile strength of stud }\left(\mathrm{N} / \mathrm{mm}^{2}\right) \\
& h_{\mathrm{ss}}
\end{aligned}
$$


$d_{\text {ss }}:$ diameter of stud (mm);

$\alpha \& \beta$ : constant.

Additionally, the ultimate slip of the headed stud was found to vary from 0.3 to 0.4 times the diameter of the stud [16].

\section{II.3.3 Block Dowel Shear Connector}

The equation for shear force-slip relationship of block dowel shear connector was also recently proposed by JSCE 2009 [2], Fig.II.7 whose equation is expressed in Eq.II.9. The equation is expressed as followings:

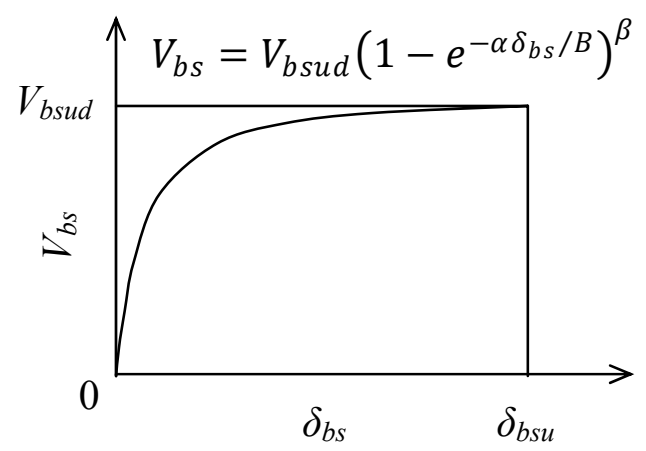

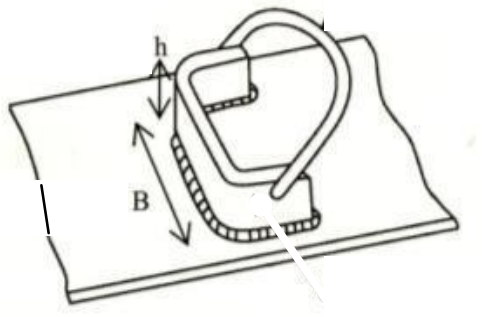

Block dowel shear connector

Figure II.7 Shear force-slip relationship of block dowel shear connector

$$
V_{b s}=V_{b s u d}\left(1-e^{-\alpha \delta_{b s} / B}\right)^{\beta}
$$

Where:

$V_{b s u d}:$ design shear strength of the shear connector (N), JSCE 2009 [2];

$f_{c}^{\prime} \quad$ : compressive strength of concrete $\left(\mathrm{N} / \mathrm{mm}^{2}\right)$;

$\delta_{b s u}:$ ultimate $\operatorname{slip}(\mathrm{mm})$

$\delta_{b s} \quad: \operatorname{slip}(\mathrm{mm}) ;$ and

$\alpha \& \beta$ : constant. 
As described above, the both shear resisting capacity and shear force-slip relationship of headed stud, plate shape, and block dowel shear connectors have already been identified. However, those of L-shape shear connector have not yet been confirmed. Therefore, this study was conducted to formulate both shear capacity and shear force-relative displacement relationship of Lshape shear connector subjected to strut compressive force in steel-concrete composite structures.

In terms of the existing test methods for the study of performance of shear connector, there are three main limitations including the ultimate state of the shear connector, stress distributions, and the large size L-shape shear connector. Fortunately, these limitations can be fulfilled by a new test method namely Beam Type Test Method which was recently initiated and used for the studying on the mechanical properties of L-shape shear connector subjected to strut compressive force $[17][18][19][20][21][22][23][24]$. The detail of this test method is described in the following chapter, Chapter III Experiment. 


\section{CHAPTER III}

\section{EXPERIMENT}

\section{III.1General}

It is important that the performance of the shear connectors obtained from tested specimens are most similar to those in the real structures. It means that test method plays a vital role in the reliability and the applicability of the test results. In the real structures, shear connectors may resist against various directions of stresses depending on the locations of the applied loads. Therefore, the study of effects of stress directions on the performance of the shear connector is necessary. Unfortunately, according to the discussions over the limitations of previous studies in chapter II, large size L-shape shear connector and different stress directions on shear connector cannot be examined by the existing test methods. In order to fulfill these limitations, a new beam type test method has been initiated, constructed and tested. Advantageously, this test method was found to be applicable for the investigation of the effects of strut angle on the performances of large size L-shape shear connector subjected to strut compressive force in steel-concrete composite structures. This chapter describes every detail of the test method and the specimens used in this study.

\section{III.2 Beam Type Test Method}

\section{III.2.1 Originality of Beam Type Specimens}

Beam type specimens were constructed to replicate a part of a possible steel-concrete composite structures as illustrated in Fig.III.1. L-shape shear connectors with different directions to shear force were welded perpendicularly to the steel skin plate to resist against strut compressive force with strut direction $\theta$. Meanwhile, there was only one shear connector in the shear span $a$. The values of strut angle could be adjusted by varying the values of the shear span $a$. Moreover, by considering the possible surrounding concrete around the shear connector in the real structure, the height of the specimen $h$ was selected to be three times the height of the shear connector $h_{\mathrm{sc}}$. In this test method, both shear connectors were located at the direct supports so that the strut and tied mechanism was carried by the shear connectors and the skin plate, respectively. 


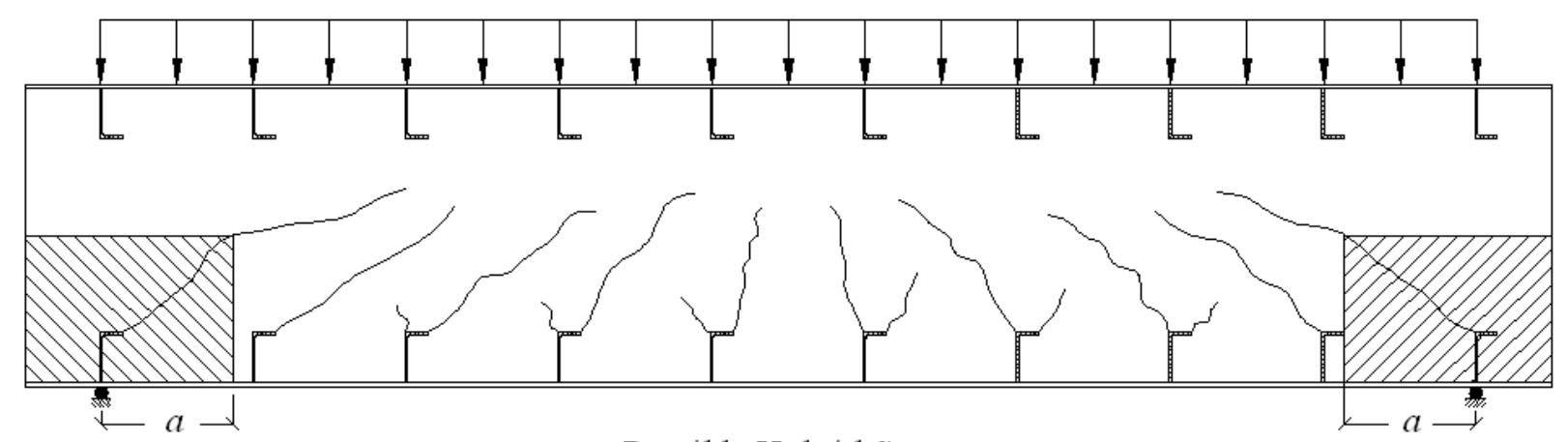

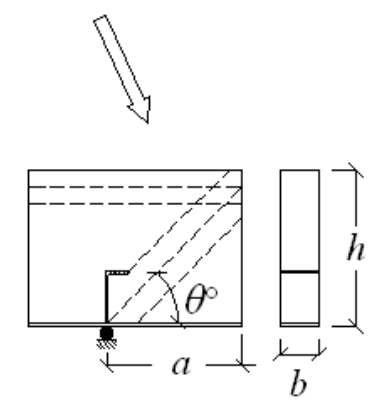

Part of observation

Possible Hybrid Structure
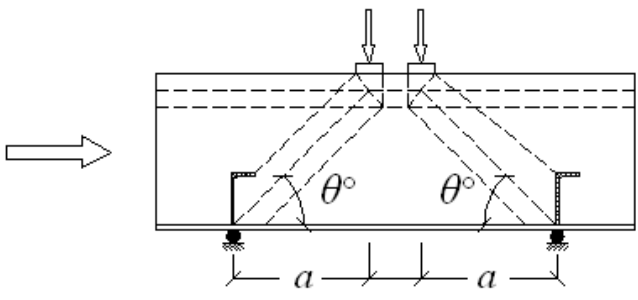

200

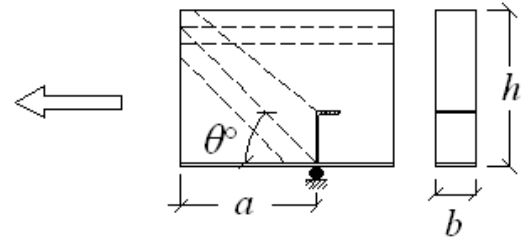

Part of observation

Specimen for testing

Figure III.1 Development of beam type specimen

More importantly, the other necessary parameters such as concrete strength $f_{c}^{\prime}$, size and mechanical properties of both shear connector and steel skin plate are carefully selected and preanalyzed to assure that the shear connector fail before yielding of the steel skin plate.

\section{III.2.2 Specimens}

The beam type specimens were symbolized as S-height of specimen-height of shear connectorthickness of shear connector-concrete strength-strut angle (S-h-h $\left.h_{s c}-t_{s c}-f_{c}^{\prime}-\theta\right)$. Two series of beam type specimens, $1^{\text {st }}$ and $2^{\text {nd }}$ test series specimens were constructed as listed in Table III.1. All specimens have the same width $(b=150 \mathrm{~mm})$ and different shear span depending on the wanted strut angle.

The $1^{\text {st }}$ test series consist of four specimens designed to study the mechanical behaviors of the shear connector by taking the effects of the concrete strength and the size of the shear connector into account. S-600-200-9-25.3-45 and S-600-200-9-38-45 whose strut angle and size of shear connector are the same were constructed to study the effects of concrete strength. Meanwhile, the effects of the size of the shear connector were investigated on S-600-200-9-25.3-45, S-450150-9-23.6, and S-300-100-9-25.1-45 whose concrete strength and strut angle are the same. 
Moreover, the $2^{\text {nd }}$ test series consisting of six specimens were specially designed after the analyses of the $1^{\text {st }}$ test series' results and FEM analyses results. These specimens were constructed to study mainly the effect of strut angle and size of shear connector on the performances of the shear connectors. S-600-200-9-43-35 \& S-600-200-9-43-30, S-450-150-9-43-30 \& S-450-150-943-25, and S-300-100-9-41.5-25 \& S-300-100-9-42.7-20 were constructed to examine the effects of strut angle when the thickness to height ratio of the shear connector $t_{1, s c} / h_{s c}=0.045$, $t_{1, s c} / h_{s c}=0.06$, and $t_{1, s c} / h_{s c}=0.09$, respectively. Fig.III.2 shows the detail of the specimens and the shear connectors. Additionally, a flexural crack initiator was inserted at mid span of the $2^{\text {nd }}$ test series specimens in order to remove the flexural resistance of the concrete.
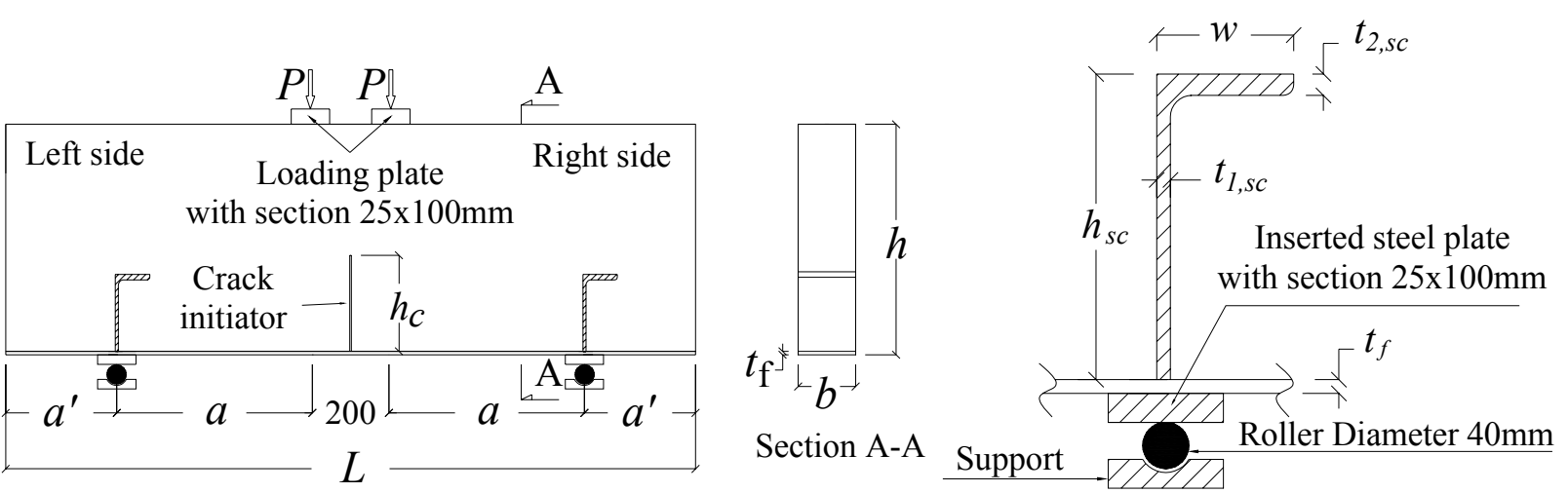

Figure III. 2 Detail of beam type specimen and shear connector

Table III. 1 Detail of specimens

\begin{tabular}{|c|c|c|c|c|c|c|c|c|c|c|c|c|c|}
\hline \multirow{2}{*}{ Specimens } & \multicolumn{7}{|c|}{$\begin{array}{c}\text { Sizes of } \\
\text { Specimens }(\mathrm{mm})\end{array}$} & \multicolumn{4}{|c|}{$\begin{array}{c}\text { Sizes of } \\
\text { shear connectors }(\mathrm{mm})\end{array}$} & \multirow{2}{*}{$\begin{array}{c}\text { Thick- } \\
\text { ness of } \\
\text { skin plate } \\
t_{\mathrm{f}}(\mathrm{mm})\end{array}$} & \multirow{2}{*}{$\begin{array}{c}\text { Concrete } \\
\text { strength } \\
f_{\mathrm{c}} \\
\left(\mathrm{N} / \mathrm{mm}^{2}\right)\end{array}$} \\
\hline & $a$ & $b$ & $h$ & $L$ & $a^{\prime}$ & $\theta$ & $h_{\mathrm{c}}$ & $h_{\mathrm{sc}}$ & $w$ & $t_{1, \mathrm{sc}}$ & $t_{2, \mathrm{sc}}$ & & \\
\hline \multicolumn{14}{|c|}{$1^{\text {st }}$ Test Series } \\
\hline S-600-200-9-38.0-45 & 510 & 150 & 600 & 1800 & 300 & 45 & - & 200 & 90 & 9 & 14 & 9 & 38.0 \\
\hline S-600-200-9-25.3-45 & 510 & 150 & 600 & 1800 & 300 & 45 & - & 200 & 90 & 9 & 14 & 9 & 25.3 \\
\hline S-450-150-9-23.6-45 & 410 & 150 & 450 & 1500 & 250 & 45 & - & 150 & 75 & 9 & 14 & 9 & 23.6 \\
\hline S-300-100-9-25.1-45 & 290 & 150 & 300 & 1100 & 200 & 45 & - & 100 & 50 & 9 & 14 & 9 & 25.1 \\
\hline \multicolumn{14}{|c|}{$2^{\text {nd }}$ Test Series } \\
\hline S-600-200-9-43.0-30 & 950 & 150 & 600 & 2700 & 300 & 30 & 300 & 200 & 90 & 9 & 14 & 9 & 43.0 \\
\hline S-600-200-9-43.0-35 & 750 & 150 & 600 & 2300 & 300 & 35 & 300 & 200 & 90 & 9 & 14 & 9 & 43.0 \\
\hline S-450-150-9-43.0-25 & 850 & 150 & 450 & 2400 & 250 & 25 & 250 & 150 & 75 & 9 & 14 & 9 & 43.0 \\
\hline S-450-150-9-43.0-30 & 650 & 150 & 450 & 2000 & 250 & 30 & 250 & 150 & 75 & 9 & 14 & 9 & 43.0 \\
\hline S-300-100-9-42.7-20 & 650 & 150 & 300 & 1900 & 200 & 20 & 150 & 100 & 50 & 9 & 14 & 9 & 42.7 \\
\hline S-300-100-9-41.5-25 & 500 & 150 & 300 & 1600 & 200 & 25 & 150 & 100 & 50 & 9 & 14 & 9 & 41.5 \\
\hline
\end{tabular}




\section{III.2.3 Materials}

\section{a) Steel Properties}

JIS G 3101 standard steels with grade SM490 and grade SS400 whose mechanical properties are given in Table III.2 were used for the steel plate and the shear connector, respectively. The different grades of steels were purposefully selected to assure that shear connector fail before yielding of skin plate. Additionally, the activities of steel's tensile strength testing as well as stressstrain relationships of the steels are available APPENDIX III.1.

Table III. 2 Characteristics of steel

\begin{tabular}{|l|c|c|}
\hline \hline & $\begin{array}{c}\text { Shear } \\
\text { Connector }\end{array}$ & Skin Plate \\
\hline Tensile yield strength $f_{y}\left(\mathrm{~N} / \mathrm{mm}^{2}\right)$ & 352 & 370 \\
\hline Ultimate strength $f_{u}\left(\mathrm{~N} / \mathrm{mm}^{2}\right)$ & 448 & 511 \\
\hline Modulus of elasticity $E\left(\mathrm{kN} / \mathrm{mm}^{2}\right)$ & 202 & 204 \\
\hline
\end{tabular}

\section{b) Concrete Product}

The mix proportions of concrete were accordingly designed depending on the required strength of the concrete. The summary of the mix proportion are given in Table III.3. Normal Portland Cement was used to produce the concrete. Additionally, the minimum size and maximum size of aggregates are $5 \mathrm{~mm}$ and $20 \mathrm{~mm}$ respectively. Water Reduction Agent (WRA) and Air Entrance Agent (AEA) were also used in the concrete product. Moreover, the direction of concrete casting was perpendicular to the big face of the specimen in order to minimize the cavities around the shear connectors. The activities of concrete and form work are available in APPEXDIX III.2.

Table III. 3 Concrete mix proportions

\begin{tabular}{|c|c|c|c|c|c|c|c|c|c|}
\hline \multirow{2}{*}{ Specimens } & \multirow{2}{*}{$\begin{array}{l}\text { Slump } \\
(\mathrm{cm})\end{array}$} & \multirow{2}{*}{$\begin{array}{l}\mathrm{W} / \mathrm{C} \\
(\%)\end{array}$} & \multirow{2}{*}{$\begin{array}{l}\mathrm{S} / \mathrm{a} \\
(\%)\end{array}$} & \multicolumn{6}{|c|}{ Unit weight $\left(\mathrm{kg} / \mathrm{m}^{3}\right)$} \\
\hline & & & & Water & Cement & Sand & $\begin{array}{c}\text { Coarse } \\
\text { Aggregate }\end{array}$ & WRA & AEA \\
\hline S-600-200-9-38.0-45 & 18 & 46 & 40 & 175 & 378 & 695 & 1059 & 3.78 & 15.1 \\
\hline $\begin{array}{l}\text { S-600-200-9-25.3-45 } \\
\text { S-450-150-9-23.6-45 } \\
\text { S-300-100-9-25.1-45 }\end{array}$ & 8 & 73 & 45 & 155 & 211 & 876 & 1070 & 2.11 & 8.4 \\
\hline $2^{\text {nd }}$ Test Series & 18 & 54 & 48.8 & 175 & 342 & 520 & 921 & 2.5 & 1.62 \\
\hline
\end{tabular}




\section{III.2.4 Experimental Set-up}

\section{a) Stain gauge installation}

Strain gauges were attached on both steel and concrete as shown in Fig.III.3. In both 1st and 2nd test series specimens, strain gauges with $30 \mathrm{~mm}$ length were attached on both sides of the concrete surface in order to measure strain development in the concrete in front of the shear connector with respect to shear force. The strain gauges L39, L41, and L43 were attached on the concrete surface of the opposite side of L40, L42, and L44, respectively. Moreover, strain gauges with $5 \mathrm{~mm}$ length were attached on both sides of the steel plate in front of the shear connector with the aims of measuring strain distribution in the steel plate. On the other hand, differently from 1st test series specimens, strain gauge L5-L6 were mounted on the shear connectors of 2nd test series specimens in order to examine the stress-strain conditions of the shear connector. Additionally, all strain gauges were attached left-right symmetrically in pairs in all specimens.

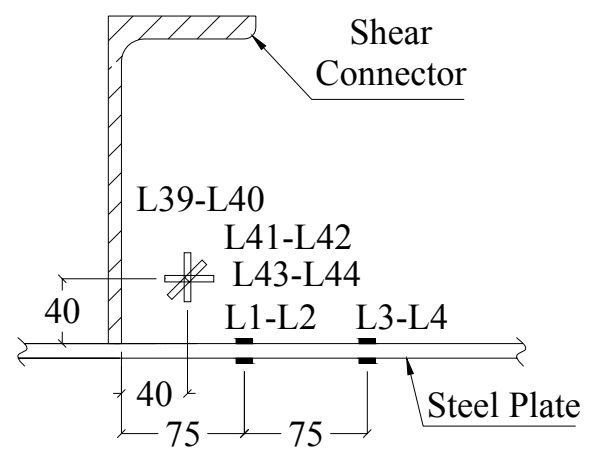

(a) $1^{\text {st }}$ test series (Unit: $\mathrm{mm}$ )

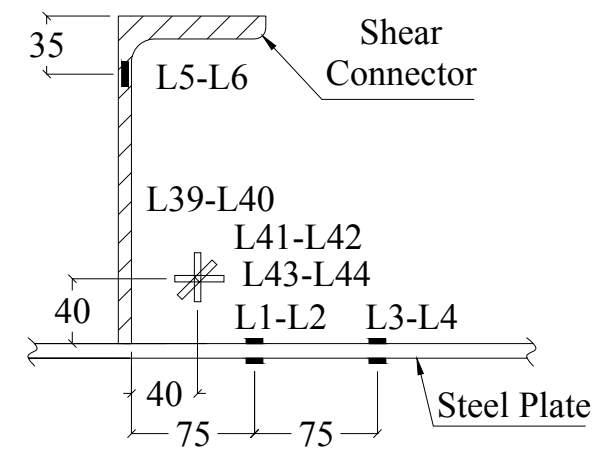

(b) $2^{\text {nd }}$ test series (Unit: $\mathrm{mm}$ )

Figure III. 3 Locations of strain gauges of $1^{\text {st }}$ test series specimens

\section{b) Instrumentations for Relative Displacement Measurement}

The relative displacements between head and toe of the shear connector were measured by two displacement transducers LD1 1 and LD12 for both $1^{\text {st }}$ and $2^{\text {nd }}$ test series specimens. The installations of the displacement transducers are illustrated in Fig.III.4. Two pins were welded perpendicularly to top of both sides of the shear connector. It means that the pins can freely move when the head of the shear connector displaces. Then the displacement transducers connected to the magnetic bases horizontally pointed against the pins in order to measure the displacement of the head of the shear connector. Meanwhile, the magnetic bases were attached on an extra inserted steel plate between the roller and the skin plate the specimen. The inserted steel plate and the 
skin plate easily rotate as one on the roller. The horizontal displacements due to the rotation of the steel plates are also considered as the relative displacements of the shear connectors. By means of the installation mentioned above, the behaviors of the shear connectors in the specimens are reasonable identical to those in the real structures. The average values obtained from LD11 and L12 were determined as the relative displacement of the shear connector.

Moreover, the inserted steel plates were inserted for not only the magnetic base but also for the supported. However, the specimens were stable during the test even though the supports were modified. Additionally, displacement transducers were installed left-right symmetrically in pairs in all specimens.
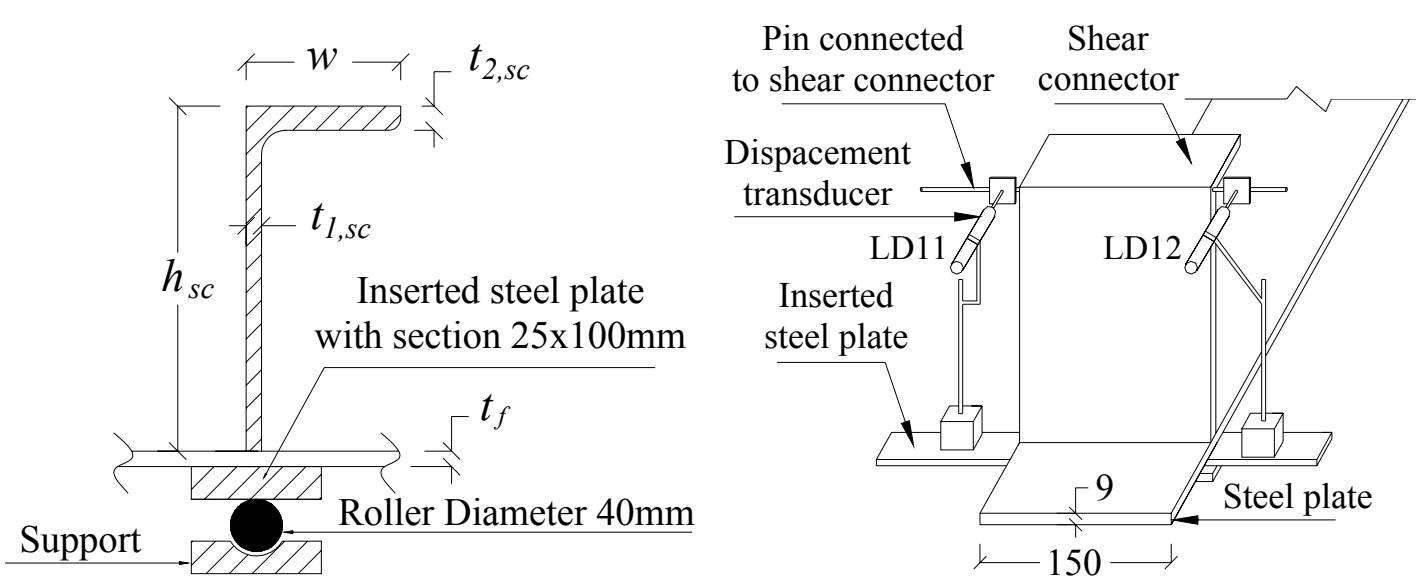

Figure III. 4 Detail of relative displacement measurement

\section{c) Instrumentations for Slip Measurement}

Concrete-skin plate slips in front of the shear connector were measured by means of four displacement transducers LD1-LD2 and LD3-LD4 for both $1^{\text {st }}$ and $2^{\text {nd }}$ test series specimens as illustrated in Fig.III.4. The displacement transducers which were connected with the magnetic bases were horizontally pointed against the angle plates which were attached on the concrete's surface. Meanwhile, the magnetic bases were attached with the bottom of the skin plate. When the concrete and the skin plate of the specimen relatively displaced due to applied load the displacement transducers detected the horizontal relative displacement between skin plate and concrete called as concrete-skin plate slip. The average values obtained from the displacement transducers LD1 to LD4 were determined as the slip. Also, displacement transducers were installed left-right symmetrically in pairs in all specimens. 


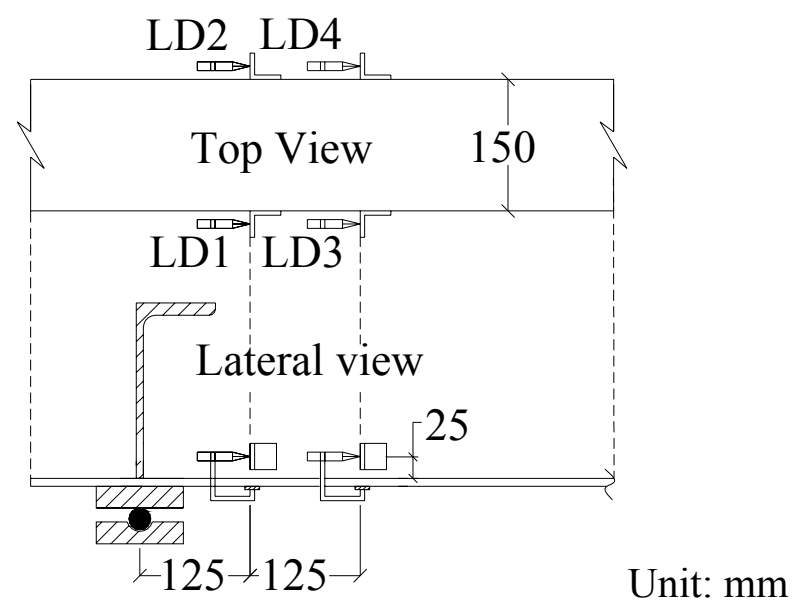

Figure III. 5 Detail of concrete-skin plate slip measurement

\section{d) Experimental Set-up}

The experimental work was conducted by a symmetric two-point loading system on the simply supported beam type specimen as illustrated in Fig.III.6. A hydraulic jack and an electrical load cell were used to apply the load and to measure the load, respectively. The hydraulic jack was fixed with a strong steel frame. Meanwhile, the support reacted against a strong steel beam which was laid on a thick steel plate. The load was applied until the shear connector fail.

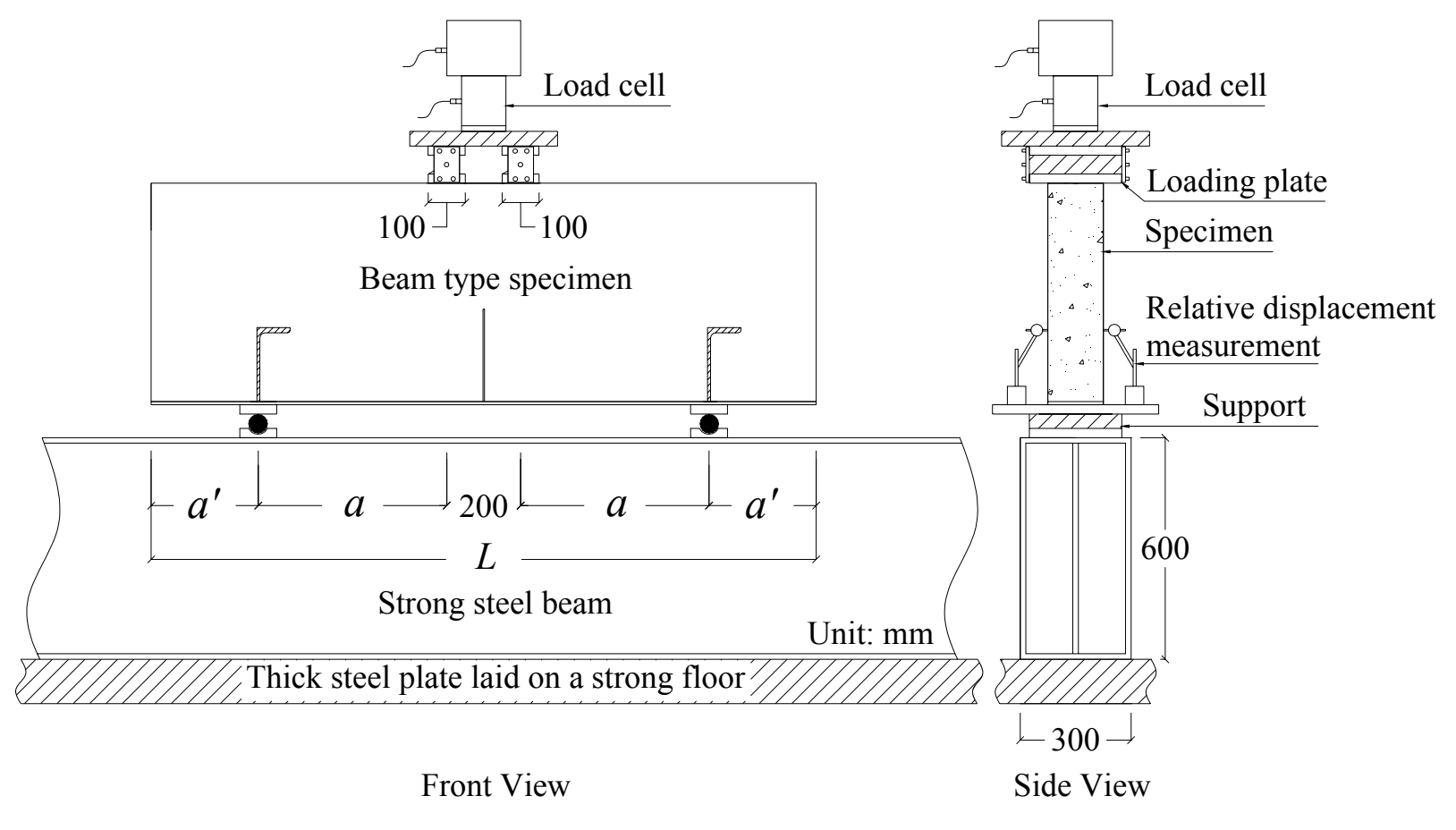

Figure III. 6 Experimental set-up 


\section{CHAPTER IV}

\section{EXPERIMENTAL RESULTS, ANALYSES, AND DISCUSSIONS}

\section{IV.1 L-Shape Shear Connector under Strut Compressive Force with Strut Angle of 45 Degrees ( $1^{\text {st }}$ Test Series Specimens)}

\section{IV.1.1 General}

The performance of L-shape shear connector subjected to strut compressive force with strut angle of 45 degrees $\left(\theta=45^{\circ}\right)$ were examined by $1^{\text {st }}$ test series specimens that consisted of four beam type specimens. As described in chapter III, they were designed to study the effects of size of shear connector and concrete strength on the mechanical behavior of the shear connector especially the shear force-relative displacement relationship. Since all specimens failed on the left side, this study focused on the left side shear connectors. Therefore, this chapter accordingly describes and discussed every detail of the results of $1^{\text {st }}$ test series specimens and FEM analyses.

\section{IV.1.2 Failure Mode of L-Shape Shear Connectors $\left(\theta=\mathbf{4 5}^{\circ}\right)$}

All specimens failed when splitting crack occurred (split failure) in the concrete from the toe of the shear connector to the loading point. No break of L-shape shear connector and also no sign of yielding of skin plate were observed. Three stages of cracking in the concrete were observed before failure. Firstly, flexural crack took place at mid span and propagated almost vertically to the upper compression zone. Secondly, first diagonal crack occurred in the concrete starting from the head of the shear connector to the loading point. Finally, at failure, splitting crack appeared in the concrete starting from the toe of the shear connector forming an angle of approximately $45^{\circ}$ with the member's horizontal axis. It was found that all specimens have almost the same crack patterns, Fig.IV.1.1. The conditions of the specimens at failures are available in APPENDIX IV.1.

During the experiment, load $P$ still could be applied on the specimens even though a diagonal crack already took place in the concrete starting from the head of the shear connector. However, the specimens could not resist against any more load when splitting crack occurred. Therefore, it 
can be said that L-shape shear connector subjected to strut compressive force failed by failure of concrete block in front of the shear connector or failed by splitting crack occurrence.

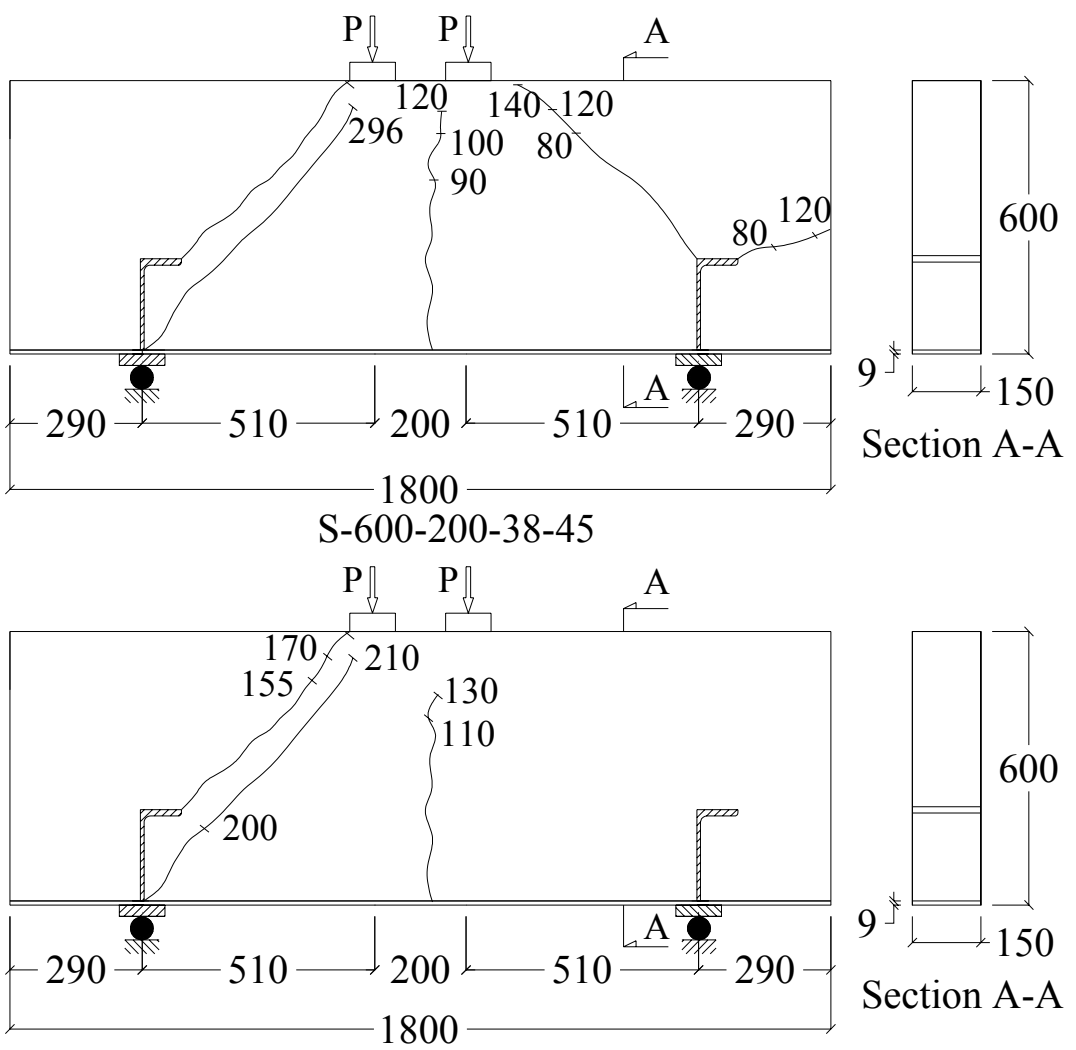

S-600-200-25.3-45
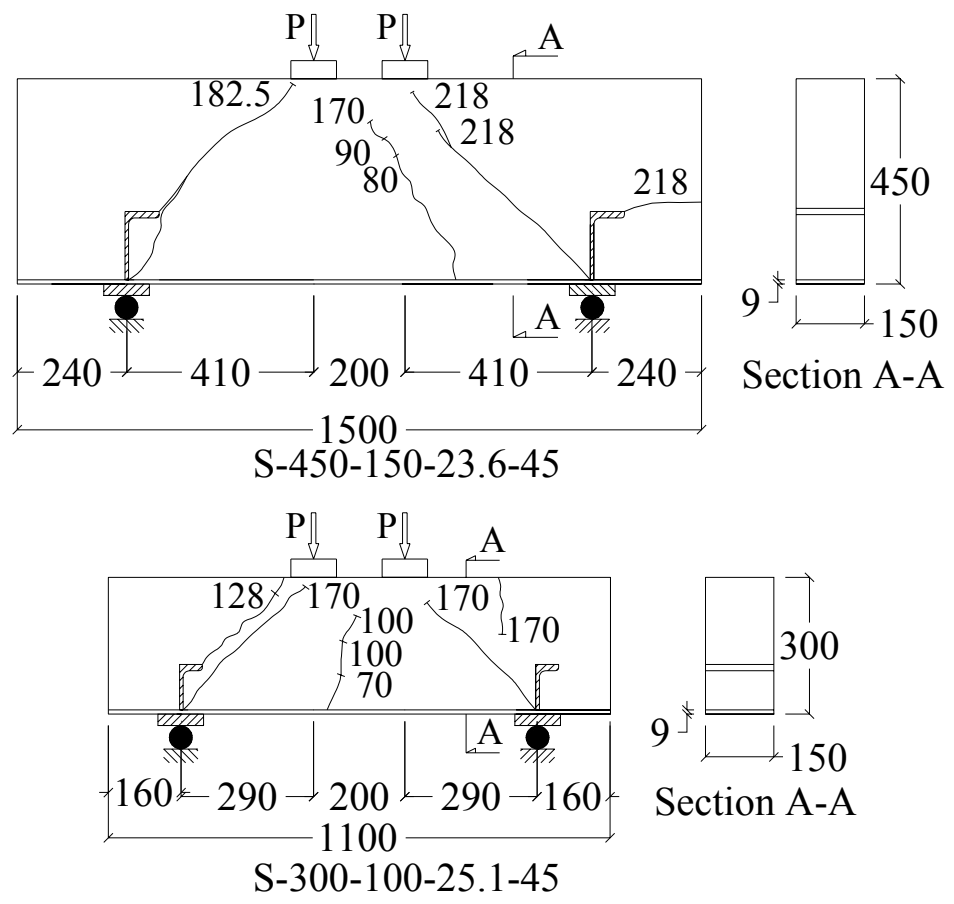

Figure IV.1. 1 Crack patterns of $1^{\text {st }}$ test series specimens 


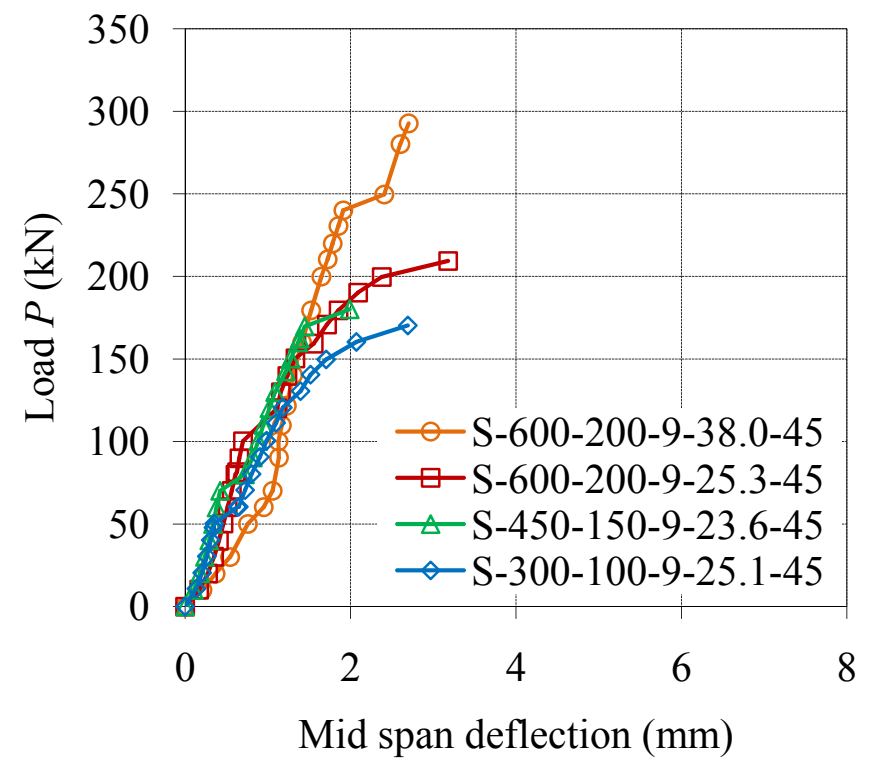

Figure IV.1. 2 Load-mid span deflection relationships of $1^{\text {st }}$ test series specimens

Furthermore, load-mid span deflection relationships of the specimens were also observed. As illustrated in Fig.IV.1.2, at the early stage the curves of the relationships are almost the same. The effect of concrete strength on load-mid span deflection relationships can be observed between S-600-200-9-38-45 and S-600-200-9-25.3-45 that with the same size of shear connector and the same strut angle, both specimens failed at similar values of deflection but the specimen with higher concrete strength failed at higher load levels. Additionally, since S-600-200-9-25.345, S-450-150-9-23.6-45, and S-300-100-9-25.1-45 behaved similarly until failure, the effect of size of shear connector on the relationships cannot be identified.

\section{IV.1.3 Ultimate Shear Force of Shear Connector Failed in Split Failure $\operatorname{Mode}\left(\theta=\mathbf{4 5}^{\circ}\right)$ \\ a) Critical Factor Controlling Ultimate Shear Force of L-shape Shear Connector}

The behavior of the shear connector and the surrounding concrete at failure indicated the most critical factor controlling ultimate shear force of L-shape shear connector subjected to strut compressive force. As illustrated in the previous subchapter, shear connector were found to lose its shear resistance ability when splitting crack took place in the concrete in front of the shear connector. Therefore, the observations were made on the behavior of concrete where splitting crack occurred. 
The development of the principal tensile strain in the concrete at which splitting crack took place may illustrate the behaviors of the concrete. The strain values obtained from LD39 to LD44 were used to calculate the principal tensile strain perpendicular to the splitting crack direction. As shown in Fig.IV.3 splitting crack took place when the principal tensile strains in the concrete reached approximately $210 \mu$, simultaneously, ultimate shear forces of the shear connectors were observed. Therefore, it can be said that splitting crack occurrence in the concrete in front of the shear connector controlled the ultimate shear force of L-shape shear connector subjected to strut compressive force.

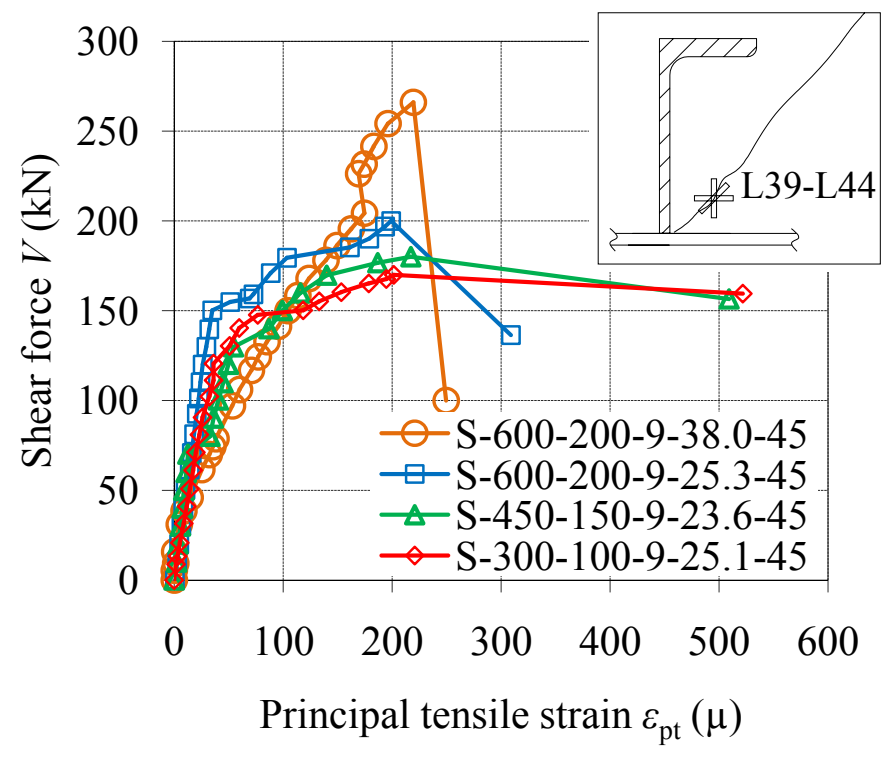

Figure IV.1.3 Shear force and principal tensile strain relationship

Furthermore, the behaviors of the shear connector can be illustrated in Fig.IV.1.4. The experimental results showed that after crack took place from the head of the shear connector, the strain in concrete in front of the shear connector transformed to principal direction and splitting crack occurred when the principal tensile stress $\sigma_{t}$ exited the tensile strength of the concrete $f_{t}$. Simultaneously, splitting crack appeared along the strut compressive axis perpendicular to the direction of the principal stress.

Additionally, splitting crack could take place unless there was a release of principal tensile stress which was controlled by the relative displacement of shear connector. As shown in Fig.IV.1.4 split failure occurred when the value of the relative displacement of the shear connector $\delta$ reached its ultimate value $\delta_{\mathrm{u}}$. Therefore, it can be said that the relative displacement of the shear 
connector indirectly controlled the ultimate shear force of the shear connector; meanwhile, the tensile strength of the concrete directly determined the ultimate shear force of the shear connector subjected to strut compressive force.

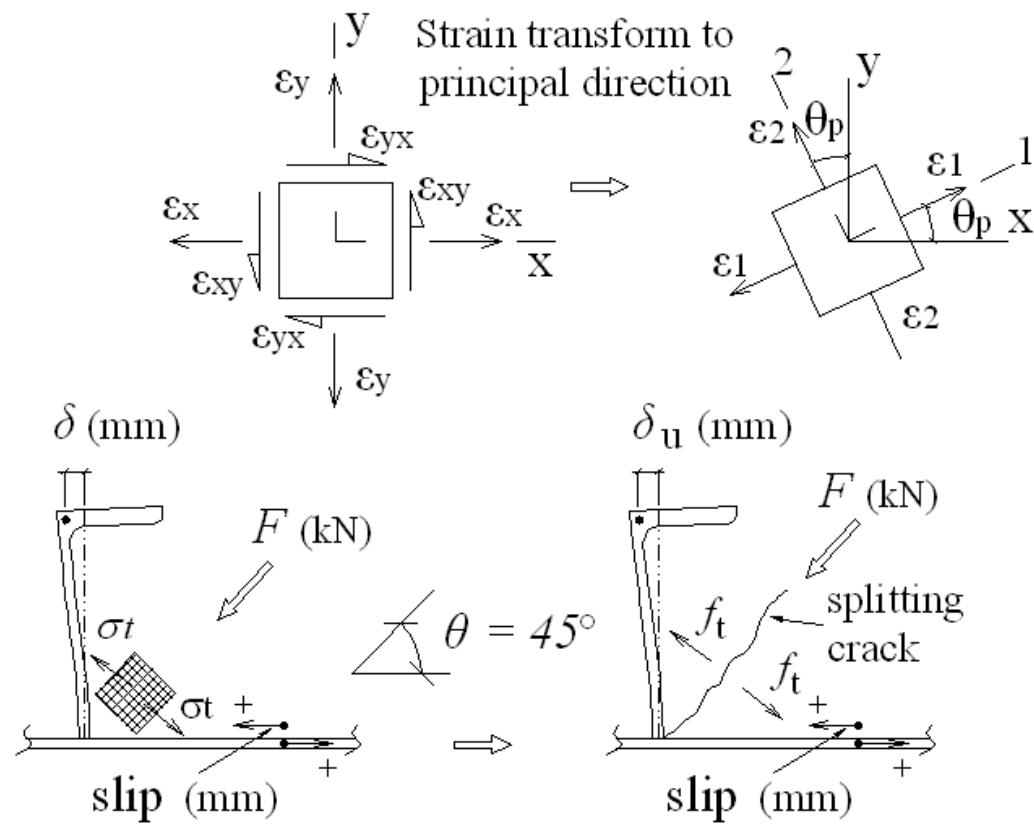
(a) after crack from head of shear connector
(b) at splitting crack occurrence

Figure IV.1.4 L-shape shear connector before and at split failure

\section{b) Ultimate Shear Force of L-shape Shear Connector}

Shear force $V$ was calculated by multiplying stress $\sigma_{\mathrm{s}}$ in the steel plate in front of the shear connector by the area of the steel plate $A_{s}\left(A_{s}=t_{f} \times b\right)$. Meanwhile, the stress was calculated by means of the stress-strain relationship of the steel skin plate, $\left(\sigma_{s}=E_{s} \varepsilon_{s}\right)$ whose strain values were obtained from the strain gauges LD1-LD4. Since there were no sign of the steel skin plate yielding until failure of the shear connector, the stress-strain relationship of the steel skin plate can be used to calculate the ultimate shear force of the shear connector $V_{\mathrm{u}}$. The relationships between load $P$ and strain in the skin plate are given in APPENDIX IV.2. 


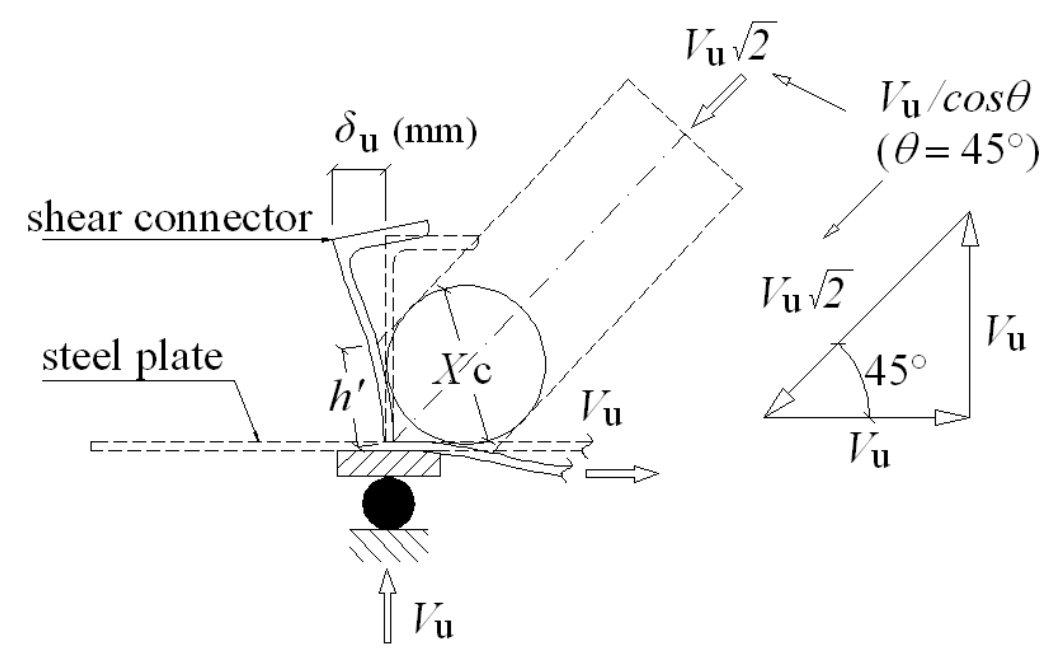

Figure IV.1. 5 Model of L-shape shear connector subjected to strut compressive force $\left(\boldsymbol{\theta}=\mathbf{4 5}^{\boldsymbol{0}}\right)$

Fig.IV.1.5 gives the model of L-shape shear connector subjected to strut compressive force with strut angle $\theta=45^{\circ}$. It has been observed that at split failure the relative displacement of the shear connector reached its ultimate value $\delta_{\mathrm{u}}$, and the height confining concrete against the shear connector was $h^{\prime}$. Meanwhile, the width of the compressive strut was $X_{c}$. It is assumed that at split failure the behavior of the concrete in front of the shear connector was the same as that in the cylinder with diameter $X_{c}$ in the split tensile strength test. Moreover, splitting crack occurred when the principal tensile stress exit the tensile strength of the concrete which can be expressed as followings:

$$
\begin{aligned}
& f_{t}=\frac{2 \times \sqrt{2} \times V_{\mathrm{u}}}{\pi \times X_{\mathrm{c}} \times b_{\mathrm{sc}}} \\
& =>V_{\mathrm{u}}=\frac{\pi}{2 \times \sqrt{2}} \times f_{t} \times b_{s c} \times X_{c}
\end{aligned}
$$

With $X_{c}=h^{\prime} \sqrt{2}$ and $f_{t}=0.44 \sqrt{f_{c}^{\prime}}$, JSCE (2005)[25] Eq.IV.1 can be given as followings:

$$
V_{u}=0.22 \times \pi \times h^{\prime} \times b_{s c} \times \sqrt{f_{c}^{\prime}}
$$

Or $\quad V_{u}=k_{1} \times \sqrt{f_{c}^{\prime}} \times b_{s c} \times h_{s c}$

That $k_{1}=0.22 \times \pi \times \frac{h^{\prime}}{h_{\mathrm{sc}}} \quad$ or $\quad k_{1}=\frac{V_{\mathrm{u}}}{\sqrt{f_{c}^{\prime}} \times b_{\mathrm{sc}} \times h_{\mathrm{sc}}}$ 
Moreover, $k_{1}$ is a constant representing the effects of other factors. Meanwhile, the value of $k_{1}$ can be calculated by means of Eq.IV.2 where $V_{\mathrm{u}}$ is the ultimate shear force of the shear connector obtained from the experimental results, Table IV.1.1. Additionally, it has been known that the strength of the shear connector is highly influenced by its thickness to height ratio $t_{1, s c} / h_{s c}$. Therefore, the relationships between $k_{1}$ and $t_{1, s c} / h_{s c}$ were observed. It can be seen in Fig.IV.1.6 that the values of $k$ linearly increased with the values of $t_{1, s c} / h_{s c}$ and the relationships can be expressed as follows:

$$
k_{1}=19.56 \times\left(\frac{t_{1, \mathrm{sc}}}{h_{\mathrm{sc}}}\right)+0.494
$$

Therefore, the ultimate shear force at split failure occurrence can be expressed as followings:

$$
V_{\mathrm{u}}=k_{1} \times \sqrt{f_{c}^{\prime}} \times b_{\mathrm{sc}} \times h_{s c}
$$

Where,

$V_{\mathrm{u}} \quad$ : ultimate shear force at splitting $\operatorname{crack}(\mathrm{N})$

$b_{s c} \quad$ : width of shear connector $(\mathrm{mm})$

$h_{s c} \quad$ : height of shear connector (mm)

$t_{1, s c}:$ thickness of shear connector (mm)

$f_{c}^{\prime} \quad$ : concrete compressive strength $\left(\mathrm{N} / \mathrm{mm}^{2}\right)$

Table IV.1. 1 Ultimate shear forces and $k_{1}$ values obtained from experimental results

\begin{tabular}{||c|c|c|c|c|c|c|c|}
\hline Specimens & $\begin{array}{c}t_{1, s c} \\
(\mathrm{~mm})\end{array}$ & $\begin{array}{c}h_{s c} \\
(\mathrm{~mm})\end{array}$ & $\frac{t_{1, s c}}{h_{s c}}$ & $\begin{array}{c}b_{s c} \\
(\mathrm{~mm})\end{array}$ & $\begin{array}{c}f_{c}^{\prime} \\
\left(\mathrm{N} / \mathrm{mm}^{2}\right)\end{array}$ & $\begin{array}{c}V_{u . e x p} \\
(\mathrm{kN})\end{array}$ & $k_{1}$ \\
\hline \hline S-600-200-9-38.0-45 & 9 & 200 & 0.045 & 150 & 38.0 & 266 & 1.438 \\
\hline S-600-200-9-25.3-45 & 9 & 200 & 0.045 & 150 & 25.3 & 200 & 1.325 \\
\hline S-450-150-9-23.6-45 & 9 & 150 & 0.06 & 150 & 23.6 & 180 & 1.647 \\
\hline S-300-100-9-25.1-45 & 9 & 100 & 0.09 & 150 & 25.1 & 170 & 2.262 \\
\hline
\end{tabular}




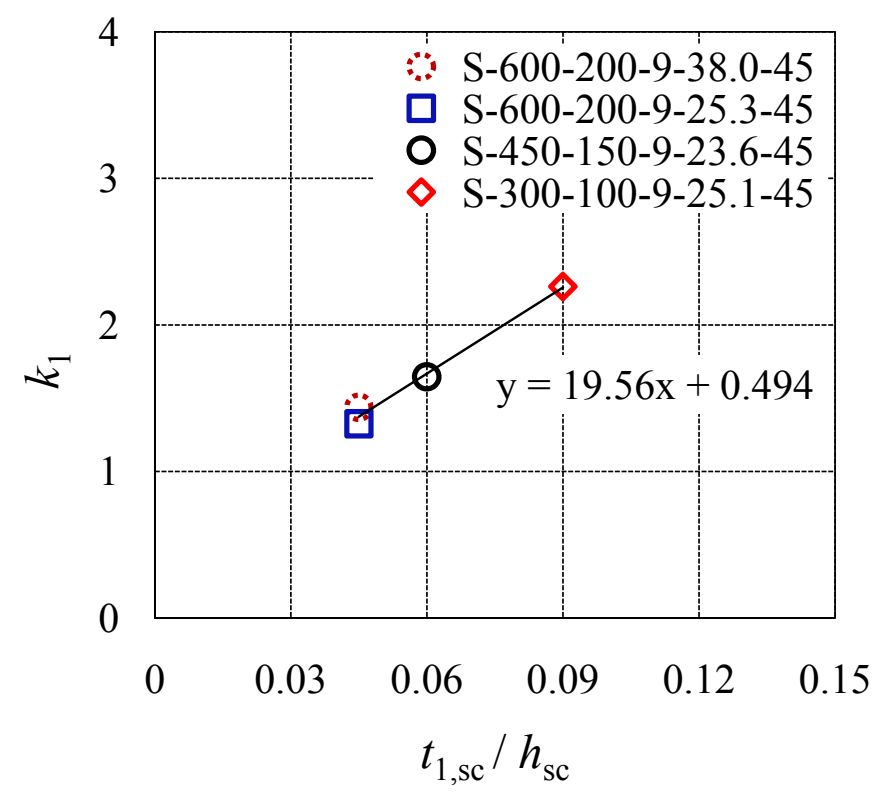

Figure IV.1. 6 Relationship between $\boldsymbol{k}_{\mathbf{1}}$ and $\boldsymbol{t}_{\mathbf{1 , s c}} / \boldsymbol{h}_{\boldsymbol{s c}}$.

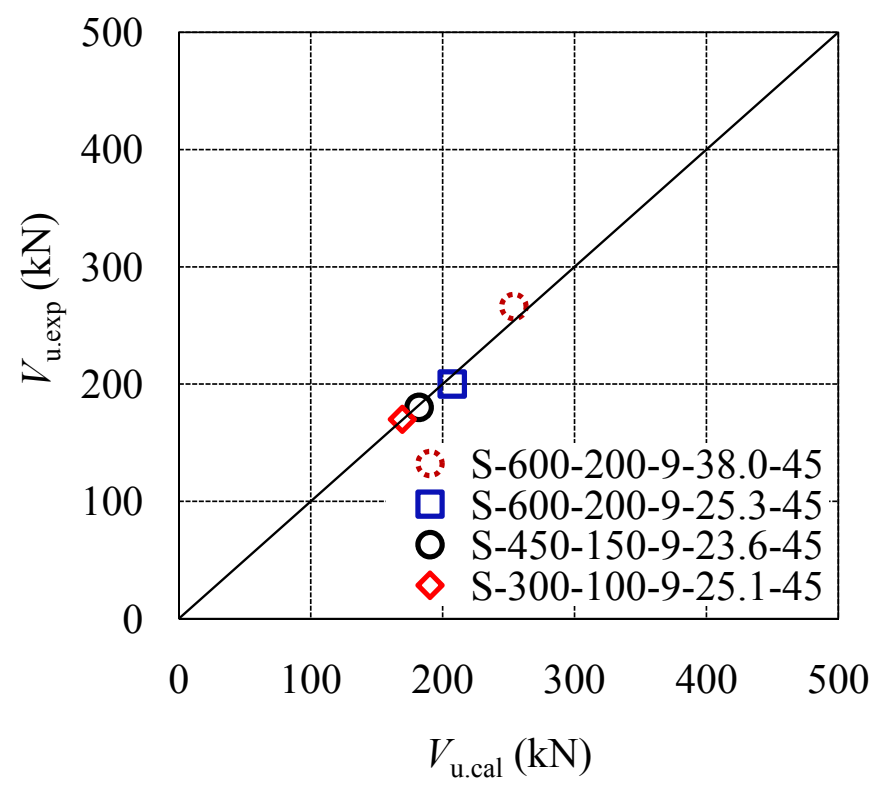

Figure IV.1. 7 The comparison between ultimate shear force from experiments and calculations

The ultimate shear forces of the shear connectors calculated by means of Eq.IV.4 $V_{u . c a l}$ were compared with those obtained from the experiment $V_{\text {u.exp. As }}$ shown in Fig.IV.1.7, the calculated ultimate shear forces $V_{u . c a l}$ agreed well with the experimental results $V_{u . \exp }$. Moreover, it can be said that Eq.IV.4 can precisely predict the ultimate shear force of L-shape shear connector at split failure with $V_{u . e x p}$ to $V_{u . c a l}$ ratios varied from 0.96 to 1.05, Table IV.1.2. However, Eq.IV.4 is applicable for the case that strut angle $\theta=45^{\circ}$. 
Table IV.1. 2 Ultimate Shear force of shear connector from experiments and calculations

\begin{tabular}{|l|c|c|c|}
\hline \multicolumn{1}{|c|}{ Specimens } & $\begin{array}{c}V_{\text {u.exp }} \\
(\mathrm{kN})\end{array}$ & $\begin{array}{c}V_{\text {u.cal }} \\
(\mathrm{kN})\end{array}$ & $\frac{V_{\text {u.exp }}}{V_{u . c a l}}$ \\
\hline \hline S-600-200-9-38.0-45 & 266 & 254 & 1.05 \\
\hline S-600-200-9-25.3-45 & 200 & 207 & 0.96 \\
\hline S-450-150-9-23.6-45 & 180 & 182 & 0.98 \\
\hline S-300-100-9-25.1-45 & 170 & 169 & 1.00 \\
\hline
\end{tabular}

\section{IV.1.4 Shear Force-Slip Relationship of L-shape Shear Connector}

The average values obtained from the displacement transducers LD1-LD4 were determined as slip between the concrete and the steel plate in front of the shear connector. Fig.IV.1.8 gives shear force-slip relationships of the shear connectors of $1^{\text {st }}$ test series specimens. It can be observed that concrete-skin plate slip of L-shape shear connector subjected to strut compressive force appeared even at low load levels. These similar behaviors were also found by Kiyomiya et al. (1986) [6], Ueda et al. (1989) [10], and Chuah et al. (1991) [9].

It can be seen that the curves of the relationships in S-600-200-9-38.0-45, S-600-200-9-25.3-45, and S-450-150-9-23.6-45 were almost the same; therefore, no effects of concrete strength and height of shear connector on the shear force-slip relationships were observed. However, the experimental results showed that for the same size shear connector, the shear connector with higher concrete strength failed at greater values of ultimate slip as compared to the shear connector with lower concrete strength. Meanwhile, the shear connectors with the same concrete strength and strut angle were found to fail at similar value of the ultimate slips. In short, it can be said that concrete strength did not affect the shear force-slip relationships' curves but the ultimate shear force of the shear connector and the ultimate value of concrete-skin plate slip.

Moreover, it can be observed in S-600-200-9-25.3-45 and S-300-100-9-25.1-45 that after crack took place in the concrete starting from the head of the shear connector, the shear connectors were found to resist against the shear force with the values of slips almost constant until splitting crack occurred in the concrete in front of the shear connector. These behaviors indicated the development of the principal tensile stress in the concrete in front of the shear connector. 
Meanwhile, it can be said that the stress in the concrete rapidly increased after crack appeared from the head of the shear connector leading to splitting crack occurrence.

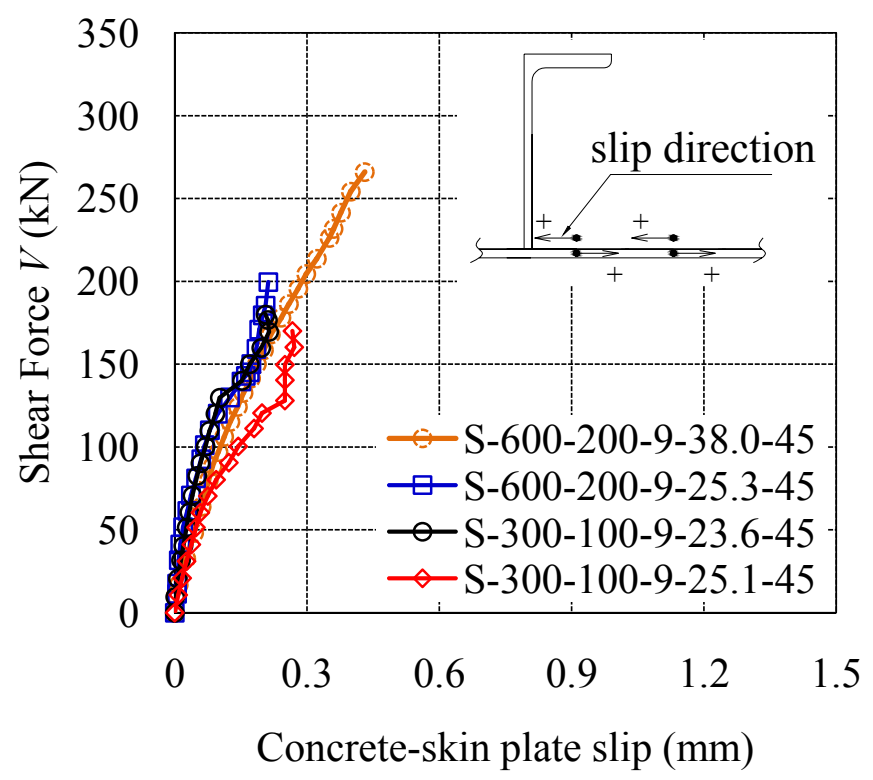

Figure IV.1. 8 Shear force-slip relationships $\boldsymbol{\theta}=\mathbf{4 5}^{\mathbf{0}}$

More importantly, the experimental results showed that shear force-slip relationship is not applicable to fully explain the partial interaction mechanisms of L-shape shear connector since this relationship cannot be clearly observed at the ultimate state of the shear connector.

\section{IV.1.5 Shear Force-Relative Displacement Relationships $\left(\theta=\mathbf{4 5}^{\circ}\right)$}

Since the relationships between shear force and relative displacement could be observed only in S-600-200-9-25.3-45 and S-300-100-9-25.1-45, the discussions were accordingly conducted. Fig.IV.1.9 give the relationship between shear force and relative displacement of S-600-200-925.3-45 before the occurrence of crack from the head of the shear connector. It can be seen that the relative displacements of the shear connector were detected negatively when the levels of shear force were less than $150 \mathrm{kN}$. The negative values of the relative displacement indicated the forward movement of the head of the shear connector. Similar behaviors were also observed in the steel-concrete sandwich beams by Makabe et al. (1991) [11] that when the load level was than $100 \mathrm{kN}$, the head of the shear connector moved forward (negative); conversely, when load level was greater than $100 \mathrm{kN}$, it moved backward (positive). However, it has been observed 
during the experiment that at $150 \mathrm{kN}$ crack started to appeared in the concrete starting from the head of the shear connector; therefore, it seemed that the occurrence of this crack induced backward movement of the head of the shear connector.

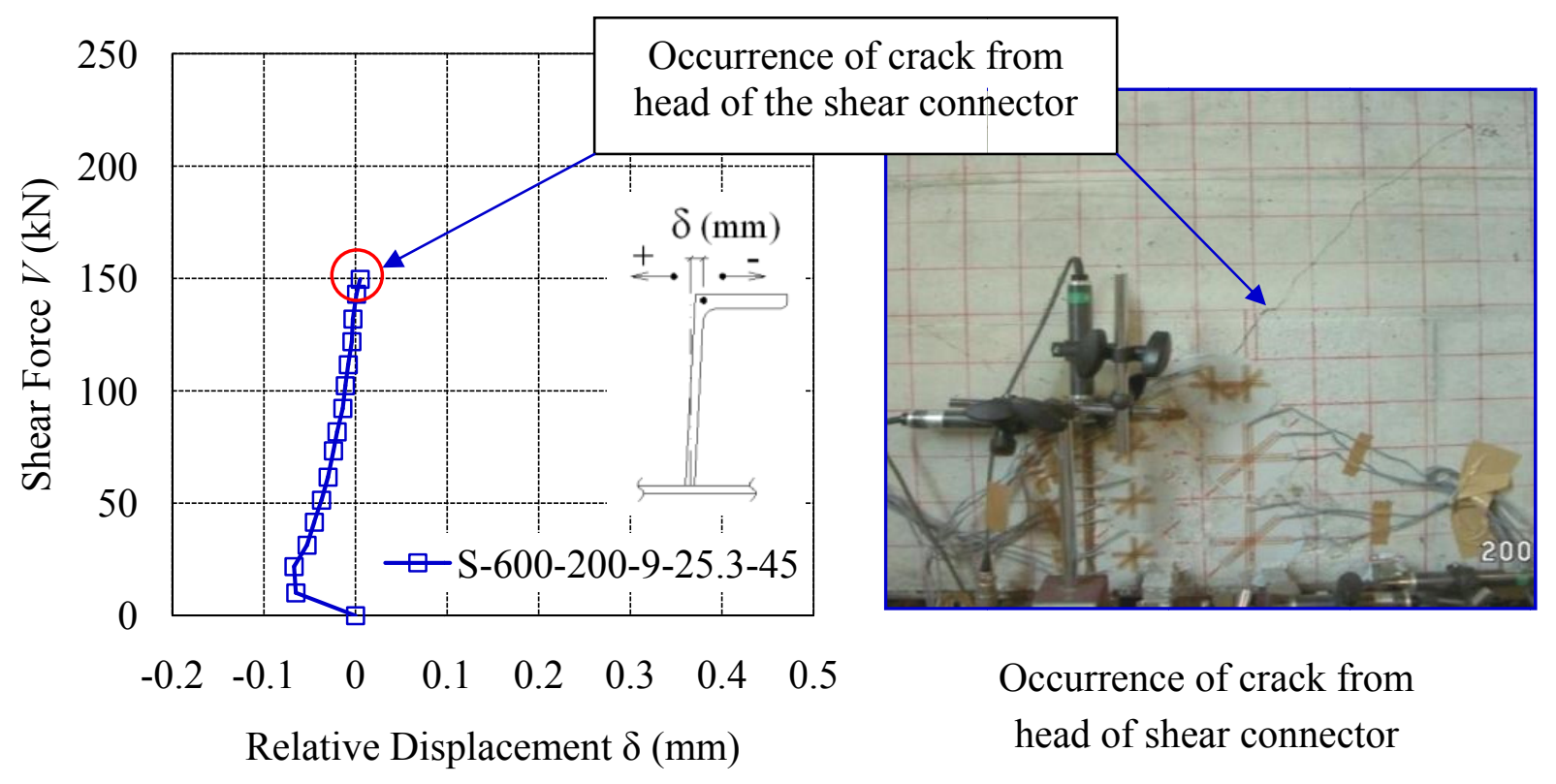

Figure IV.1. 9 Shear force-relative displacement relationship before the occurrence of crack from the head of the shear connector

Furthermore, it can be observed in Fig.IV.1.10 that the relative displacements of the shear connectors were very small for both S-600-200-9-25.3-45 and S-300-100-9-25.1-45 before the occurrences of crack in the concrete starting from the head of the shear connectors. On the other hand, the sudden increment of the relative displacement at low level of shear force in S-300-1009-25.1 was due to the unexpected sudden rotation of the inserted steel plate before it fully touched the steel plate of the specimen. Moreover, after the occurrence of the crack in the concrete from the head of the shear connector, big increments of the relative displacements with small increments of shear force were observed until failure of the shear connector. Similar behaviors were also observed in steel-concrete sandwich beam by Saidi et al. (1998 [12], 1999 [13], and 2008 [14]). Moreover, it was observed that larger size L-shape shear connector failed at greater value of ultimate shear force and ultimate relative displacement than the smaller size Lshape shear connector. 
Additionally, the shapes of shear force-relative displacement relationships' curves of L-shape shear connector subjected to strut compressive force were clearly observed in the interval of the occurrence of crack from the head of the shear connector and failure of the shear connector. More importantly, it can be observed that shear force-relative displacement is suitable to use to explain the partial interaction mechanisms of L-shape shear connector subjected to strut compressive force at its ultimate state. The ultimate relative displacement corresponding to the ultimate shear force of the shear connector can be clearly observed from the experimental results. Therefore, it is important to identify the equations of shear force-relative displacement relationship of the shear connector in this interval.

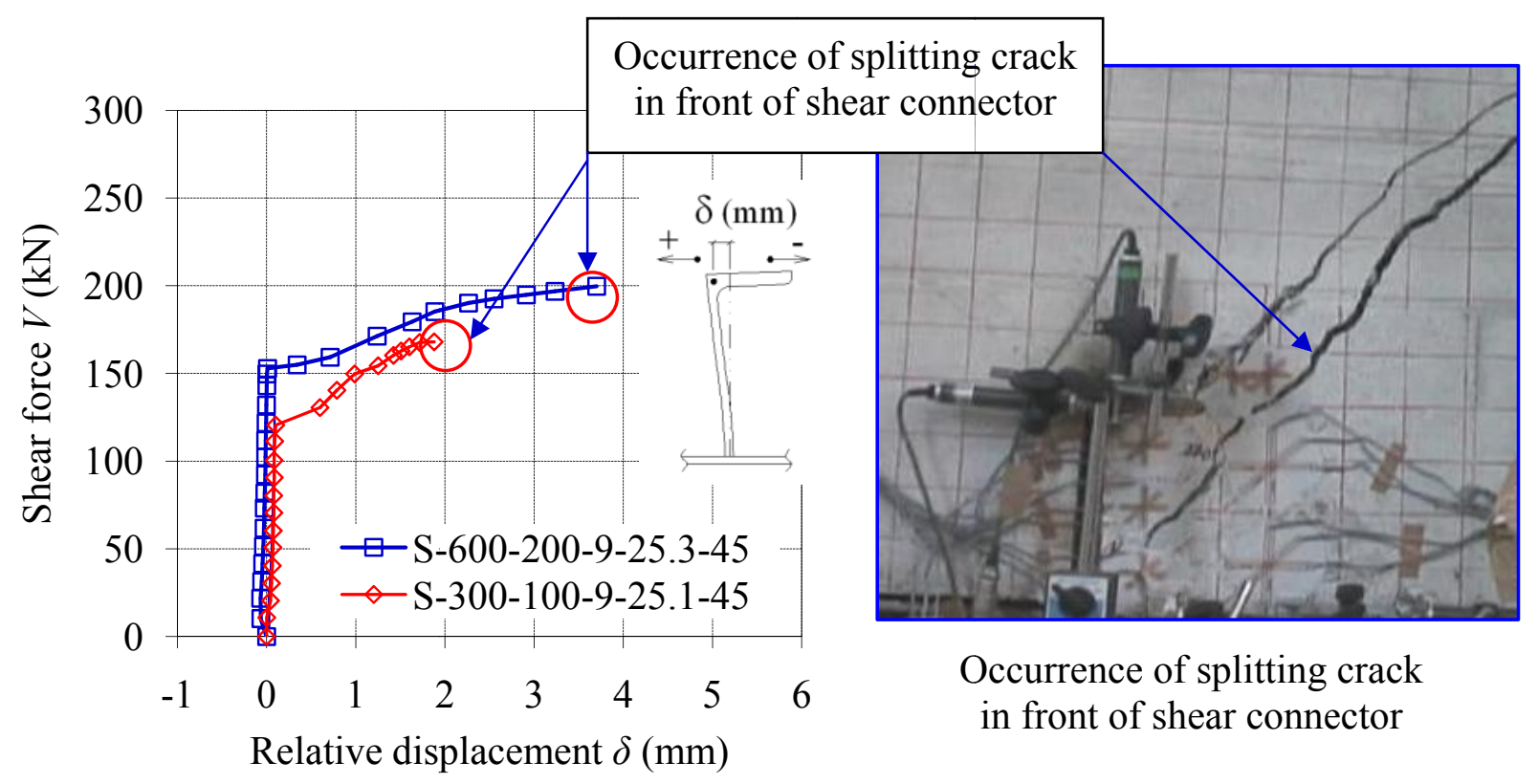

Figure IV.1. 10 Shear force-relative displacement relationship $\boldsymbol{\theta}=\mathbf{4 5}^{\boldsymbol{o}}$

\section{IV.1.6 FEM Analyses for Shear Force-Relative Displacement Relationships $\left(\theta=45^{\circ}\right)$}

Finite element analyses were conducted to verify the experimental results. There were three material types for the element: plain concrete, steel and bond link or joint element. Based on elasto-plastic and fracture model, Okamura and Maekawa (1997) [26] a constitutive model for the concrete before cracking was constructed. Meanwhile, a constitutive model of cracked concrete consisted of tension stiffening, compression and shear transfer model. A twodimensional failure criterion in tension-tension and compression-tension was applied to the analyses. Since steel plates and shear connectors were in elastic ranges until failure of the 
specimens, elastic plate was selected and assumed to be steel plate and shear connector in the analyses. On the other hand, bond link element was originated from a linear bond stress-slip relationship. It was applied along the contact between the steel and the concrete. Bond link element's normal stiffness in compression direction was maintained a great value, 300 times greater than the shear stiffness in order to avoid element overlap. Meanwhile, the stiffness in tension was maintained a low value for easy parting between the steel elements and the concrete elements. The detail of bond link element is available in APPENDIX IV.3.

As mentions in the previous subchapter, the shape of the shear force-relative displacement relationships' curves were clearly observed after the occurrence of crack from the head of the shear connector. Therefore, FEM analyses were according conducted. Fig.IV.1.11 illustrates the development of FEM mesh of beam type specimen after the occurrence of flexural crack and crack from the head of the shear connector. As shown in Fig.IV.1.11, in the analyses, the flexural crack and the crack in the concrete starting from the head of the shear connector were accordingly introduced to make it agree with the conditions of the specimens in the experiments.

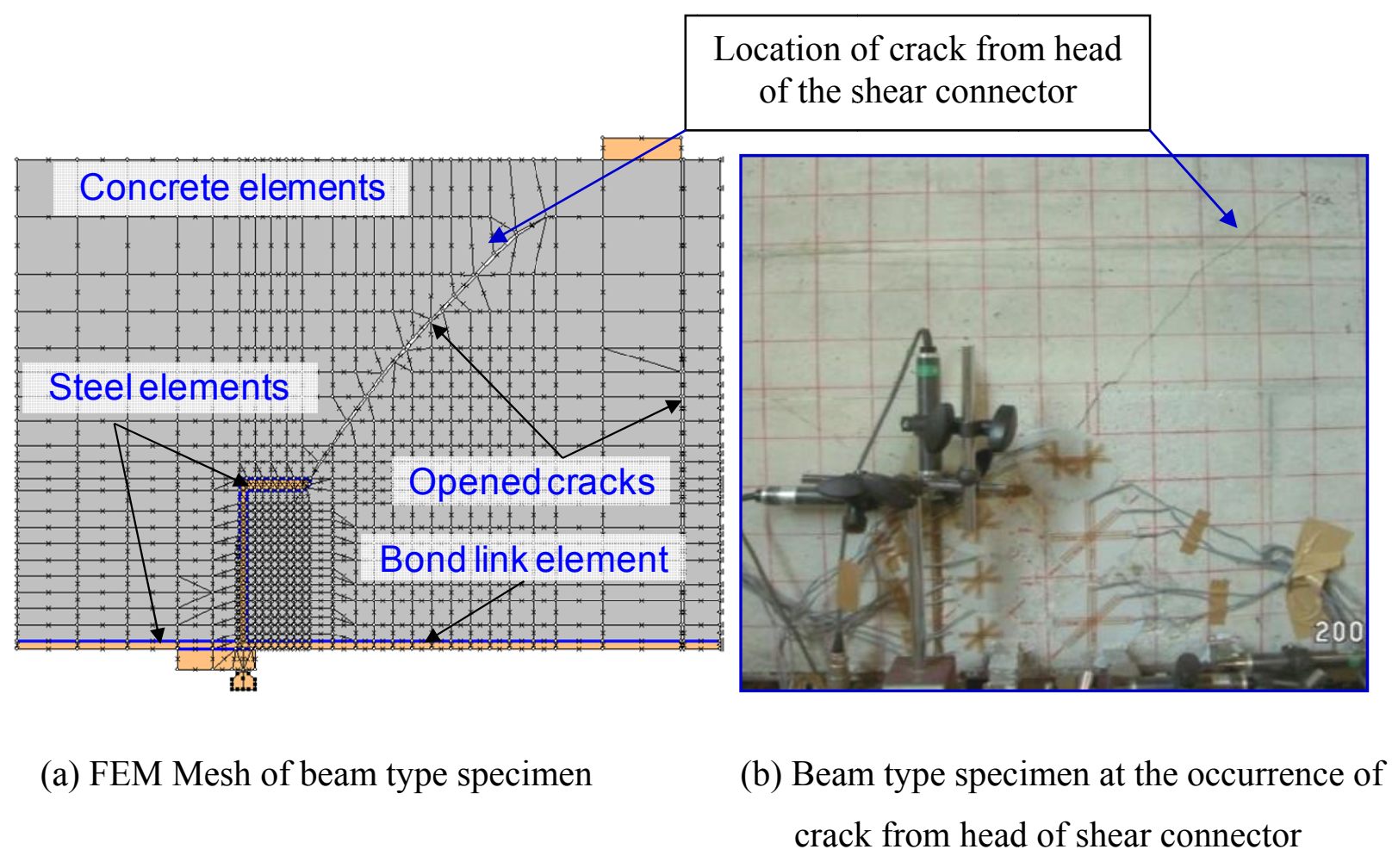

Figure IV.1. 11 Development of FEM Mesh of beam type specimen 
Fig.IV.1.12 shows the comparison between the failure mode observed in the FEM analyses and the experimental results. It can be seen that good agreements between the analyses results and the experimental results were observed in terms of the deformations of L-shape shear connector at failure and the crack distributions. Furthermore, as shown in Fig.IV.1.12 (b), the locations and the directions of splitting cracks appeared in the FEM mesh were found to be the same as those appeared in beam type specimens.

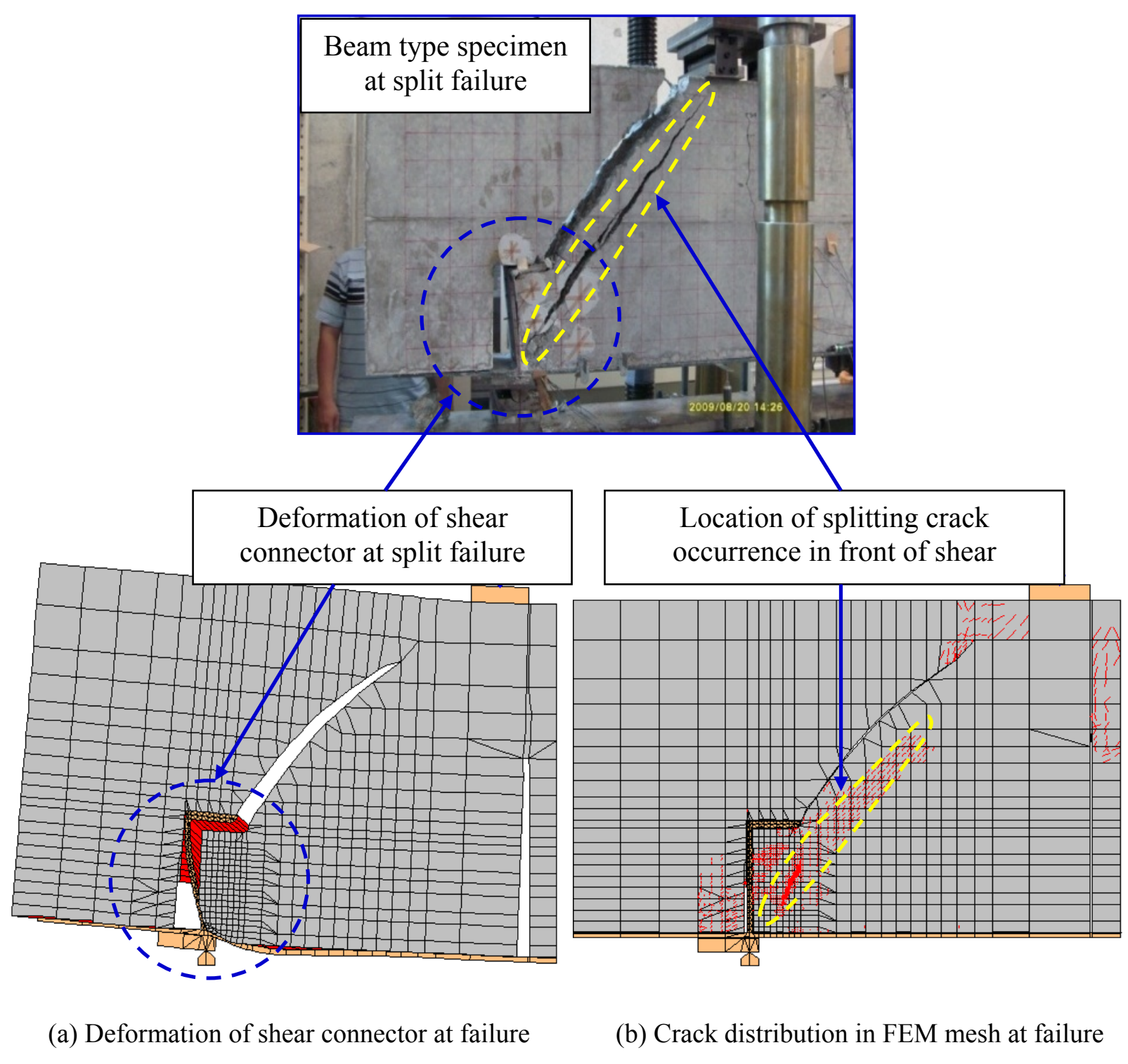

Figure IV.1. 12 Failure mode of shear connector in FEM analysis and beam type specimen

Moreover, the experimental results and FEM analyses results were also compared for S-600-2009-25.3-45 and S-300-100-9-25.1-45 in Fig.IV.1.13 and Fig.IV.1.14, respectively. It can be seen 
that the FEM analyses results agreed well with the experimental results in terms of ultimate shear force of L-shape shear connector, ultimate relative displacement, shear force-relative displacement relationships, and load-deflection relationships. Additionally, the stiffness of Lshape shear connectors in the FEM analyses were found a little smaller than those in the experiments due to the fact that flexural crack and crack from the head of the shear connector were initially introduced. However, most similar behaviors of L-shape shear connector subjected to strut compressive force were observed between the FEM analyses results and the experimental results.

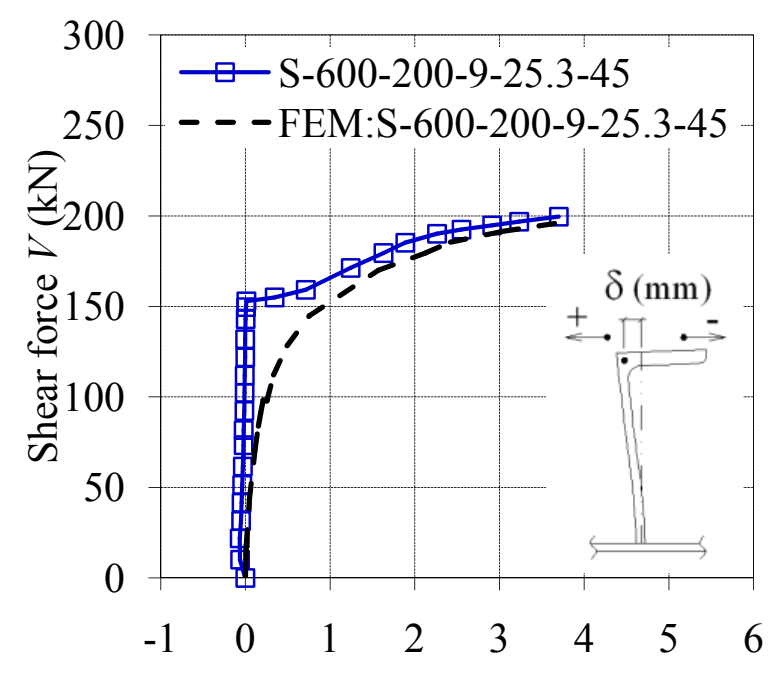

Relative displacement $\delta(\mathrm{mm})$

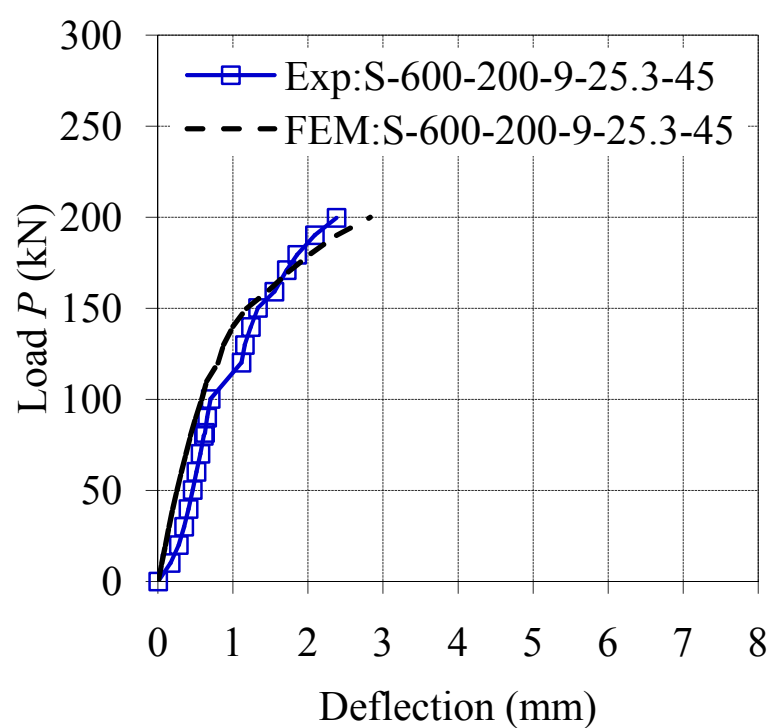

Deflection (mm)

Figure IV.1. 13 Experimental Results and FEM analyses results S-600-200-9-25.3-45
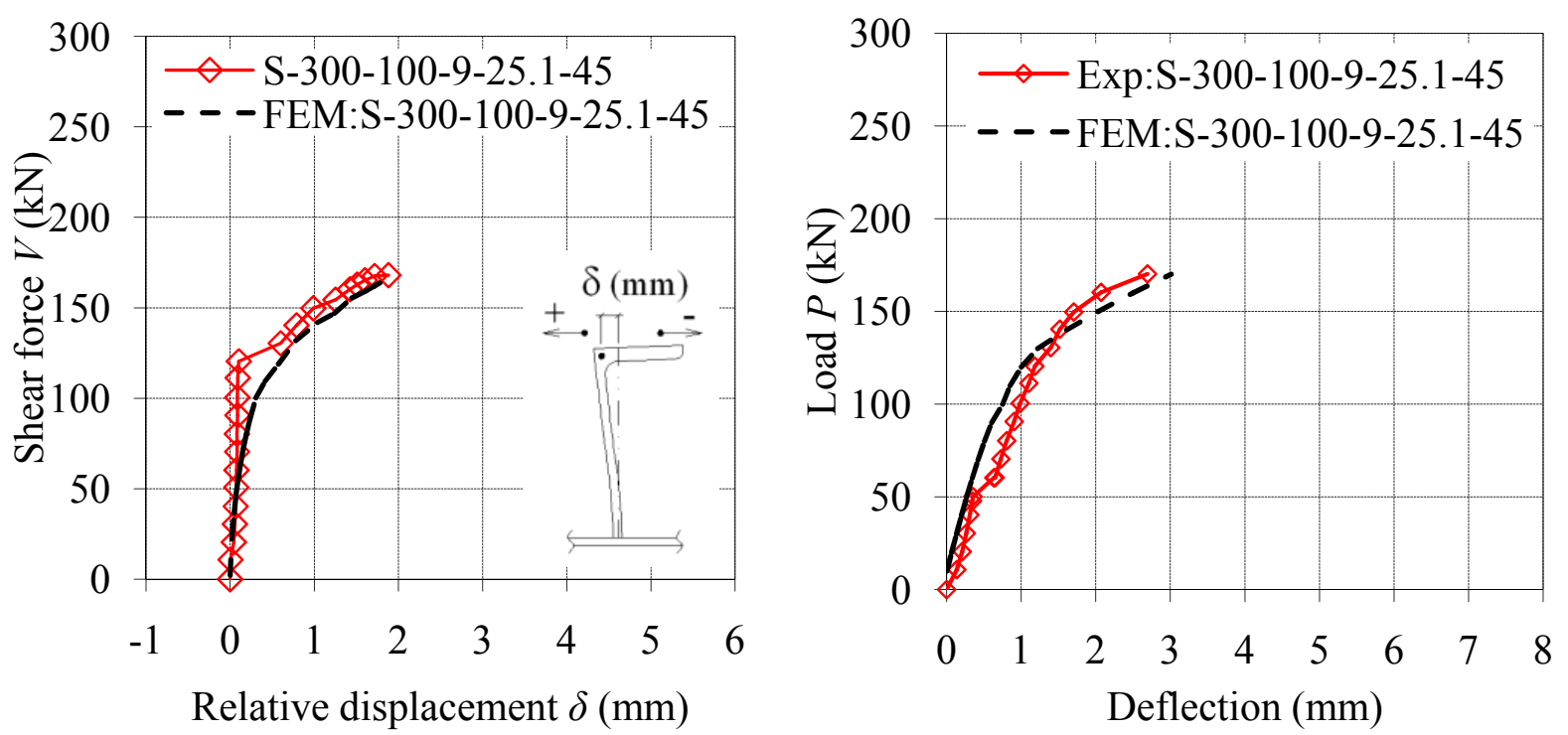

Figure IV.1. 14 Experimental Results and FEM analyses results S-300-100-9-25.1-45 
It has been known that FEM Analyses with different sizes of element mesh division may give different results. However, according to this study the concrete element in front of the shear connector was divided into small meshes, $10 \mathrm{~mm}$ to $20 \mathrm{~mm}$. The analyses results showed that the opened crack in concrete element in front of the shear connector occurred at the same location and direction of the splitting crack in the test specimens, and at the same level of ultimate shear force. Moreover, by means of joint element in steel-concrete element interface, steel-concrete interaction was set to zero in tension direction. It was observed that shear force-relative displacement relationships of shear connectors obtained from FEM analyses agreed well with experimental results.

Since FEM analyses results were found to agree with experimental results, it can be said that the results of FEM analyses are reliable. Therefore, the formulation for shear force-relative displacement of L-shape shear connector subjected to strut compressive force with strut direction $45^{\circ}$ will be developed by means of FEM analyses together with the experimental results. The formulation will be applicable for the case after the occurrence of crack from the head of the shear connector until failure of the shear connector, split failure.

\section{IV.1.7 FEM Analyses for Eq.IV.4 Verification}

\section{a) Verifications of Ultimate Shear Force by Means of Eq.IV.4}

A series of FEM analyses were conducted on the beam type specimens meshes with different sizes of L-shape shear connectors and concrete strengths but the same strut angle $\theta=45^{\circ}$ in case the flexural crack and the crack in the concrete starting from the head of the shear connector already existed. These analyses were conducted to verify the ultimate shear force of shear connector given by Eq.IV.4 and also to formulate an equation for shear force-relative displacement relationships of the shear connector.

The FEM meshes were symbolized as F- $h-h_{\mathrm{sc}}-t_{1, \mathrm{sc}}-f_{\mathrm{c}}^{\prime}$ and the characteristics of the meshes are given in Table IV.1.3. In the FEM analyses the ultimate shear forces $V_{\text {u.FEM }}$ were decided when the block of concrete element in front of the shear connector failed. Also the calculations of all specimens in FEM analyses stopped when opened cracks in the concrete elements in front of shear connector reached the loading point. Meanwhile, the opened cracks took place along the compressive strut's axis identically to the splitting cracks in the tested specimens. Table IV.1.3 lists of the ultimate shear forces obtained from the FEM analyses $V_{\text {u.FEM }}$ and the those calculated 
by means of Eq.(4) $V_{\text {u.Eq4}}$. It has been observed that $V_{\text {u.FEM }}$ agreed well with $V_{\text {u.Eq4 }}$ that $V_{\text {u.FEM }}$ to $V_{\text {u.Eq4 }}$ ratios varied from 0.92 to 1.06. Additionally, as shown in Fig.IV.1.15 Eq.IV.4 can precisely predict the ultimate shear force of L-shape shear connector when $\theta=45^{\circ}$.

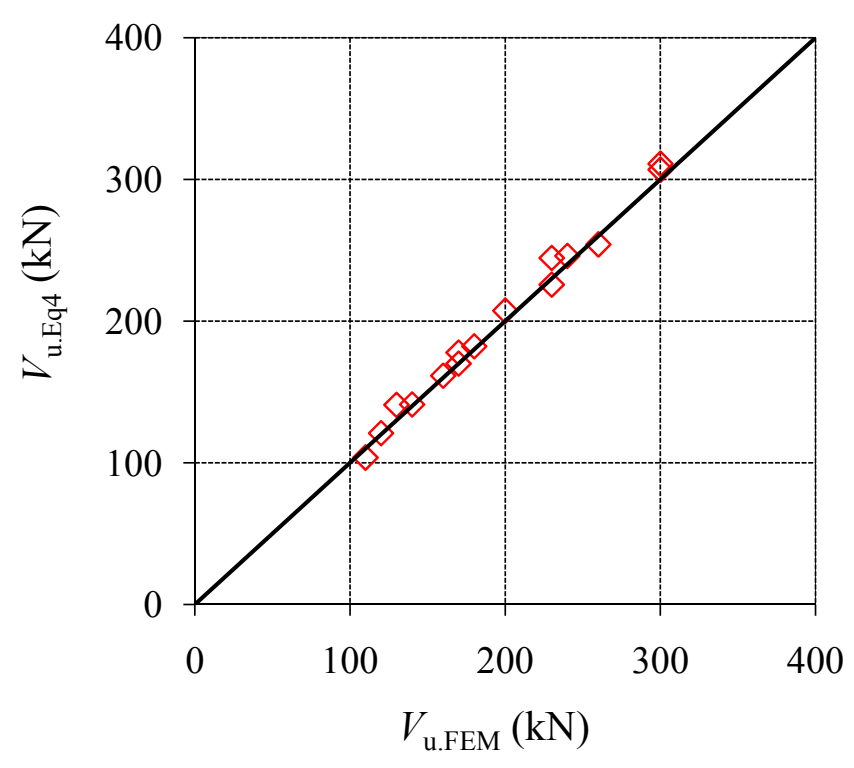

Figure IV.1. 15 The comparison between $\boldsymbol{V}_{\text {u.Eq4 }}$ and $\boldsymbol{V}_{\text {u.FEM }}$

Table IV.1. 3 Ultimate shear forces from FEM analyses and calculation by means of Eq.IV.4

\begin{tabular}{|c|l|c|c|c|c|c|c|c|c|c||}
\hline No & \multicolumn{1}{|c|}{ Specimens } & $\begin{array}{c}h \\
(\mathrm{~mm})\end{array}$ & $\begin{array}{c}h_{s c} \\
(\mathrm{~mm})\end{array}$ & $\begin{array}{c}b_{s c} \\
(\mathrm{~mm})\end{array}$ & $\begin{array}{c}t_{s c 1} \\
(\mathrm{~mm})\end{array}$ & $\begin{array}{c}t_{f} \\
(\mathrm{~mm})\end{array}$ & $\begin{array}{c}f_{c}^{\prime} \\
\left(\mathrm{N} / \mathrm{mm}^{2}\right)\end{array}$ & $\begin{array}{c}V_{u . F E M} \\
(\mathrm{kN})\end{array}$ & $\begin{array}{c}V_{u . E q .4} \\
(\mathrm{kN})\end{array}$ & $\begin{array}{c}V_{u . F E M} \\
V_{u . E q .4}\end{array}$ \\
\hline \hline 1 & F-300-100-9-25.3 & 300 & 100 & 150 & 9 & 9 & 25.3 & 170 & 170 & 1.00 \\
\hline 2 & F-450-150-9-23.6 & 450 & 150 & 150 & 9 & 9 & 23.6 & 180 & 182 & 0.99 \\
\hline 3 & F-600-200-9-25.3 & 600 & 200 & 150 & 9 & 9 & 25.3 & 200 & 207 & 0.97 \\
\hline 4 & F-600-200-9-30 & 600 & 200 & 150 & 9 & 9 & 30 & 230 & 225 & 1.02 \\
\hline 5 & F-600-200-9-38 & 600 & 200 & 150 & 9 & 9 & 38 & 260 & 254 & 1.02 \\
\hline 6 & F-300-100-4.5-25.3 & 300 & 100 & 150 & 4.5 & 4.5 & 25.3 & 110 & 104 & 1.06 \\
\hline 7 & F-600-200-7-25.3 & 600 & 200 & 150 & 7 & 7 & 25.3 & 170 & 177 & 0.96 \\
\hline 8 & F-600-200-4.5-25.3 & 600 & 200 & 150 & 4.5 & 4.5 & 25.3 & 130 & 141 & 0.92 \\
\hline 9 & F-900-300-13.5-25.3 & 900 & 300 & 150 & 13.5 & 13.5 & 25.3 & 300 & 311 & 0.96 \\
\hline 10 & F-450-150-5-30 & 600 & 150 & 150 & 5 & 9 & 30 & 140 & 141 & 0.99 \\
\hline 11 & F-600-200-5-30 & 600 & 200 & 150 & 5 & 9 & 30 & 160 & 161 & 0.99 \\
\hline 12 & F-300-100-5-30 & 600 & 100 & 150 & 5 & 9 & 30 & 120 & 121 & 0.99 \\
\hline 13 & F-900-300-9-25.3 & 900 & 300 & 150 & 9 & 9 & 25.3 & 230 & 244 & 0.94 \\
\hline 14 & F-1200-400-9-30 & 1200 & 400 & 150 & 9 & 9 & 30 & 300 & 307 & 0.98 \\
\hline 15 & F-750-250-9-30 & 750 & 250 & 150 & 9 & 9 & 30 & 240 & 246 & 0.97 \\
\hline
\end{tabular}


Moreover, the FEM analyses were also conducted to examine the applicable ranges of the proposed equation Eq.IV.4 in case of the sizes of the surrounding concrete are different. It can be observed in Table IV.1.4 that the increase of size of surrounding concrete does not effect on the shear capacity of the shear connector.

Table IV.1. 4 FEM analyses and calculations for size of surrounding concrete effects

\begin{tabular}{|c|c|c|c|c|c|c|c|c|c|c|c||}
\hline No & Specimens & $\begin{array}{c}a^{\prime} \\
(\mathrm{mm})\end{array}$ & $\begin{array}{c}h \\
(\mathrm{~mm})\end{array}$ & $\begin{array}{c}h_{s c} \\
(\mathrm{~mm})\end{array}$ & $\begin{array}{c}b_{s c} \\
(\mathrm{~mm})\end{array}$ & $\begin{array}{c}t_{s c 1} \\
(\mathrm{~mm})\end{array}$ & $\begin{array}{c}t_{f} \\
(\mathrm{~mm})\end{array}$ & $\begin{array}{c}f_{c}^{\prime} \\
\left(\mathrm{N} / \mathrm{mm}^{2}\right)\end{array}$ & $\begin{array}{c}V_{u . F E M} \\
(\mathrm{kN})\end{array}$ & $\begin{array}{c}V_{u . E q .4} \\
(\mathrm{kN})\end{array}$ & $\frac{V_{u . F E M}}{V_{u . E q .4}}$ \\
\hline \hline 1 & F-200-9-25.3 & 300 & 600 & 200 & 150 & 9 & 9 & 25.3 & 200 & 207 & 0.97 \\
\hline 2 & F-200-9-25.3 & 400 & 600 & 200 & 150 & 9 & 9 & 25.3 & 200 & 207 & 0.97 \\
\hline 3 & F-200-9-25.3 & 500 & 600 & 200 & 150 & 9 & 9 & 25.3 & 200 & 207 & 0.97 \\
\hline 4 & F-200-9-25.3 & 300 & 500 & 200 & 150 & 9 & 9 & 25.3 & 200 & 207 & 0.97 \\
\hline 5 & F-200-9-25.3 & 300 & 800 & 200 & 150 & 9 & 9 & 25.3 & 200 & 207 & 0.97 \\
\hline
\end{tabular}

\section{b) Shear Force-Relative Displacement Relationships $\left(\theta=45^{\circ}\right)$}

The relationships between shear force and relative displacement of the shear connectors were also observed. As shown in Fig.IV.1.16, the behaviors of the shear connectors with respect to shear forces observed in the FEM analyses are similar to those observed in the experiments.

Furthermore, it can be seen that the curves of shear force-relative displacement relationships are different with sizes of shear connectors and concrete strengths especially the ultimate shear force and the ultimate relative displacements.
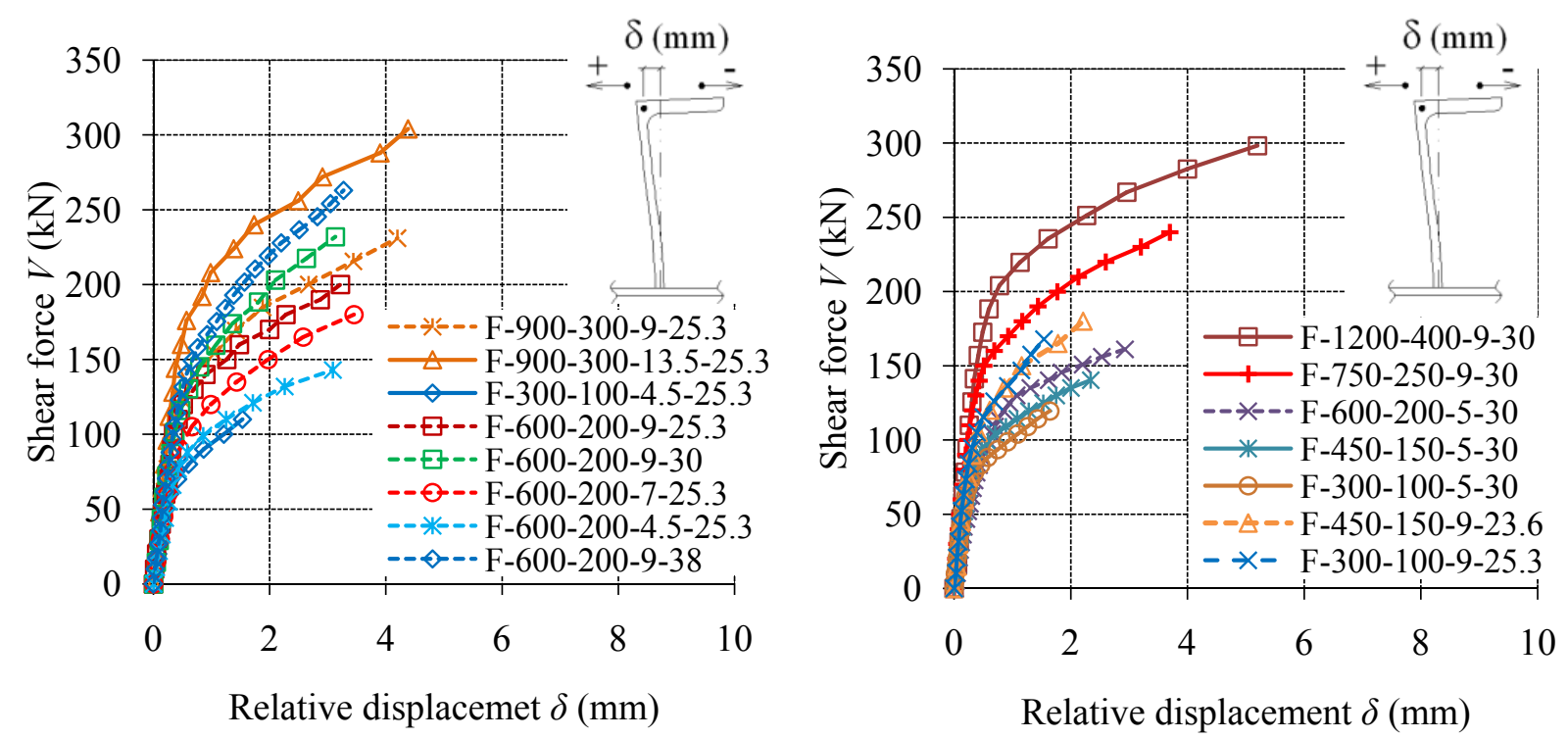

Figure IV.1. 16 Shear force-relative displacement relationship observed in FEM analyses 


\section{IV.1.8 Formulation for Shear Force-Relative Displacement Relationships $\left(\theta=\mathbf{4 5}^{\circ}\right)$}

Since the results obtained from the FEM analyses agreed well with those obtained from the experiments, it can be said that the results of the FEM analyses are reliable. Therefore, the equation for the shear force-relative displacement relationship in case $\theta=45^{\circ}$ was developed from the results of FEM analyses.

First of all, the observations were made on shear force-horizontal relative displacement relationships in F-300-100-4.5-25.3, F-600-200-9-25.3, and F-900-300-13.5-25.3 whose concrete strength and thickness to height ratios of the shear connectors are the same. Also, the thicknesses of the steel skin plates are the same as the thicknesses of the shear connectors. It can be observed in Fig.IV.1.17 that the ultimate shear force of the shear connector and the ultimate relative displacement seems to proportionally increase with size of shear connector. Also, the shapes of shear force-relative displacement relationships' curves of the shear connector are similar.

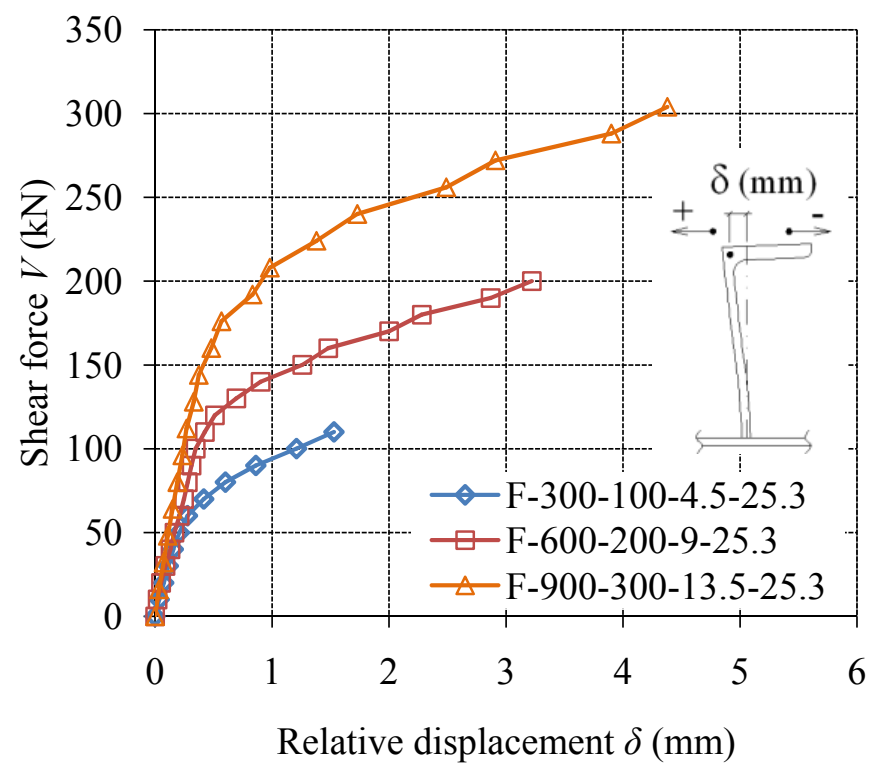

Figure IV.1. $17 \boldsymbol{V}-\boldsymbol{\delta}$ relationships for the same size proportion shear connectors

Moreover, when the shear force was normalized by the ultimate shear force $V / V_{u}$ and the relative displacement by the height of the shear connector $\delta / h_{s c}$ the curves of the relationships became unique as shown in Fig.IV.1.18. This results indicated that the relationship between shear force $V$ and relative displacement $\delta$ can be represented by that between $V / V_{\text {max.FEM }}$ and 
$\delta / h_{s c}$. More importantly, the curves fitting analyses have been conducted and an equation representing the relationships' enveloped curve can be expressed as followings:

$$
\frac{V}{V_{u}}=\left(1-e^{-180 \frac{\delta}{h_{s c}}}\right)^{0.6}
$$

Where,

$V_{u} \quad$ : ultimate shear force of shear connector $(\mathrm{N})$

$\delta \quad$ : relative displacement of the shear connector $(\mathrm{mm})$

$h_{s c} \quad$ : height of shear connector $(\mathrm{mm})$

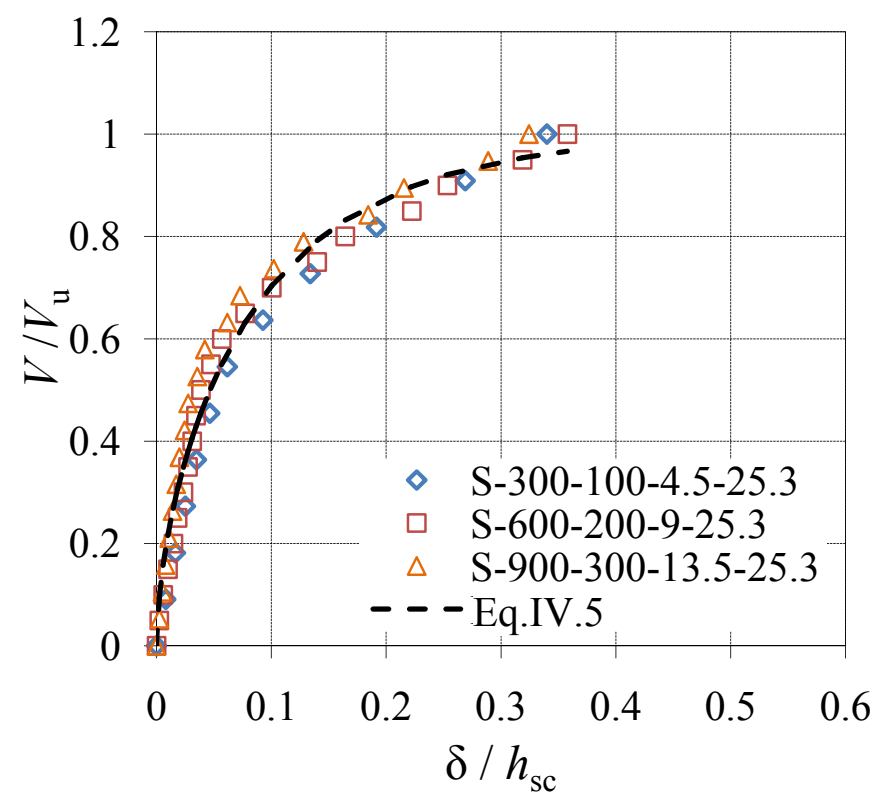

Figure IV.1. $18 \boldsymbol{V} / \boldsymbol{V}_{\boldsymbol{u}}-\boldsymbol{\delta} / \boldsymbol{h}_{\boldsymbol{s c}}$ relationships for the same size proportion shear connectors

It can be seen in Fig.IV.1.18 that Eq.IV.5 can precisely predict the enveloped curve of the shear force-relative displacement relationships of L-shape shear connector subjected to strut compressive force with $\theta=45^{\circ}$. 


\section{a) Effects of $t_{1, s c}$ on Shear Force-Relative Displacement Relationships}

The effect of the thickness of the shear connector $t_{1, s c}$ on shear force $V$ and relative displacement $\delta$ relationships was also observed. Fig.IV.1.19 gives $V$ and $\delta$ relationships of the shear connectors with different thickness $t_{1, s c}$ but the same heights of shear connector $h_{s c}$ and concrete strength $f_{c}^{\prime}$. It can be seen that the thin shear connector has greater displacement than the thick shear connector when the same level of shear force were carried. This similar behavior was also found in plate shape shear connector by Chuah et al. (1991) [9]. Additionally, the same height shear connectors were found to have similar ultimate relative displacement despite different $t_{1, s c}$.

Moreover, as shown in Fig.IV.1.20 a unique enveloped curve was also observed when the shear forces $V$ were normalized by the ultimate shear force $V_{\mathrm{u}}$ and the relative displacements $\delta$ by the height of the shear connector $h_{s c}$. Meanwhile, the enveloped curve fitted best with the curve of the relationships between $V / V_{u}$ and $\delta / h_{s c}$ calculated by means of Eq.IV.5. It means that Eq.IV.5 is also applicable fore different thickness of L-shape shear connector.

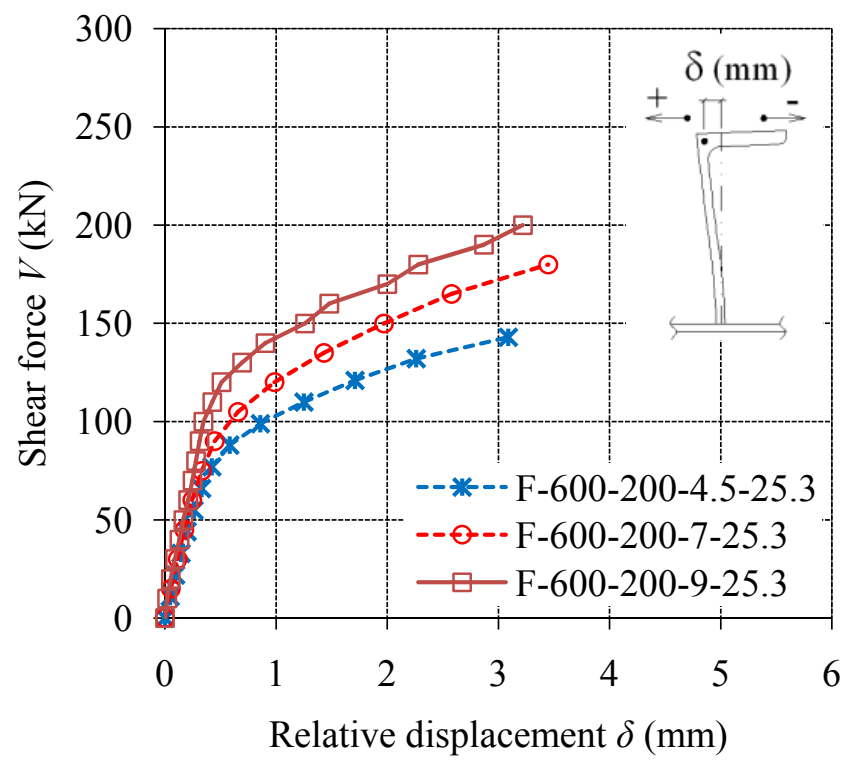

Figure IV.1. 19 $\boldsymbol{V}-\boldsymbol{\delta}$ relationships for different thickness of shear connectors 


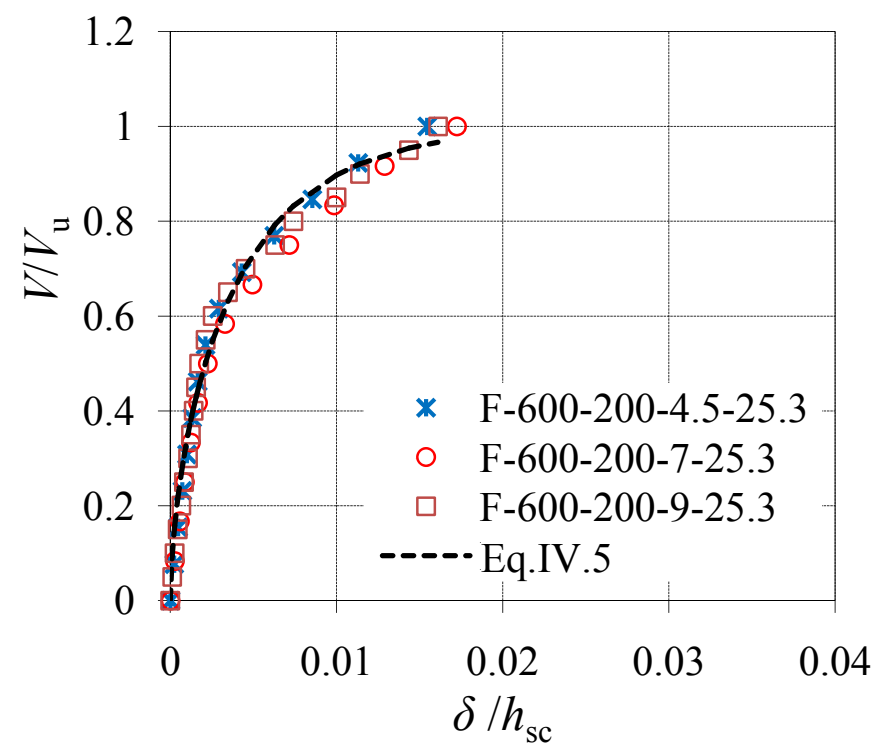

Figure IV.1. $20 \boldsymbol{V} / \boldsymbol{V}_{\boldsymbol{u}}-\boldsymbol{\delta} / \boldsymbol{h}_{\boldsymbol{s c}}$ relationships for different thickness of shear connectors

\section{b) Effects of $f_{c}^{\prime}$ on Shear Force-Relative Displacement Relationships}

Furthermore, the effect of concrete strength $f_{c}^{\prime}$ on shear force $V$ and horizontal relative displacement $\delta$ relationships was also observed. Fig.IV.1.21 gives the relationships between shear force $V$ and relative displacement $\delta$ of the same size shear connectors but different concrete strengths $f_{c}^{\prime}$. It can be seen that when shear forces are less than approximately $120 \mathrm{kN}$ no effect of concrete strength on the relationships can be observed. However, when the level of shear force became higher, the shear connector with lower concrete strength displaced more as compared to the shear connector with higher concrete strength when the same level of shear force was carried. Also the ultimate relative displacements of the shear connectors were almost the same despite different levels of ultimate shear forces. These results show that there is no effect concrete strength on the ultimate relative displacement but the ultimate shear force of the shear connector.

Regardless of concrete strength, a unique enveloped curve was also observed for the relationships between $V / V_{u}$ and $\delta / h_{s c}$ as given in Fig.IV.1.22. Moreover, the calculation results by means of Eq.IV.5 agreed well with the normalized curves. Therefore, it can be said that Eq.IV.5 is applicable fore $V / V_{u}$ and $\delta / h_{s c}$ relationship of the connectors with different concrete strength. 


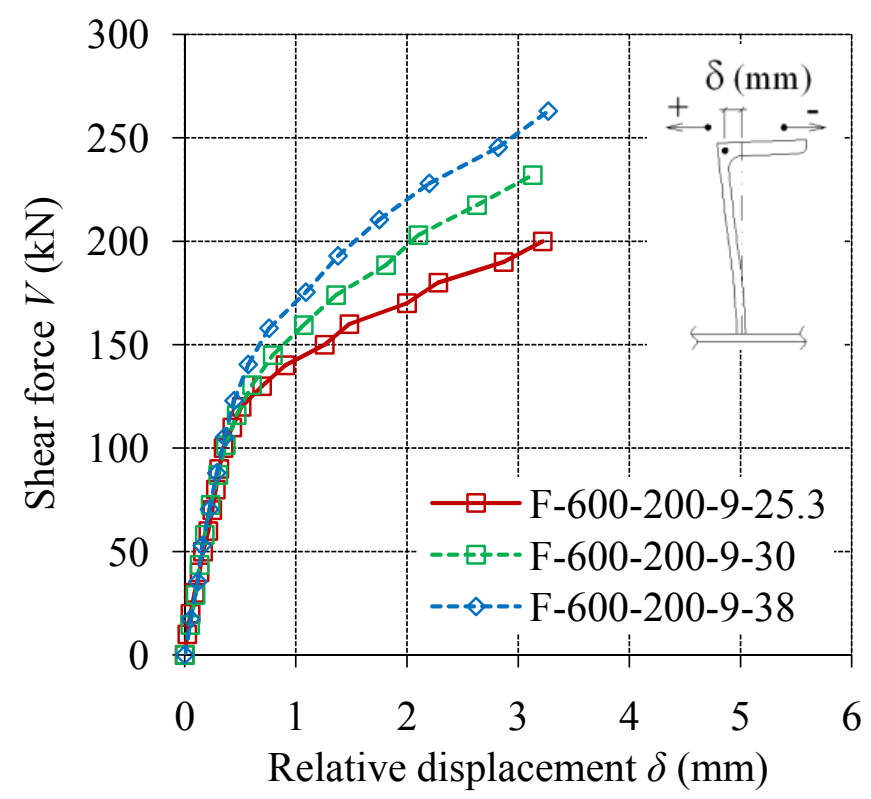

Figure IV.1. $21 \boldsymbol{V}-\boldsymbol{\delta}$ relationships for different concrete strength

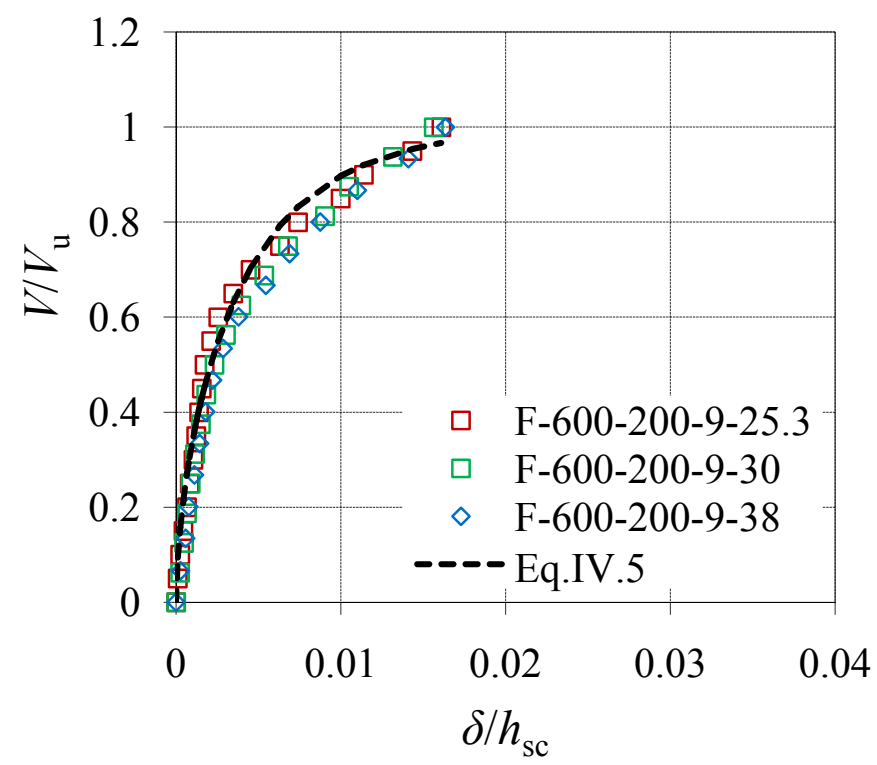

Figure IV.1. $22 \boldsymbol{V} / \boldsymbol{V}_{\boldsymbol{u}}-\boldsymbol{\delta} / \boldsymbol{h}_{\boldsymbol{s c}}$ relationships for different concrete strength

\section{c) Effects of $h_{s c}$ on Shear Force-Relative Displacement Relationships}

Moreover, the effect of height of shear connector $h_{s c}$ on shear force $V$ and horizontal relative displacement $\delta$ relationships can be observed in Fig.IV.1.23. It can be observed that with same 
thickness of shear connector $t_{1, s c}$ and the same concrete strength $f_{c}^{\prime}$, the greater height shear connectors failed at higher level of ultimate shear force $V_{u}$ and also at greater value of ultimate relative displacements $\delta_{u}$ as compared to the smaller height shear connectors. However, the shear connectors were found to have similar stiffness even thought the height of the shear connector $h_{s c}$ were different.

Again, as shown in Fig.IV.1.24, when shear forces $V$ were normalized by the ultimate shear force $V / V_{u}$ and relative displacement $\delta$ by the height of the shear connector $h_{s c}, \delta / h_{s c}$, a unique enveloped curve was obtained. Fortunately, the results obtained from the calculations by means of Eq.IV.5 fitted best with the data. Therefore, it means that Eq.IV.5 is also applicable for the prediction of shear force-relative displacement relationship of different height shear connectors.

In short, Eq.IV.5 was found to be applicable to predict shear force-relative displacement relationships of different size of shear connectors and also different concrete strength. However, the equation is applicable only in case that strut angle is equal to $45^{\circ}, \theta=45^{\circ}$.

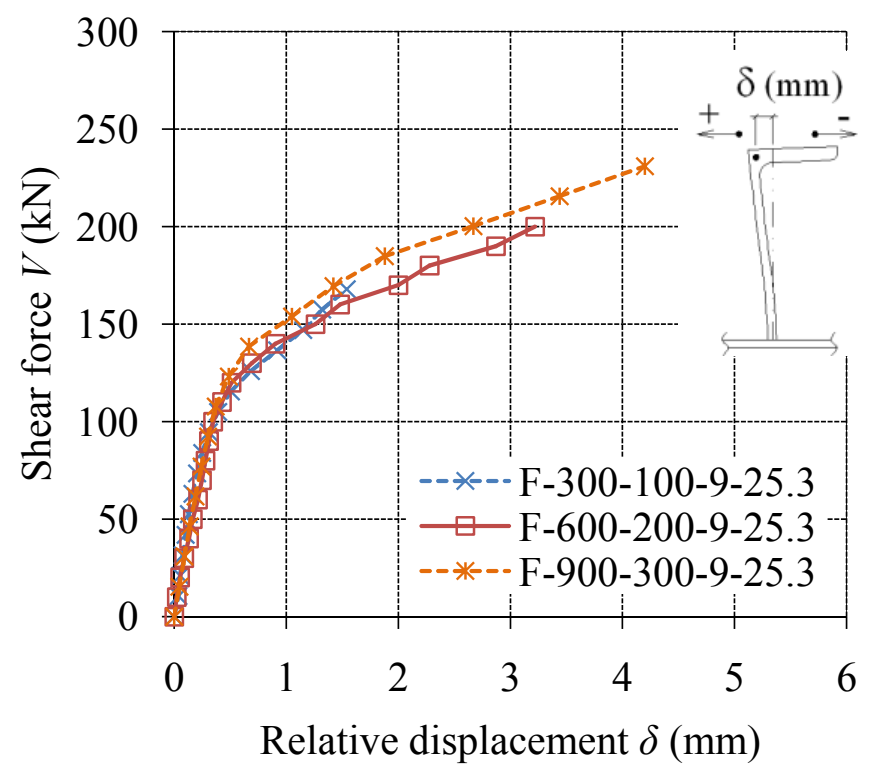

Figure IV.1. $23 \boldsymbol{V}-\boldsymbol{\delta}$ relationships for different height of shear connectors 


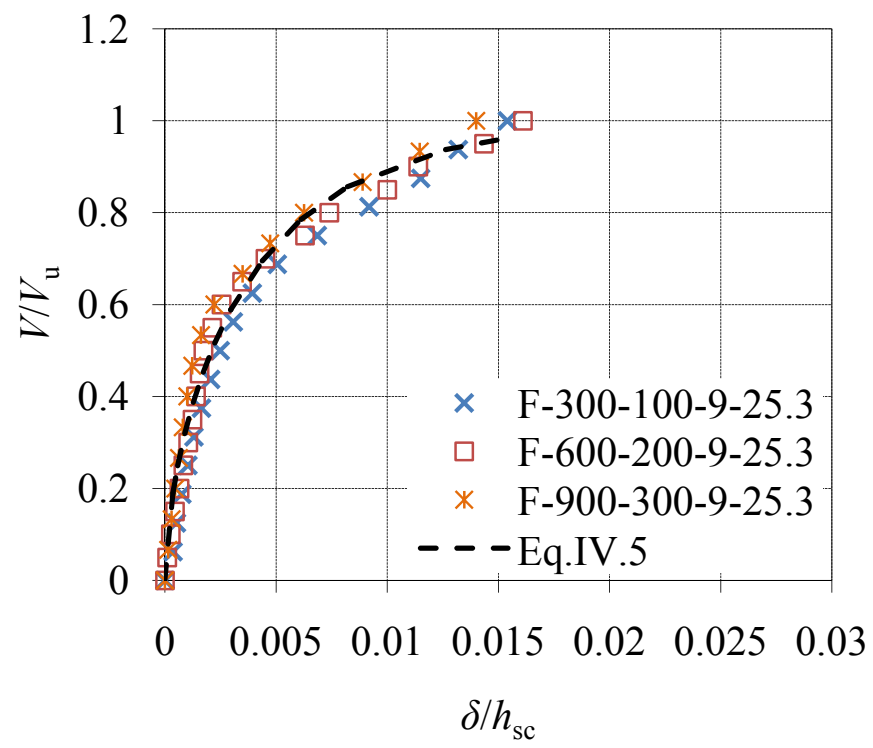

Figure IV.1. $24 \boldsymbol{V} / \boldsymbol{V}_{\boldsymbol{u}}-\boldsymbol{\delta} / \boldsymbol{h}_{\boldsymbol{s c}}$ relationships for different height of shear connector

\section{c) Experimental Results and Calculation Results by Means of Eq.IV.5 Comparison}

The relationships between $V / V_{u}$ and $\delta / h_{s c}$ calculated by means of Eq.IV.5 were compared with those obtained from the experimental results, shown in Fig.IV.1.25. It can be observed that the calculated relationships agreed well with those obtained from the experimental results from the occurrence of crack in the concrete starting from the head of the shear connector to the occurrence of split failure of the shear connector.

Furthermore, the relationships between ultimate shear forces $V_{u}$ and the maximum values of $\delta / h_{s c}$ obtained from the FEM analyses can be observed in Fig.IV.1.26. It can be seen that the values of $\delta_{u} / h_{s c}$ varied from 0.014 to 0.017 regardless of the size of the shear connector and the concrete strength. On the other hand, as shown in Fig.IV.1.25 the experimental results showed that the ultimate relative displacements of the shear connector were approximately 0.02 times the height of the shear connector.

However, the equations for the ultimate shear force Eq.IV.4 and the relationship between $V / V_{u}$ and $\delta / h_{s c}$ Eq.IV.5 were found only for the case that strut angle was $45^{\circ}\left(\theta=45^{\circ}\right)$ and the shear connector failed by split failure mode. Therefore, the formulations for the ultimate shear force and the shear force-relative displacement relationships of L-shape shear connector for the case 
that strut angle smaller than $45^{\circ}\left(\theta<45^{\circ}\right)$ are necessary. The following subchapter discussed the results of $2^{\text {nd }}$ test series shear connectors whose strut angle smaller than $45^{\circ}\left(\theta<45^{\circ}\right)$.

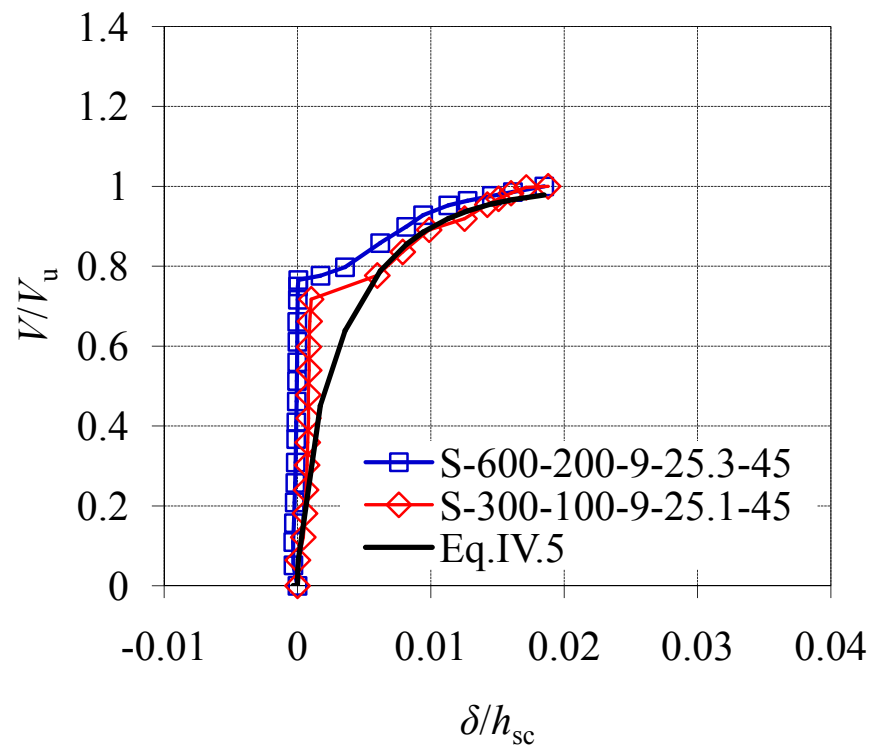

Figure IV.1. $25 V / V_{u}-\delta / h_{s c}$ relationships from experimental results and Eq.IV.5

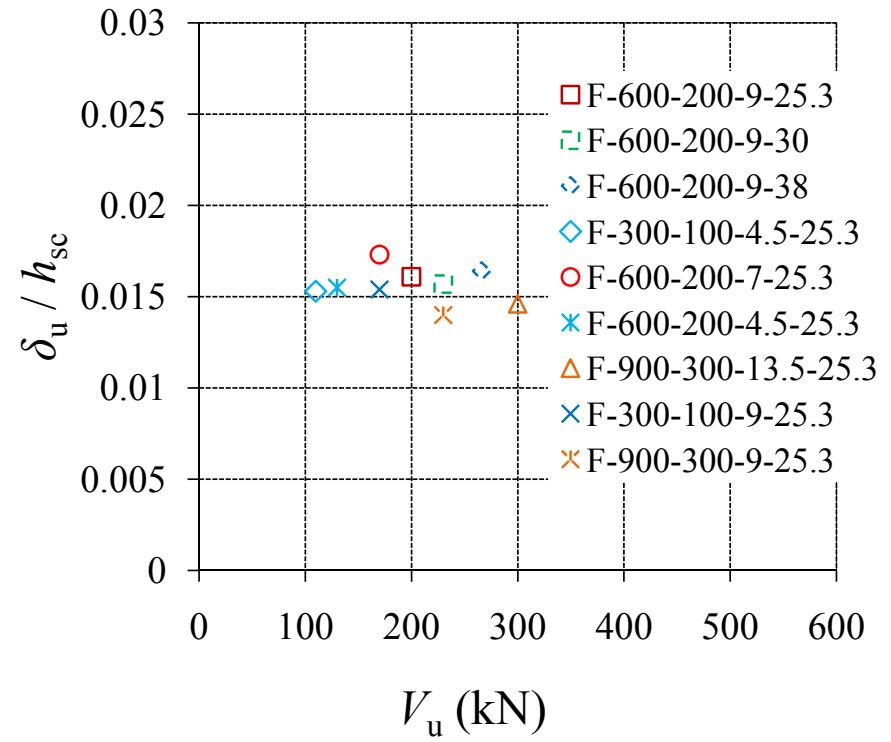

Figure IV.1. 26 Relationships between $\boldsymbol{\delta}_{\boldsymbol{u}} / \boldsymbol{h}_{\boldsymbol{s c}}$ and $\boldsymbol{V}_{\boldsymbol{u}}$ 


\section{IV.2 L-Shape Shear Connector under Strut Compressive Force with Strut Angle Smaller Than 45 Degrees $\left(2^{\text {nd }}\right.$ Test Series Specimens)}

\section{IV.2.1 General}

The $2^{\text {nd }}$ test series consists of six specimens whose strut angle $\theta<45^{\circ}$. The focused parameters of the $2^{\text {nd }}$ test series specimens were performed by means of a pre-study through FEM analyses. Based on $1^{\text {st }}$ test series results and finite element analyses (FEM) results described in the previous subchapter, when strut angle is equal to $45^{\circ}\left(\theta=45^{\circ}\right)$ splitting crack occurrence in the concrete in front of the shear connector occurred (split failure) regardless of size of shear connector and concrete strength. Moreover, good agreements between the experimental results and the FEM analyses results in terms of the final failure mode, the ultimate shear force $V_{\mathrm{u}}$, and the shear force-relative displacement relationships of the shear connectors were observed.

Therefore, prior to the selection of the focused parameters for $2^{\text {nd }}$ test series specimens, the effects of strut angle, concrete strength, and size of shear connector on the performance of the shear connectors were examined by means of FEM analyses as given in the following subchapter.

\section{IV.2.2 FEM Analyses for Parameter Selection for $2^{\text {nd }}$ Test Series Specimens}

Based on FEM analyses study, different final failure modes, split failure and shear failure of Lshape shear connector which is dependent on the strut angle and the size of the shear connector were observed. More importantly, as shown in Fig.IV.2.1, the critical strut angle $\theta_{0}$ representing the border between split failure and concrete crush was found to vary with thickness to height ratio of the shear connector $t_{1, \mathrm{sc}} / h_{\mathrm{sc}}$. The criteria of shear failure and split failure are respectively illustrated in Fig.IV.2.2 and Fig.IV.2.3. More details of these two different failure modes are given in the following subchapter.

The selection of the strut angle and the size of the shear connector for $2^{\text {nd }}$ test series specimens were according made in order to clarify the performance of L-shape shear connectors observed in the test preparation study. As given in Fig.IV.2.1, three specimens were expected to fail in split failure mode while three others were expected to fail in shear failure mode. The next subchapter describes and discusses every detail of the $2^{\text {nd }}$ test series results. 


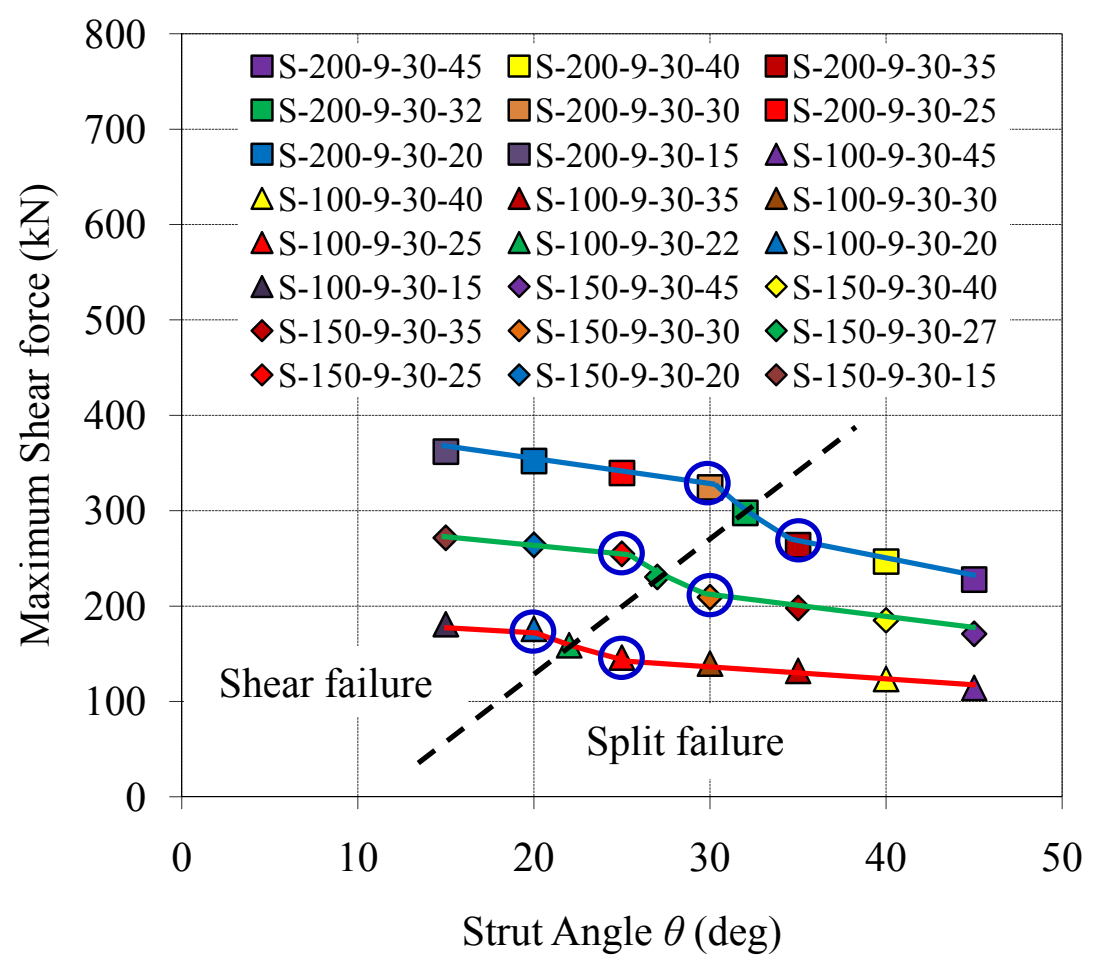

Figure IV.2.1 Ultimate shear force and strut angle

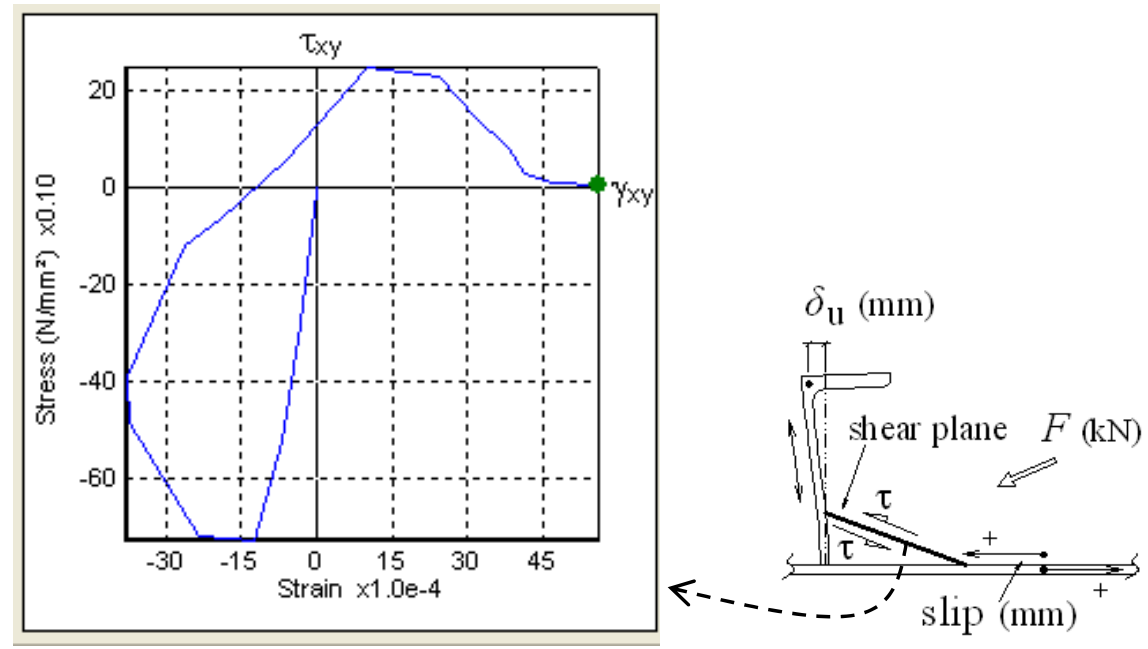

Figure IV.2.2 Shear failure criteria 


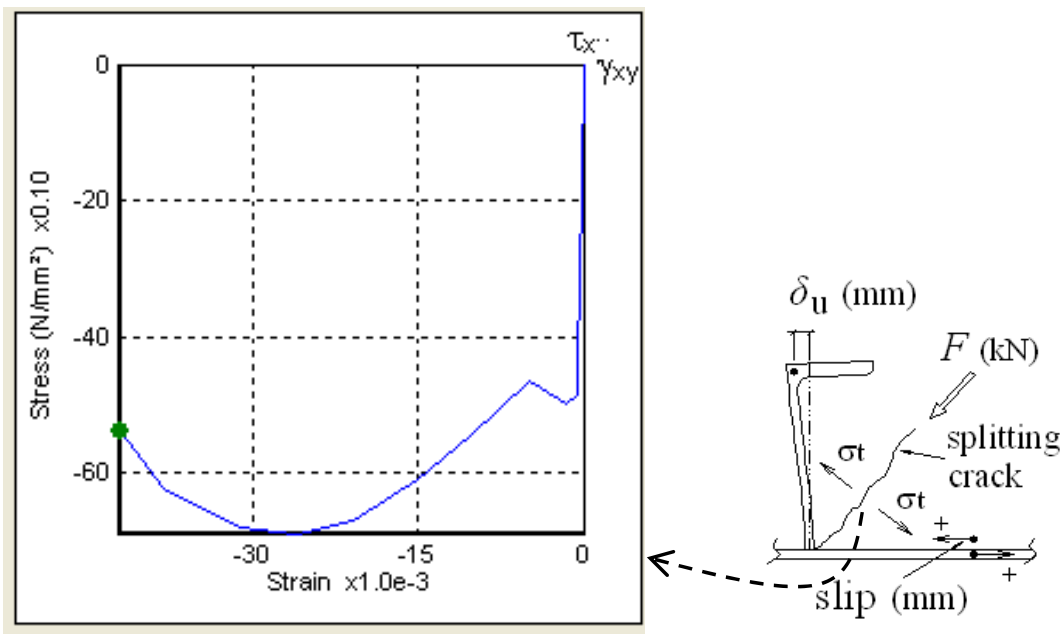

Figure IV.2.3 Split failure criteria

\section{IV.2.3 Failure Mode of $2^{\text {nd }}$ Test Series Shear Connectors $\left(\theta<45^{\circ}\right)$}

\section{a) Failure Mode}

Since only left size shear connectors failed, the discussions are accordingly made in this study. The conditions of the shear connectors at failures observed in $2^{\text {nd }}$ test series specimens are illustrated in Fig.IV.2.4. Different failure modes of the shear connectors, split failure, shear-split failure, concrete crush, and shear failure were identified. Meanwhile, crack patterns of the specimens failed in split failure mode and in non-split failure mode are given in Fig.IV.2.5 and Fig.IV.2.6, respectively. The numbers in the figures represent load $P$ for $1^{\text {st }}$ series specimens and $2 P$ for $2^{\text {nd }}$ series specimens.

As shown in Fig.IV.2.5, the shear connectors were found to fail in split failure mode in S-450150-9-43-30 and S-300-100-9-41.5-25. However, S-450-150-9-43-30 was found to have a sudden split failure at the same time with the occurrence of crack from the head of the shear connector; this indicated that the level of load carrying capacity at splitting crack in front of the shear connector in this specimen was lower than that at the occurrence of crack from the head of the shear connector. Therefore, the ultimate shear force $V_{\mathrm{u}}$ in this specimen cannot be discussed with those in other specimens whose split failure order occurred after the occurrence of cracks from the head of the shear connectors. Moreover, break of shear connector was observed only in S-600-200-9-43-30, Fig.IV.2.6(a) after small crush of concrete appeared. However, the breaking part was at welding liquid-skin plate interface which was due to low welding quality. Therefore, 
the ultimate shear force $V_{\mathrm{u}}$ observed in S-600-200-9-43-30 also cannot be discussed with those of other specimens.

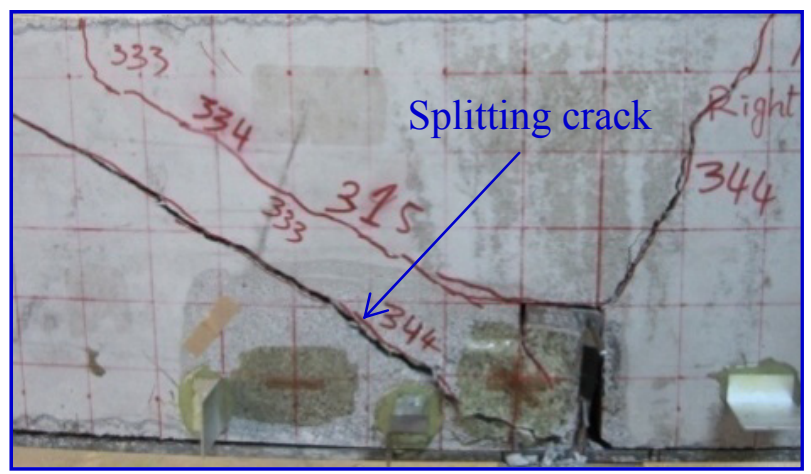

(a) Split failure S-300-100-9-41.5-25

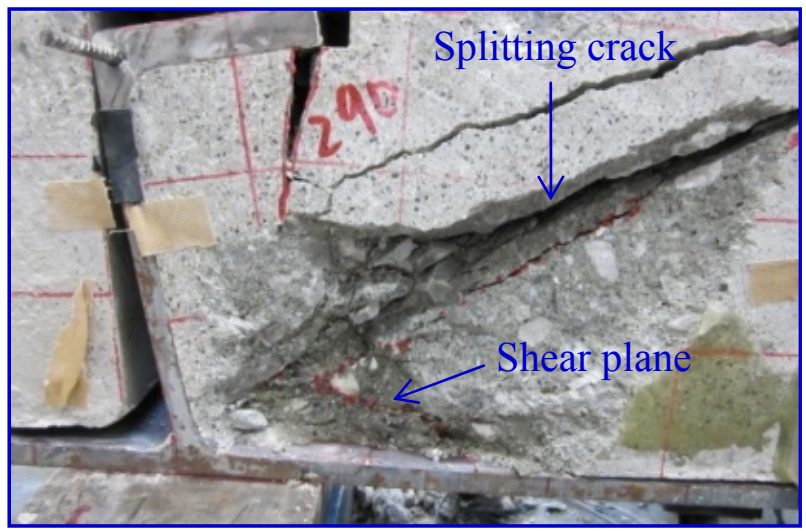

(b) Shear-split failure S-450-150-9-43-25

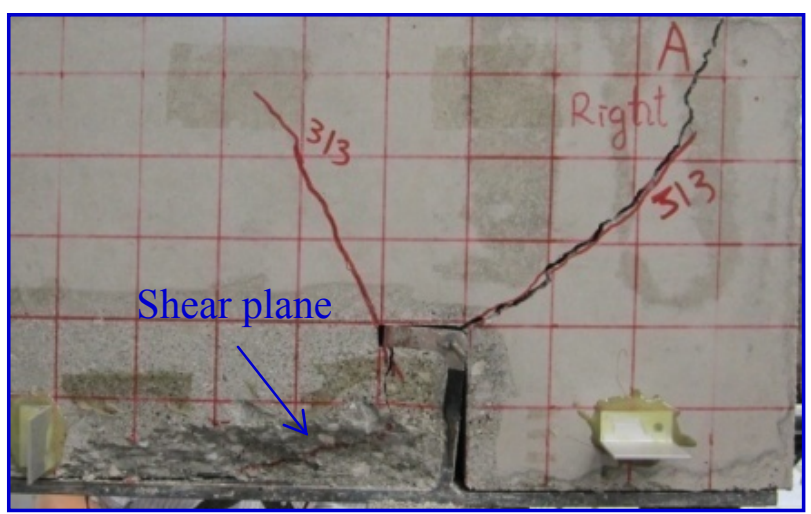

(c) Shear failure S-300-100-9-42.7-20

Figure IV.2. 4 Different failure modes of shear connectors in $2^{\text {nd }}$ test series specimens. 


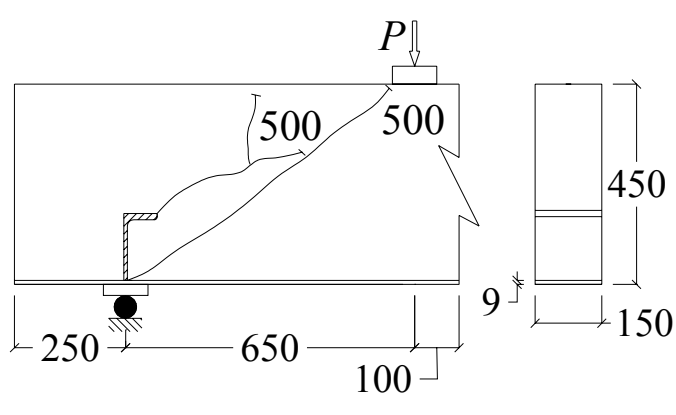

(a) S-450-150-9-43-30

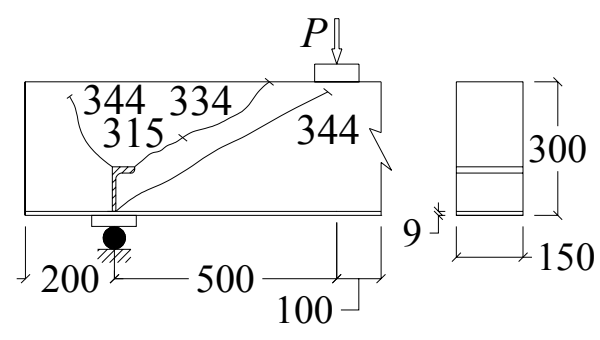

(b) S-300-100-9-41.5-25

Figure IV.2. 5 Crack patterns of specimens failed in split failure mode.

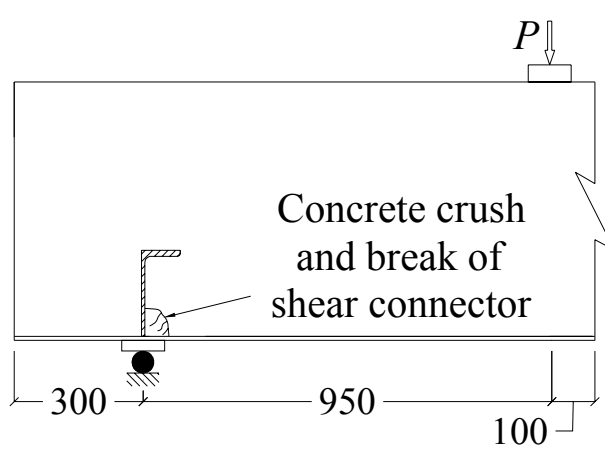

(a) S-600-200-9-43-30

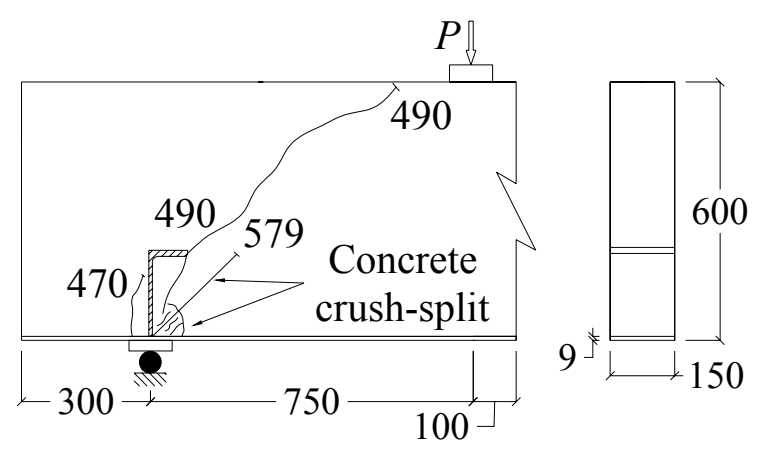

(b) S-600-200-9-43-35

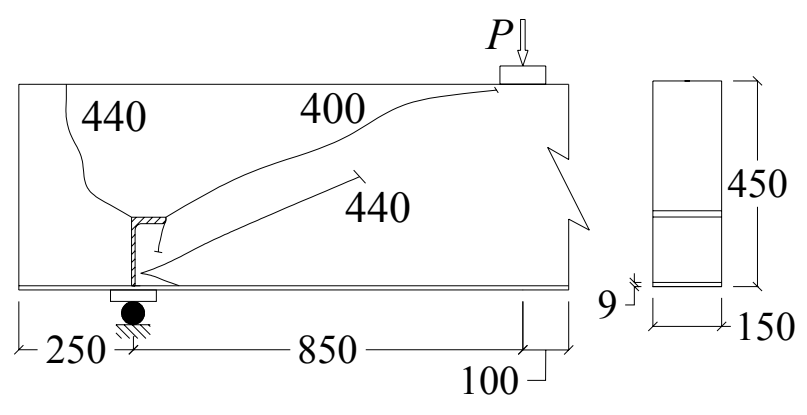

(c) S-450-150-9-43-25

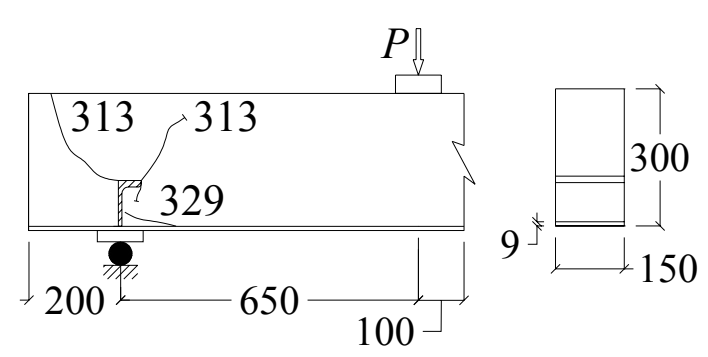

(d) S-300-100-9-42.7-20

Figure IV.2. 6 Crack patterns of specimens failed in concrete crush and shear failure mode.

More importantly, the experimental results showed that the possibility of split failure, concrete crush or shear failure occurrences depend on the strut angle $\theta$ and the size of the shear connector. It can be seen in S-300-100-9-41.5-25 and S-300-100-9-42.7-20 whose concrete strength and size of shear connector are the same that the shear connector failed in split failure mode and in shear failure mode when strut angle $\theta$ is equal to $25^{\circ}$ and $20^{\circ}$, respectively. Meanwhile, shearsplit failure mode and split failure mode appeared when $h_{\mathrm{sc}}=150 \mathrm{~mm}$ and $h_{\mathrm{sc}}=100 \mathrm{~mm}$, 
respectively despite the same concrete strength and strut angle, S-450-150-9-43-25 and S-300$100-9-41.5-25$.

\section{a) Border Line between Split Failure Mode and Concrete Crush or Shear Failure Mode}

It was found that the strut angle $\theta$ and the size of the shear connector influenced not only the failure modes of the shear connectors, but also the shear resisting mechanism. Fig.IV.2.7 gives the relationships between shear force and strain in the vertical part of the shear connectors in $2^{\text {nd }}$ test series specimens. It can be seen that for the same size shear connectors, tensile strains in the shear connectors with smaller strut angle were found much greater value than those with bigger strut angle. It means that the shear connectors with smaller strut angle or the shear connectors which failed in concrete crush or shear failures modes resisted against an uplifting mechanism.

Furthermore, as shown in Fig.IV.2.7(a), when $t_{1, \mathrm{sc}} / h_{\mathrm{sc}}$ is equal to 0.09 , the shear connectors were found to have different shear resisting mechanism and were found to fail in shear failure mode and split failure mode between strut angle $\theta=20^{\circ}$ and $\theta=25^{\circ}$. These results indicated that the border of split failure modes and shear failure modes of L-shape shear connector subjected to strut compressive force located between $20^{\circ}$ and $25^{\circ}$ of strut angle when $t_{1, \mathrm{sc}} / h_{\mathrm{sc}}=0.09$. Similarly, for S-450-150-9-43-25 and S-450-150-9-43-30 shown in Fig.IV.2.7(b), shear-split failure mode and split failure mode occurred when the strut angle $\theta=25^{\circ}$ and $\theta=30^{\circ}$, respectively. It would mean that the border of split failure mode and shear failure mode located between $25^{\circ}$ and $30^{\circ}$ of strut angle when $t_{1, \mathrm{sc}} / h_{\mathrm{sc}}=0.06$. Additionally, concrete crush and concrete crush with splitting crack were observed in S-600-200-9-43-30 and S-600-200-9-43-35, respectively. These different failure modes and different shear resisting mechanisms of the shear connectors shown in Fig.IV.2.7(c) also indicated that the border line between split failure mode and shear failure modes is reasonably located between the strut angle of $30^{\circ}$ and $35^{\circ}$ when $t_{1, \mathrm{sc}} / h_{\mathrm{sc}}=0.045$. These experimental results showed that thickness to height ratio of the shear connector $t_{1, \mathrm{sc}} / h_{\mathrm{sc}}$ and strut angle $\theta$ controlled the final failure mode of L-shape shear connector subjected to strut compressive force. It also means that the experimental results of $2^{\text {nd }}$ test series specimens confirmed the border line between split failure zone and concrete crush or shear failure zone observed in the FEM analyses during the experimental preparation. 


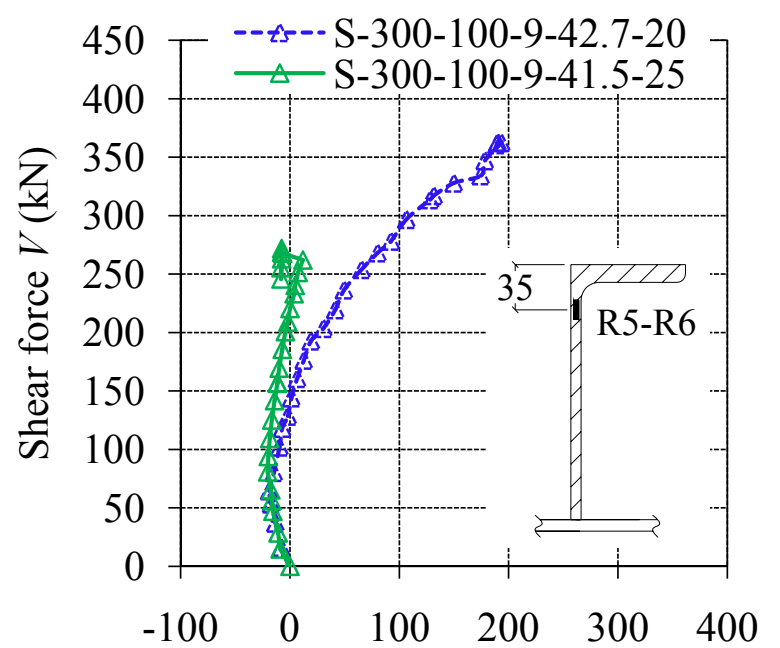

Strain in shear connector $(\mu)$

(a) $h_{\mathrm{sc}}=100 \mathrm{~mm}\left(t_{1, \mathrm{sc}} / h_{\mathrm{sc}}=0.09\right)$

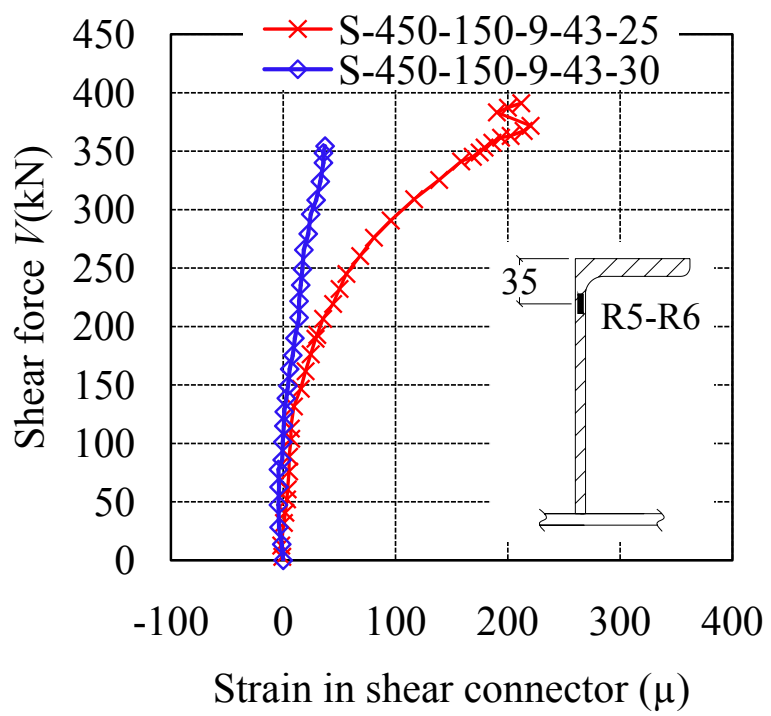

(b) $h_{\mathrm{sc}}=150 \mathrm{~mm}\left(t_{1, \mathrm{sc}} / h_{\mathrm{sc}}=0.06\right)$

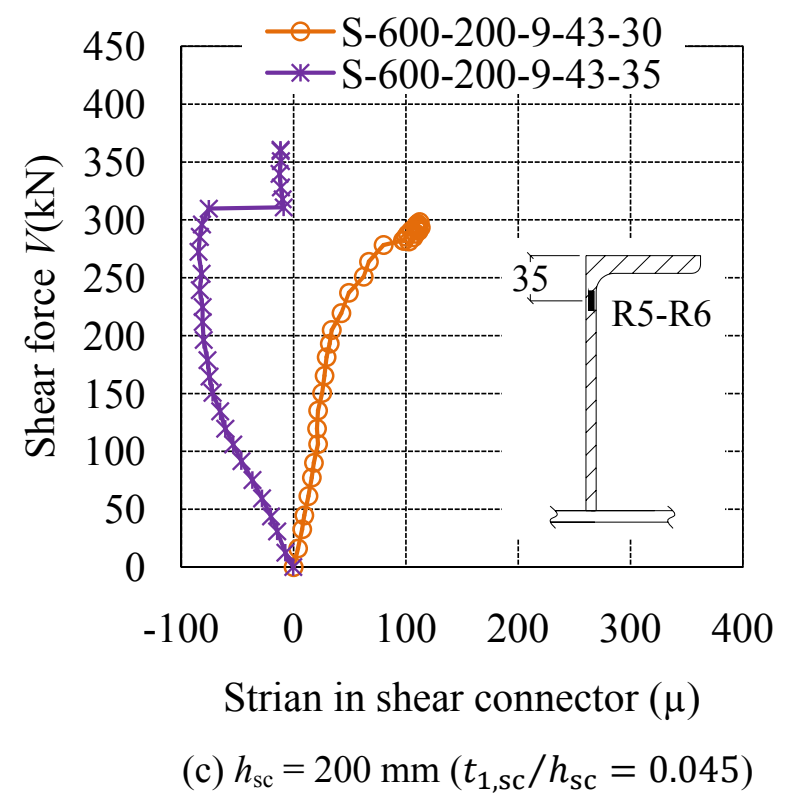

Figure IV.2. 7 Relationships between shear force and strain in the vertical part of the shear connectors in $2^{\text {nd }}$ series specimens.

Therefore, an equation for a critical strut angle $\theta_{0}$ representing the border between split failure modes and concrete crush or shear failure modes can be reasonably developed from the experimental results of $2^{\text {nd }}$ test series specimens which is a function of $t_{1, \mathrm{sc}} / h_{\mathrm{sc}}$. The relationships between $\theta$ and $t_{1, \mathrm{sc}} / h_{\mathrm{sc}}$ are given in Fig.IV.2.8. The equation of the critical strut angle $\theta_{\mathrm{o}}$ can be given as follows: 


$$
\theta_{\mathrm{o}}=-210\left(\frac{t_{1, \mathrm{sc}}}{h_{\mathrm{sc}}}\right)+41
$$

Where,

$\theta_{\mathrm{o}} \quad$ : critical strut angle (degree),

$t_{1, s c}:$ thickness of the shear connector $(\mathrm{mm})$,

$h_{s c} \quad:$ height of the shear connector $(\mathrm{mm})$.

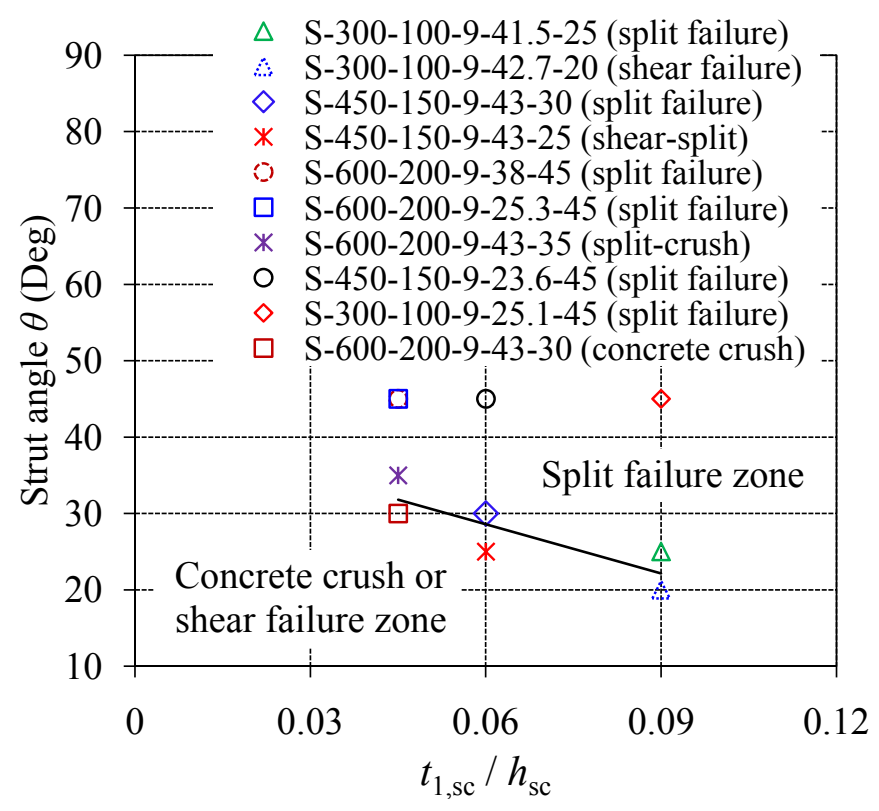

Figure IV.2. 8 Relationships between shear force and strain in the vertical

It means that split failure mode and concrete crush or shear failure mode of L-shape shear connector occurred when strut angle $\theta>\theta_{\mathrm{o}}$ and $\theta \leq \theta_{\mathrm{o}}$, respectively.

Additionally, the different performance of L-shape shear connectors failed in split failure mode and in concrete crush or shear failure mode can be simply illustrated by Fig.IV.2.9 and Fig.IV.2.9, respectively. As shown in Fig.IV.2.8(a), when $\theta>\theta_{0}$ the concrete in front of the shear connector seemed to resist against multi-direction stresses; and the release of the principal tensile stress $\sigma_{\mathrm{t}}$ of the concrete depended on the relative displacement of the shear connector. Then, when the relative displacement reached its ultimate value $\delta_{\mathrm{u}}$, splitting crack took place in the concrete along the compressive strut axis perpendicular to the principal tensile stress 
direction, Fig.IV.2.9(b). Differently, as shown in Fig.IV.2.10(a), when $\theta \leq \theta_{0}$ the concrete in front of the shear connector tried to escape from the crushing point along the direction of the principal tensile stress $\sigma_{\mathrm{t}}$. This mechanism induced vertical confinement of concrete in front of the shear connector and resulted in high tensile stress or tensile strain in the vertical part of the shear connector shown in Fig.IV.2.7. Furthermore, due to the vertical confinement upon the concrete in front of the shear connector, due to the relative displacement of the shear connector, and due to the strut compressive force with $\theta \leq \theta_{0}$, the concrete in front of the shear connector failed in concrete crush or shear failure mode at ultimate relative displacement $\delta_{\mathrm{u}}$ of the shear connector and at a shear compressive stress $\tau$ forming a shear plane as shown in Fig.IV.2.4(b), Fig.IV.2.4(c), and Fig.IV.2.10(b).

Additionally, it is not easy to distinguish split failure mode from shear-split failure mode. However, these two failure modes can be distinguished by observing the appearance of the shear crack at the toe of the shear connector as shown in Fig.IV.2.4(b) \& (c) and Fig.IV.2.6(c) \& (d). The appearance of shear plane indicated the changing of failure mode of the concrete in front of the shear connector due to the decrease of strut angle. Moreover, the differences in tensile strain in the vertical part of the shear connector as shown in Fig.IV.2.7 also showed the changing of shear resisting mechanisms of the shear connectors. When the strut angle was small enough e.g. S-300-100-42.7-20 $\left(\theta=20^{\circ}\right)$, only shear plane appeared in front of the shear connector as shown in Fig.IV.2.4(c) and Fig.IV.2.6(d) and this shear failure mode is quite different from split failure mode shown in Fig.IV.2.4(a) and Fig.IV.2.5.
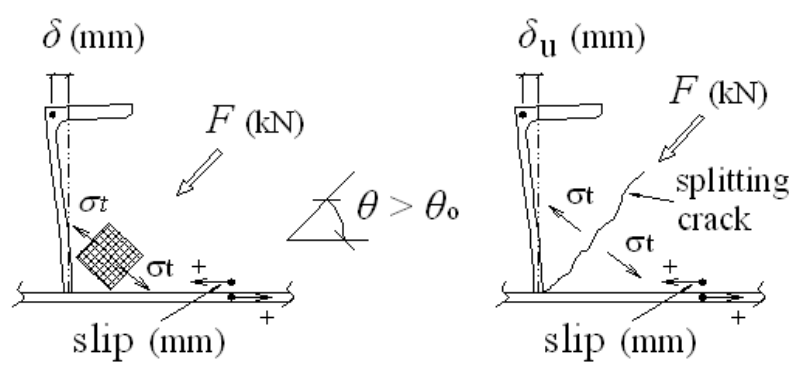

(a) Before split failure

(b) At split failure

Figure IV.2. 9 L-shape shear connector with $\left(\theta>\theta_{\mathrm{o}}\right)$. 


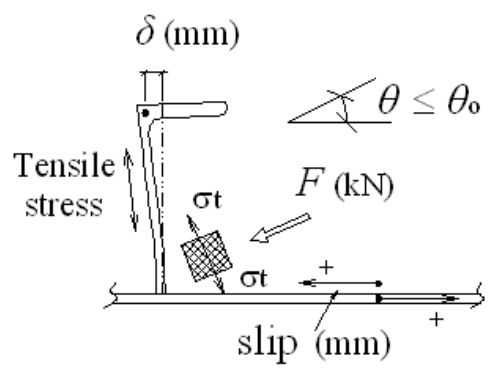

(a) Before shear failure
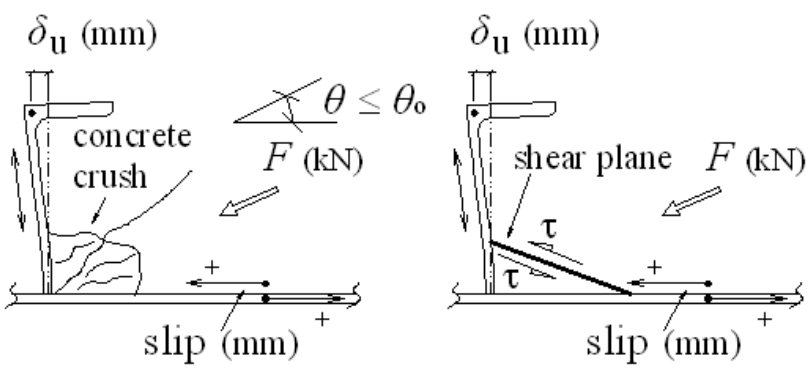

(b) At concrete crush or shear failure

Figure IV.2. 10 L-shape shear connector with $\left(\theta \leq \theta_{0}\right)$.

\section{IV.2.4 Ultimate Shear Force of L-shape Shear Connector $\left(\theta \leq \mathbf{4 5}^{\circ}\right)$}

Table IV.2.1 gives the summary of the ultimate shear forces $V_{\text {u.exp }}$ obtained from the experimental results and the calculation results $V_{\mathrm{sc} 1}$ by means of the guidelines for performance verification of steel-concrete hybrid structures of JSCE (2006) [1] with all safety factors 1.0. Meanwhile, since there is only one shear connector in the shear span, the spacing of the shear connector used to calculate $V_{\mathrm{sc} 1}$ was infinite. It can be observed that $V_{\mathrm{sc} 1}$ agreed with $V_{\text {u.exp }}$ by chance for $1^{\text {st }}$ series shear connectors with $V_{\mathrm{u} . \exp }$ to $V_{\mathrm{sc} 1}$ ratios varied from 1.02 to 1.11 . However, $V_{\text {u.exp }}$ to $V_{\text {sc } 1}$ varied from 1.37 to 1.69 for $2^{\text {nd }}$ series shear connectors whose strut angles were small. These results showed that the formula given by the guidelines for performance verification of steel-concrete hybrid structures of JSCE (2006) [1] can conservatively predict the shear capacity of the shear connector.

However, the value of $V_{\mathrm{u} \text { exp }}$ to $V_{\mathrm{sc} 1}$ ratio is up to 1.69 which means that the shear capacity of Lshape shear connector calculated by means of the formula given by JSCE (2006) [1] is too conservative when the strut angle is small. Therefore, new formulas for the ultimate shear forces of L-shape shear connectors $V_{\mathrm{u}}$ failed in split failure mode and in concrete crush or shear failure mode are necessary. 
Table IV.2. 1 Ultimate shear force of shear connector obtained from experiment and calculation results.

\begin{tabular}{||l|c|c|c|c||}
\hline \multicolumn{1}{|c|}{ Specimens } & Final failure mode & $V_{\text {u.exp }}(\mathrm{kN})$ & $V_{\text {sc1 }}(\mathrm{kN})$ & $V_{\text {u.exp }} / V_{\text {sc1 }}$ \\
\hline \hline S-600-200-9-38-45 & Split failure & 266 & 240 & 1.11 \\
\hline S-600-200-9-25.3-45 & Split failure & 200 & 195 & 1.02 \\
\hline S-450-150-9-23.6-45 & Split failure & 182 & 171 & 1.06 \\
\hline S-300-100-9-25.1-45 & Split failure & 170 & 154 & 1.11 \\
\hline S-600-200-9-43-35 & Split-concrete crush failure & 362 & 254 & 1.42 \\
\hline S-450-150-9-43-30 & Split failure & 357 & 231 & 1.54 \\
\hline S-450-150-9-43-25 & Shear-split failure & 391 & 231 & 1.69 \\
\hline S-300-100-9-41.5-25 & Split failure & 272 & 198 & 1.37 \\
\hline S-300-100-9-42.7-20 & Shear failure & 360 & 202 & 1.63 \\
\hline
\end{tabular}

\section{IV.2.5 Ultimate Shear Force of Shear Connector, Split Failure Mode $\left(\boldsymbol{\theta}_{\boldsymbol{o}}<\theta \leq \mathbf{4 5}^{\mathbf{o}}\right)$}

The ultimate shear force $V_{\mathrm{u}}$ of L-shape shear connector at split failure occurrence was previously proposed based on the experimental results of $1^{\text {st }}$ test series specimens mentioned in the previous subchapter that the concrete in which splitting crack occurred was assumed to behave like a cylinder in the split tensile strength test, Eq.IV.4.

It can be seen in Table IV.2.2 that Eq.IV.4 can precisely predict the ultimate shear forces only in case $\theta=45^{\circ}$. However, this equation was found to underestimate the ultimate shear force when $\theta<45^{\circ}$, S-300-100-9-41.5-25 that $V_{\text {u.exp }}$ to $V_{\text {u.Eq4 }}$ ratio was equal to 1.25 .

Table IV.2. 2 Ultimate shear forces obtained from experiments and calculations by means of Eq.IV.4 and Eq.IV.7.

\begin{tabular}{||c|c|c|c|c|c|c|c||}
\hline Specimens & $\begin{array}{c}\theta \\
(\mathrm{deg})\end{array}$ & $\begin{array}{c}f_{\mathrm{c}}^{\prime} \\
\left(\mathrm{N} / \mathrm{mm}^{2}\right)\end{array}$ & $\begin{array}{c}V_{\mathrm{u} . \exp } \\
(\mathrm{kN})\end{array}$ & $\begin{array}{c}V_{\mathrm{u} . \mathrm{Eq} 4} \\
(\mathrm{kN})\end{array}$ & $\begin{array}{c}V_{\text {u.exp }} / \\
V_{\text {u.Eq4 }}\end{array}$ & $\begin{array}{c}V_{\text {u.Eq7 }} \\
(\mathrm{kN})\end{array}$ & $\begin{array}{c}V_{\text {u.exp }} / \\
V_{\text {u.Eq7 }}\end{array}$ \\
\hline \hline S-600-200-9-38-45 & 45 & 38 & 266 & 254 & 1.05 & 256 & 1.04 \\
\hline S-600-200-9-25.3-45 & 45 & 25.3 & 200 & 207 & 0.96 & 209 & 0.96 \\
\hline S-450-150-9-23.6-45 & 45 & 23.6 & 180 & 182 & 0.98 & 184 & 0.98 \\
\hline S-300-100-9-25.1-45 & 45 & 25.1 & 170 & 169 & 1.00 & 171 & 0.99 \\
\hline S-300-100-9-41.5-25 & 25 & 41.5 & 272 & 218 & 1.25 & 282 & 0.97 \\
\hline
\end{tabular}


Therefore, the revision of Eq.IV.4 is necessary. It can be observed in the previous model of (Ros and Shima, 2010 [20]), Fig.IV.2.11(a) that the strut compressive force on the shear connector was equal to $V_{\mathrm{u}} \sqrt{2}$ which is equal to $\left(V_{\mathrm{u}} / \cos 45\right)$. It means that $\cos 45$ was included in the equation of $k_{1}$, Eq.IV.3. That is why Eq.IV.2 cannot predict the ultimate shear forces of the shear connector when the strut angle $\theta<45^{\circ}$. Therefore, the authors decided to remove $\cos 45$ from the equation of $k_{1}$, Eq.IV.3 and keep $\cos \theta$ in Eq.IV.4, Fig.IV.2.11(b). Eq.IV.4 and Eq.IV.3 can be replaced by Eq.IV.7 and Eq.IV.8, respectively.

$$
\begin{aligned}
& V_{\mathrm{u}}=k_{1} \times \sqrt{f_{\mathrm{c}}^{\prime}} \times b_{\mathrm{sc}} \times h_{\mathrm{sc}} \times \cos \theta \\
& k_{1}=28 \times\left(\frac{t_{1, s c}}{h_{s c}}\right)+0.70
\end{aligned}
$$

Where,

$V_{\mathrm{u}} \quad$ : ultimate shear force in split failure mode $(\mathrm{N})$,

$b_{\text {sc }} \quad$ : width of shear connector $(\mathrm{mm})$,

$\mathrm{h}_{\mathrm{sc}} \quad$ : height of shear connector $(\mathrm{mm})$,

$\mathrm{t}_{1, \mathrm{sc}} \quad$ : thickness of shear connector $(\mathrm{mm})$,

$\mathrm{f}_{\mathrm{c}}^{\prime} \quad$ : concrete compressive strength $\left(\mathrm{N} / \mathrm{mm}^{2}\right)$,

$\theta \quad:$ strut angle $\left(\theta>\theta_{\mathrm{o}}\right)$ (degree)

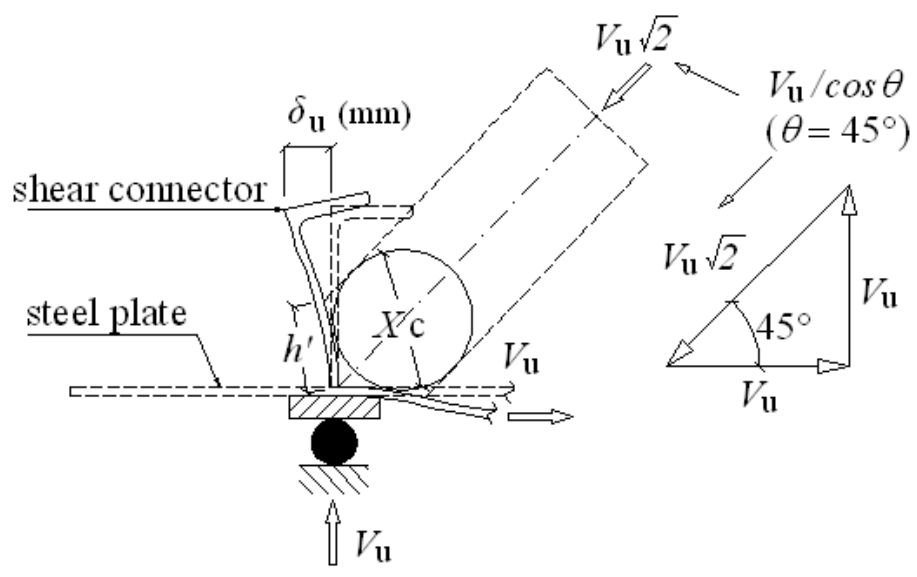

a) Previous consideration with $\theta=45^{\circ}$ 


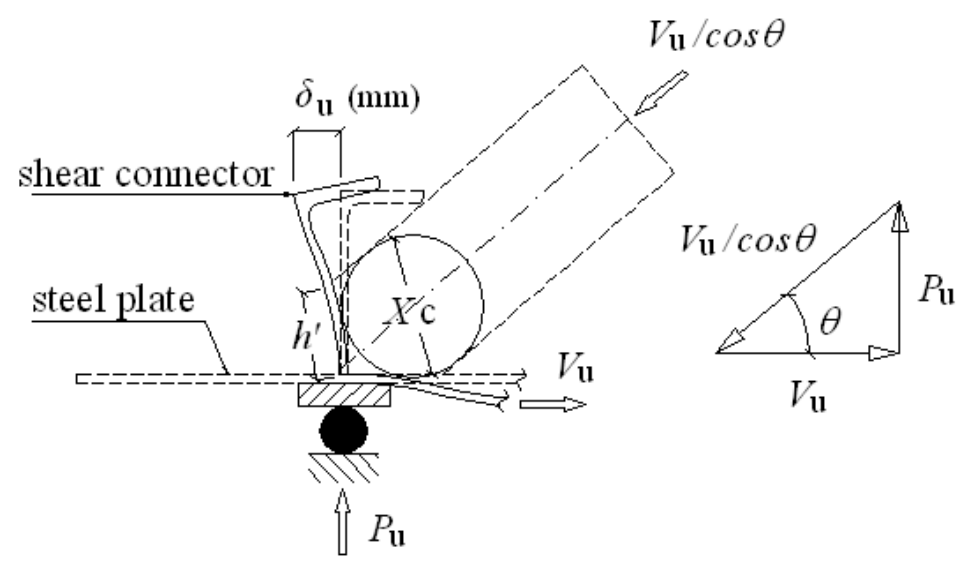

b) New consideration with $\theta_{o}<\theta \leq 45^{\circ}$

Figure IV.2. 11 Model of L-shape shear connector failed in split failure mode.

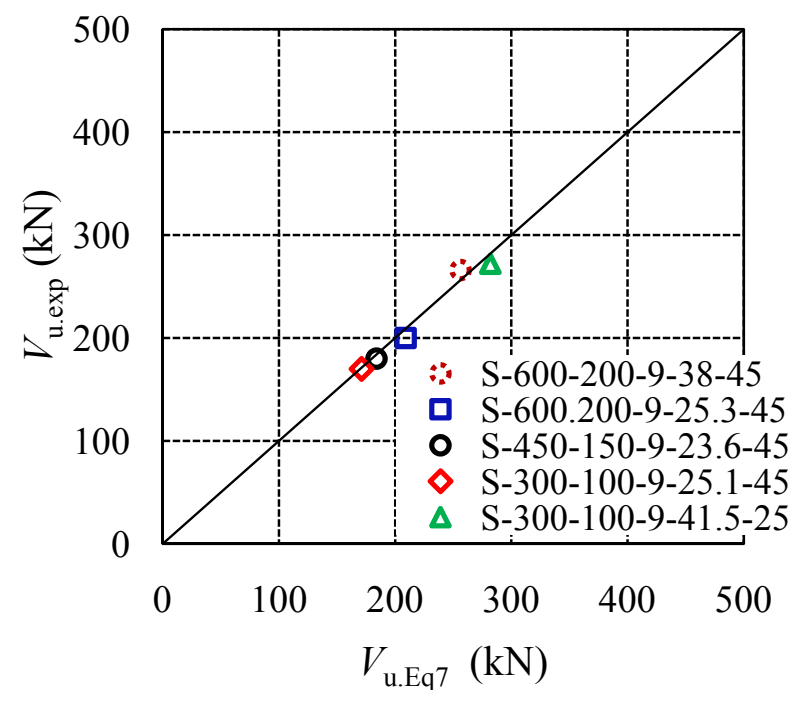

Figure IV.2. 12 Ultimate shear force of shear connectors in split failure mode.

As shown in Table IV.2.2 and Fig.IV.2.12, Eq.7 can precisely predict the ultimate shear forces of L-shape shear connector at split failure occurrence under different strut angle with $V_{\mathrm{u} \text { exp }}$ to $V_{\text {u.Eq7 }}$ ratio varied from 0.96 to 1.04 . However, when $\theta \leq \theta_{\mathrm{o}}$ the shear connectors were found to fail in concrete crush or shear failure modes. Therefore, another formula for ultimate shear force of L-shape shear connector at concrete crush or shear failure mode is necessary. 


\section{IV.2.6 Ultimate Shear Force of Shear Connector in Concrete Crush/Shear Failure Mode}

Three specimens of the $2^{\text {nd }}$ test series were found to fail in concrete crush or shear failure modes, Fig.IV.2.4. A shear plane was clearly observed in front of the shear connector, Fig.IV.2.13(b); also the shear connectors were found to resist against an uplifting mechanism. Therefore, a simplified model of L-shape shear connector in shear failure mode was developed as illustrated in Fig.IV.2.13(a). At failure, shear plane resisted against the shear compressive stress $\tau$, $(\tau=$ $1.25 \sqrt{f_{c}^{\prime}}$, JSCE, 2006 [1]) and the ultimate shear force at shear failure occurrence can be expressed as followings:

$$
V_{1}-V_{2}=\tau \times b_{\mathrm{sc}} \times l
$$

Where,

$\tau$ : shear compressive stress $\left(\mathrm{N} / \mathrm{mm}^{2}\right)$,

$l$ : length of shear plane (mm), $l=h^{\prime \prime} / \sin i$,

$b_{\text {sc }}$ : width of the shear connector $(\mathrm{mm})$.

Since $V_{1}=F_{1} \times \cos i, V_{2}=F_{2} \times \sin i, \quad F_{1}=F \times \cos \theta, \quad$ and $\quad F_{2}=F \times \sin \theta, \quad$ Fig.IV.2.13(a) Eq.IV.9 can be expressed as followings:

$$
F \times(\cos \theta \times \cos i-\sin \theta \times \sin i)=1.25 \sqrt{f_{\mathrm{c}}^{\prime}} \times b_{\mathrm{sc}} \times \frac{h^{\prime \prime}}{\sin i}
$$

Or $F \times \cos (\theta+i)=1.25 \sqrt{f_{\mathrm{c}}^{\prime}} \times b_{\mathrm{sc}} \times \frac{h^{\prime \prime}}{\sin i}$

Since $h^{\prime \prime}=h_{\mathrm{sc}} \times(\tan i / \tan j)$ and $F=V_{\mathrm{u}} / \cos \theta$, Eq.IV.10 can be given as followings:

$$
V_{\mathrm{u}}=\frac{1}{\cos i \times \cos (\theta+i) \times \tan j} \times 1.25 \sqrt{f_{\mathrm{c}}^{\prime}} \times b_{\mathrm{sc}} \times h_{\mathrm{sc}} \times \cos \theta
$$

Or $\quad V_{\mathrm{u}}=k_{2} \times \sqrt{f_{\mathrm{c}}^{\prime}} \times b_{\mathrm{sc}} \times h_{\mathrm{sc}} \times \cos \theta$

That $k_{2}$ is the constant representing other controlling factors which can be calculated by Eq.IV.12.

$$
k_{2}=\frac{V_{\mathrm{u}}}{\sqrt{f_{\mathrm{c}}^{\prime}} \times b_{\mathrm{sc}} \times h_{\mathrm{sc}} \times \cos \theta}
$$




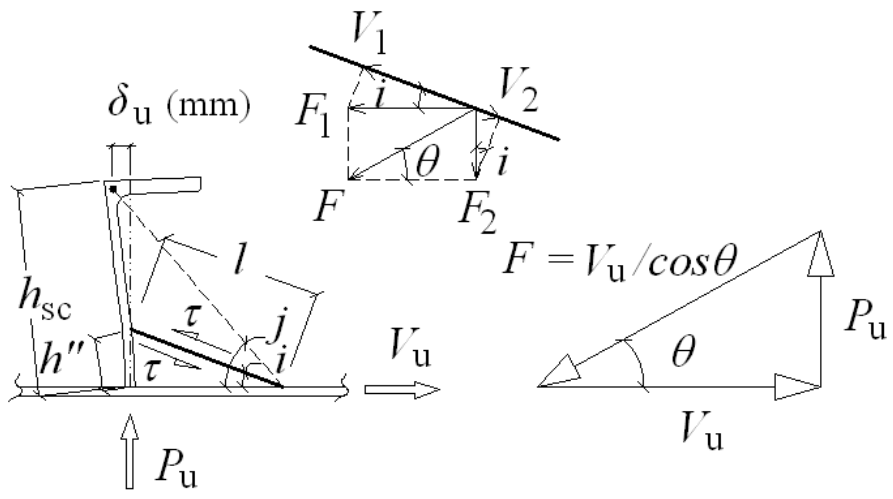

(a) Model of shear connector in shear failure mode

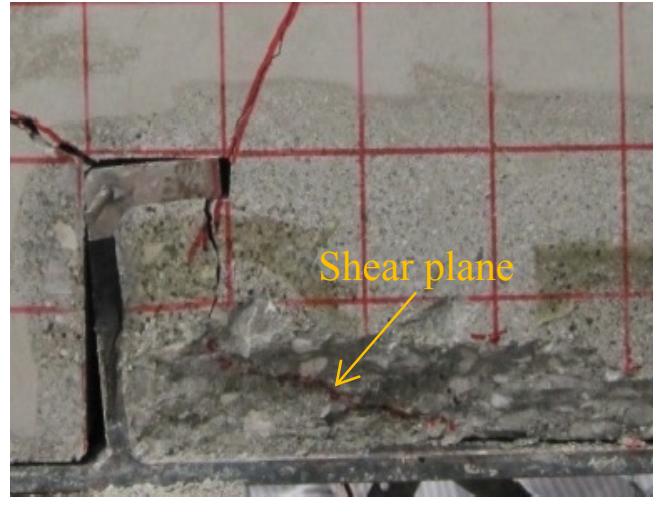

(b) Tested specimen in shear failure mode

Figure IV.2. 13 L-shape shear connector in shear failure mode.

Table IV.2.3 gives the values of $k_{2}$ obtained from Eq.IV.9 where $V_{\mathrm{u}}$ is the ultimate shear force of shear connector failed in shear failure modes or by concrete crush observed during the experiments. Moreover, it has been known that the strength of the shear connector is highly influenced by its thickness to height ratio $t_{1, \mathrm{sc}} / h_{\mathrm{sc}}$. Meanwhile, the angle $i$ and $j$ varied depending on the $t_{1, \mathrm{sc}} / h_{\mathrm{sc}}$. Therefore, the values of $k_{2}$ are reasonably influenced by the values of $t_{1, \mathrm{sc}} / h_{\mathrm{sc}}$. The relationships between $k_{2}$ and $t_{1, \mathrm{sc}} / h_{\mathrm{sc}}$ of the shear connectors failed in shear failure mode or by concrete crush were plotted against those between $k_{1}$ and $t_{1, \mathrm{sc}} / h_{\mathrm{sc}}$ of shear connectors failed in split failure mode as given in Fig.IV.2.14. It can be seen two different lines of $k_{1}$ and $k_{2}$ which represent the two different failure modes mentioned in the previous subchapter. Particularly, the values of $k_{2}$ linearly increases with the values of $t_{1, \mathrm{sc}} / h_{\mathrm{sc}}$ whose equation can be expressed as follows:

$$
k_{2}=36 \times\left(\frac{t_{1, \mathrm{sc}}}{h_{\mathrm{sc}}}\right)+0.66
$$

Table IV.2. 3 The values of $k_{2}$ obtained from Eq.IV.12.

\begin{tabular}{|c|c|c|c|c|c|c|c||}
\hline Specimens & $\begin{array}{c}t_{1, \mathrm{sc}} \\
(\mathrm{mm})\end{array}$ & $\begin{array}{c}h_{\mathrm{sc}} \\
(\mathrm{mm})\end{array}$ & $t_{1, \mathrm{sc}} / h_{\mathrm{sc}}$ & $\begin{array}{c}\theta \\
(\mathrm{deg})\end{array}$ & $\begin{array}{c}f_{\mathrm{c}}^{\prime} \\
\left(\mathrm{N} / \mathrm{mm}^{2}\right)\end{array}$ & $\begin{array}{c}V_{\mathrm{u}} \\
(\mathrm{kN})\end{array}$ & $k_{2}$ \\
\hline \hline S-600-200-9-43-30 & 9 & 200 & 0.045 & 35 & 43.0 & 362 & 2.25 \\
\hline S-450-150-9-43-25 & 9 & 150 & 0.06 & 25 & 43.0 & 391 & 2.92 \\
\hline S-300-100-9-42.7-20 & 9 & 100 & 0.09 & 20 & 42.7 & 360 & 3.91 \\
\hline
\end{tabular}




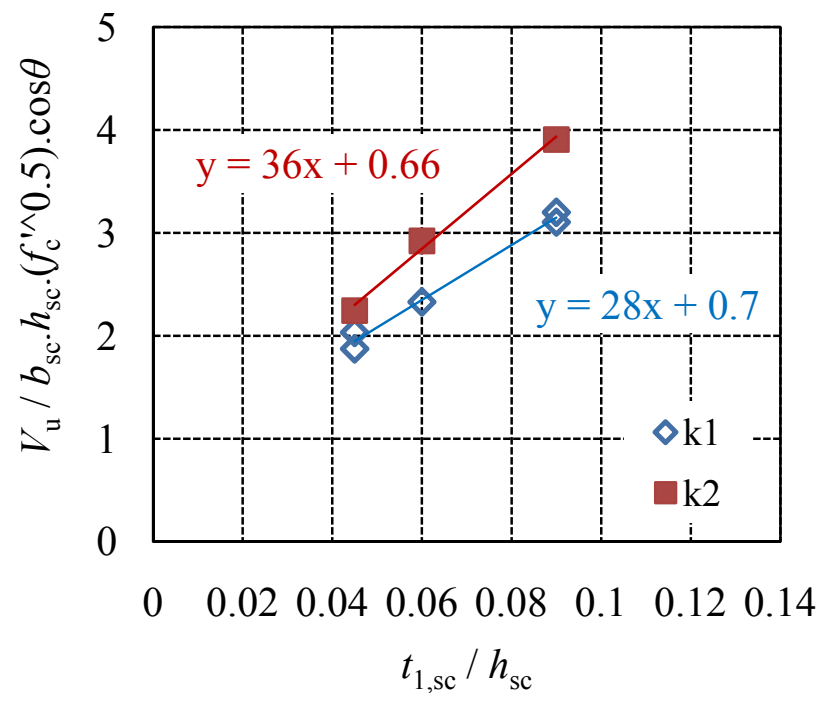

Figure IV.2. 14 Relationship between $k_{2}$ and $t_{1, \mathrm{sc}} / h_{\mathrm{sc}}$.

Therefore, the ultimate shear force of L-shape shear connector at concrete crush or shear failure mode can be given as followings:

$$
\begin{aligned}
& V_{\mathrm{u}}=k_{2} \times \sqrt{f_{\mathrm{c}}^{\prime}} \times b_{\mathrm{sc}} \times h_{\mathrm{sc}} \times \cos \theta \\
& k_{2}=36 \times\left(\frac{t_{1, \mathrm{sc}}}{h_{\mathrm{sc}}}\right)+0.66
\end{aligned}
$$

Where,

$V_{\mathrm{u}} \quad$ : ultimate shear force in shear failure mode or by concrete crush $(\mathrm{N})$,

$b_{\text {sc }} \quad$ : width of shear connector $(\mathrm{mm})$,

$h_{\mathrm{sc}}:$ height of shear connector $(\mathrm{mm})$,

$t_{1, \mathrm{sc}}:$ thickness of shear connector $(\mathrm{mm})$,

$f_{\mathrm{c}}^{\prime} \quad$ : concrete compressive strength $\left(\mathrm{N} / \mathrm{mm}^{2}\right)$,

$\theta \quad$ : strut angle $\left(\theta \leq \theta_{\mathrm{o}}\right)$ (degree).

Table IV.2.4 gives the values of the ultimate shear forces obtained from the experimental

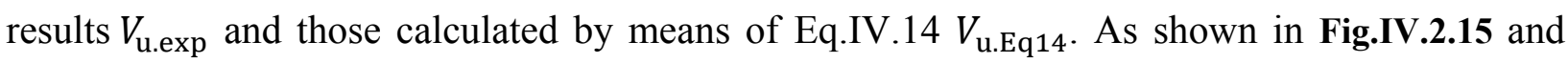
Table IV.2.4, Eq.IV.14 can precisely predict the ultimate shear force with $V_{\text {u.exp }}$ to $V_{\text {u.Eq14 }}$ ratio 0.99 to 1.04 . 
Table IV.2. 4 Calculated ultimate shear force $V_{\text {u.exp }}$ and $V_{\text {u.Eq14 }}$.

\begin{tabular}{|l|c|c|c|}
\hline \multicolumn{1}{|c|}{ Specimens } & $\begin{array}{c}V_{\text {u.exp }} \\
(\mathrm{kN})\end{array}$ & $\begin{array}{c}V_{\text {u.Eq14 }} \\
(\mathrm{kN})\end{array}$ & $V_{\text {u.exp }} / V_{\text {u.Eq14 }}$ \\
\hline S-600-200-9-43-35 & 362 & 367 & 0.99 \\
\hline S-450-150-9-43-25 & 391 & 377 & 1.04 \\
\hline S-300-100-9-42.7-20 & 360 & 359 & 1.00 \\
\hline
\end{tabular}

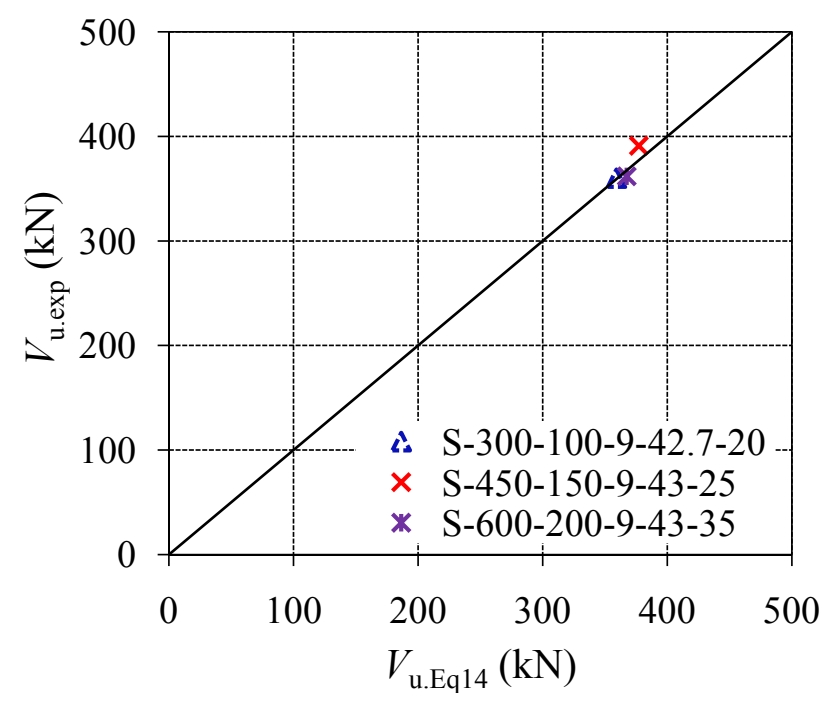

Figure IV.2. 15 Comparison between $V_{\text {u.Eq14 }}$ and $V_{\text {u.exp }}$.

Therefore, the ultimate shear capacity of shear connector in split failure mode and in concrete crush or shear failure mode can be predicted through Eq.IV.7 and Eq.IV.14, respectively. However, it is difficult to determine the strut angle in the design work for a real structure; therefore, the strut angle which gives conservative strength of the shear connector should be selected. Since, the applicable ranges of the proposed equations are in the interval of strut angle $\left(20^{\circ} \leq \theta \leq 45^{\circ}\right)$, the strut angle of $45^{\circ}$ is recommended for conservative strength. In additions, the maximum height of shear connector applicable for the proposed equation was $h_{\mathrm{sc}}=$ $400 \mathrm{~mm}$ which is large enough for L-shape shear connector sizes available on market.

Additionally, the equation of $V_{\mathrm{u}}$ can be expressed as follows: 


$$
V_{\mathrm{u}}=\left\{\begin{array}{lr}
\left(28 t_{1, s c}+0.70 h_{s c}\right) \times \sqrt{f_{\mathrm{c}}^{\prime}} \times b_{\mathrm{sc}} \times \cos \theta & (\text { Split failure }) \\
\left(36 t_{1, s c}+0.66 h_{s c}\right) \times \sqrt{f_{\mathrm{c}}^{\prime}} \times b_{\mathrm{sc}} \times \cos \theta & (\text { Shear failure })
\end{array} \quad\right. \text { Eq.IV.15 }
$$

Based on these expressions, the effect of thickness $t_{1, \mathrm{sc}}$ and height $h_{\mathrm{sc}}$ of shear connector on its shear capacity can be clearly observed. $t_{1, \mathrm{sc}}$ was found to have much higher effect on the shear capacity than $h_{\text {sc. }}$.

Furthermore, only the ultimate shear capacity of the shear connector is not enough to fully understand the performance of the shear connector. Therefore, shear force-slip relationships and shear force-relative displacement relationships of the shear connector are also discussed in the following sub-chapters.

\section{IV.2.7 Shear Force-Slip Relationship of L-shape Shear Connector $\left(\theta \leq 4^{\circ}\right)$}

The relationships between shear force and concrete-skin plate slip in front of the shear connector of $1^{\text {st }}$ and $2^{\text {nd }}$ test series specimens are given in Fig.IV.2.16. The experimental results showed that the stiffness of the same size shear connectors was the same despite different concrete strength and different strut angle. However, the shear connectors with smaller strut angle were found to be capable to resist against higher level of shear forces and gave greater ultimate slip values as compared to those with greater strut angle even though the concrete strengths and the size of shear connectors are the same. Additionally, it can be said that the shear connectors which failed in concrete crush or shear failure modes gave greater values of ultimate slip than those failed in split failure modes.

Moreover, L-shape shear connectors in beam type specimens were found to have shear resistance even crack already appeared in the concrete from the head of the shear connector. These results proved the advantage of the test method as compared to push-out and pull-out test methods. Based on the experimental results of Kiyomiya et al. (1986) [6], Ueda et al. (1989) [10], and Chuah et al. (1991) [9], in push-out and pull-out tests the shear connectors were found to gradually lose their shear resisting ability after crack took place in the concrete from the head of the shear connectors. However, they also found similar behaviors of the shear connectors that the slip between concrete and skin plate in front of the shear connector occurred even under low load levels.

Furthermore, as shown in Fig.IV.2.17, no an effect of the height of the shear connector on shear force-slip relationships of the shear connector was observed. However, based on the 


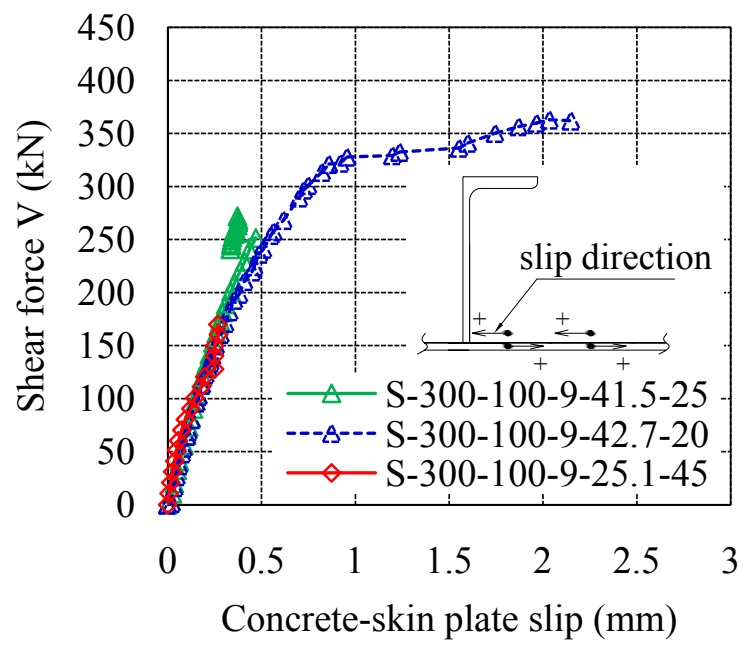

(a) $h_{\mathrm{sc}}=100 \mathrm{~mm}$

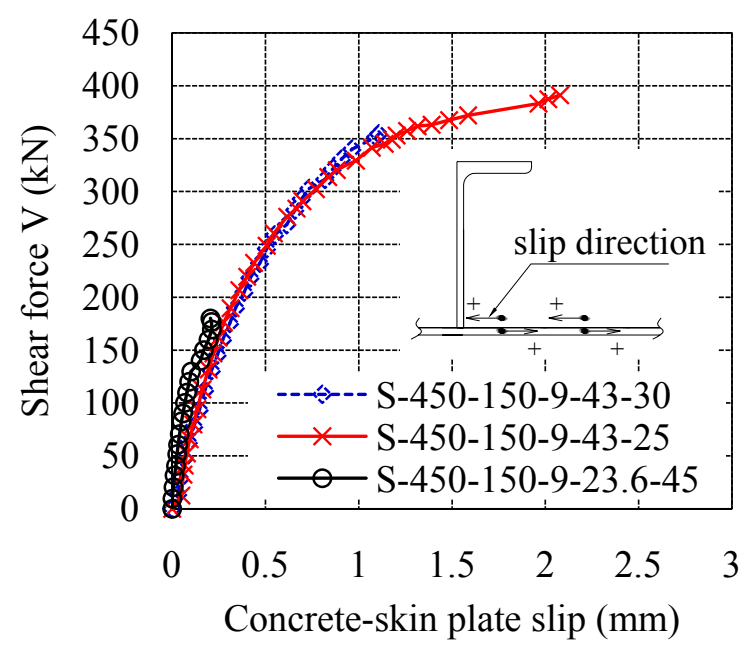

(b) $h_{\mathrm{sc}}=150 \mathrm{~mm}$

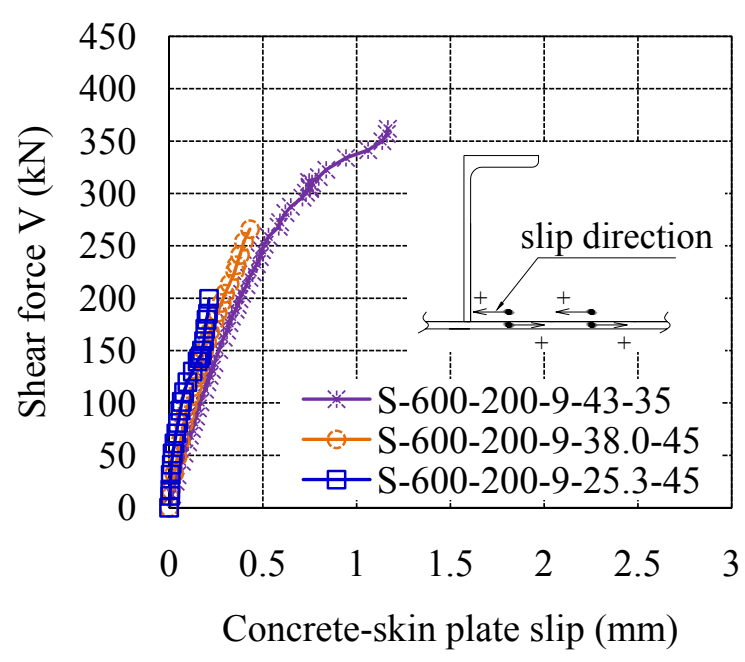

(c) $h_{\mathrm{sc}}=200 \mathrm{~mm}$

Figure IV.2. 16 Shear force-slip relationships of $1^{\text {st }}$ and $2^{\text {nd }}$ test series shear connectors. 


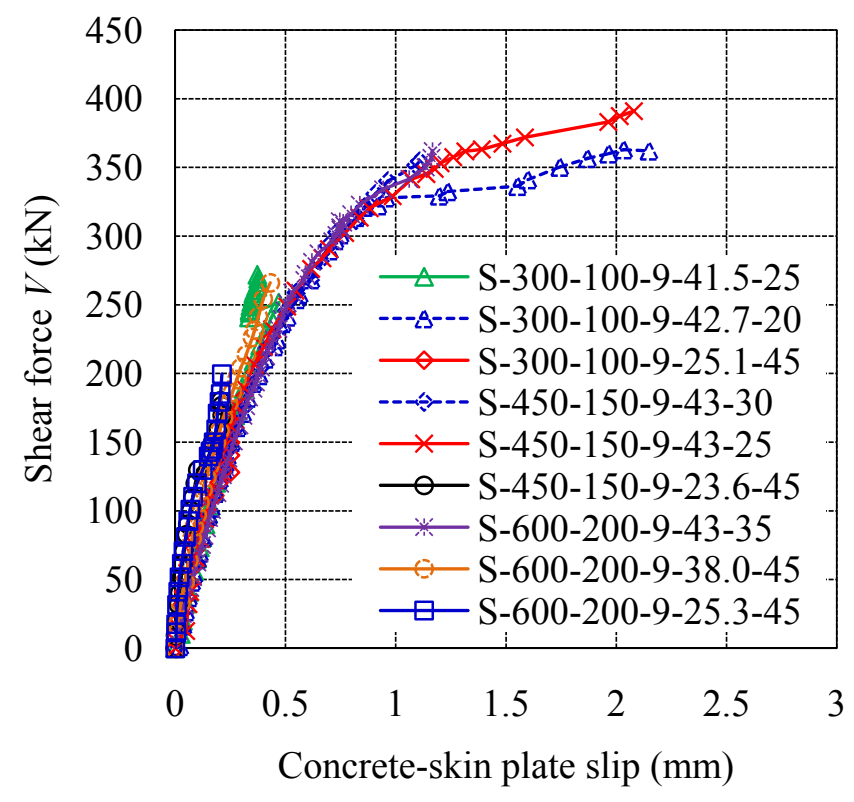

Figure IV.2.17 Shear force-slip relationships of shear connectors.

experimental results, the final failure mode of the shear connector and the strut angle were found to have effect on the ultimate shear force $V_{\mathrm{u}}$ and the ultimate concrete-skin plate slip in front of the shear connector.

\section{IV.2.8 Shear Force-Relative Displacement Relationships $\left(\theta \leq \mathbf{4 5}^{\circ}\right)$}

The relationships between shear force and relative displacement obtained from the $1^{\text {st }}$ and $2^{\text {nd }}$ test series specimens were compared and discussed. Shear force-relative displacement relationships of the shear connectors with $h_{\mathrm{sc}}=100 \mathrm{~mm}$ and with $h_{\mathrm{sc}}=200 \mathrm{~mm}$ are given in Fig.IV.2.18 and Fig.IV.2.19, respectively. Big increments of relative displacement with small increments of shear force were observed after crack took place from the head of the shear connector. These showed that the stiffness of the shear connectors suddenly reduced when the first diagonal crack occurred. These similar behaviors were also found for L-shape shear connector in steel-concrete sandwich beam by (Saidi et al. 1998 [12], 1999 [13], 2008 [14]). However, differently from the steel concrete sandwich beam test, the ultimate relative displacements $\delta_{u}$ and the ultimate shear force $V_{\mathrm{u}}$ of L-shape shear connectors could be observed in the beam type test method.

Moreover, it can be observed in S-300-100-9-41.5-25 and S-300-100-9-42.7-20 that at the same value of relative displacement, the shear connector with smaller strut angle could resist higher level of shear force than that with greater strut angle. However, the same size shear connectors 
gave similar values of ultimate relative displacement despite different strut angle, concrete strength, and final failure mode. Therefore, it can be said that the strut angle, the concrete strength, and the final failure mode were found to have no effect on the ultimate relative displacement $\delta_{\mathrm{u}}$ of the shear connector but the shear resisting ability. Moreover, as shown in Fig.IV.2.20, the height of the shear connector was found to have effect on the ultimate relative displacement $\delta_{\mathrm{u}}$. It can be seen that the specimens with larger size shear connectors failed at greater values of ultimate relative displacements $\delta_{\mathrm{u}}$ regardless of the strut angle, the concrete strength, and the final failure mode.

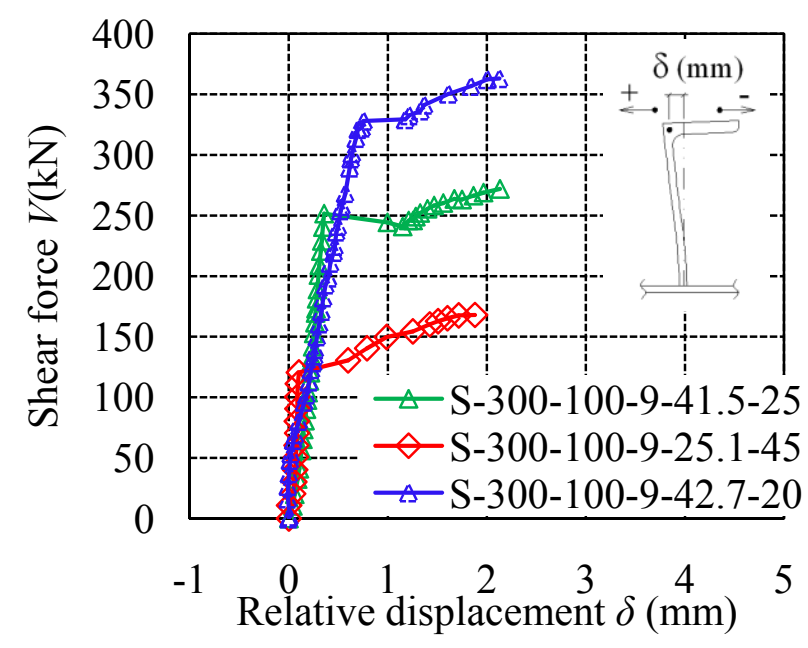

Figure IV.2. $18 \mathrm{~V}-\delta$ relationships for $h_{\mathrm{sc}}=100 \mathrm{~mm}$.

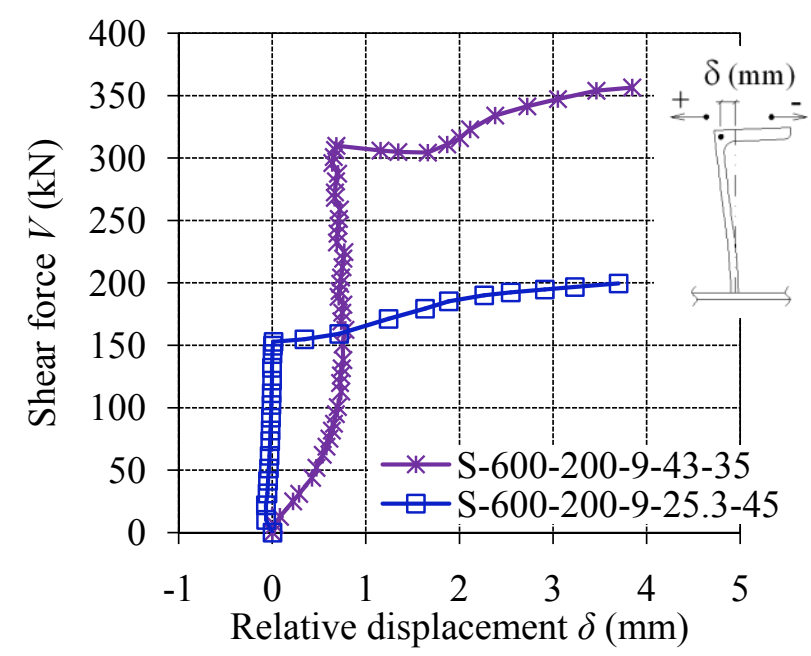

Figure IV.2. $19 V-\delta$ relationships for $\boldsymbol{h}_{\text {sc }}=200 \mathrm{~mm}$. 


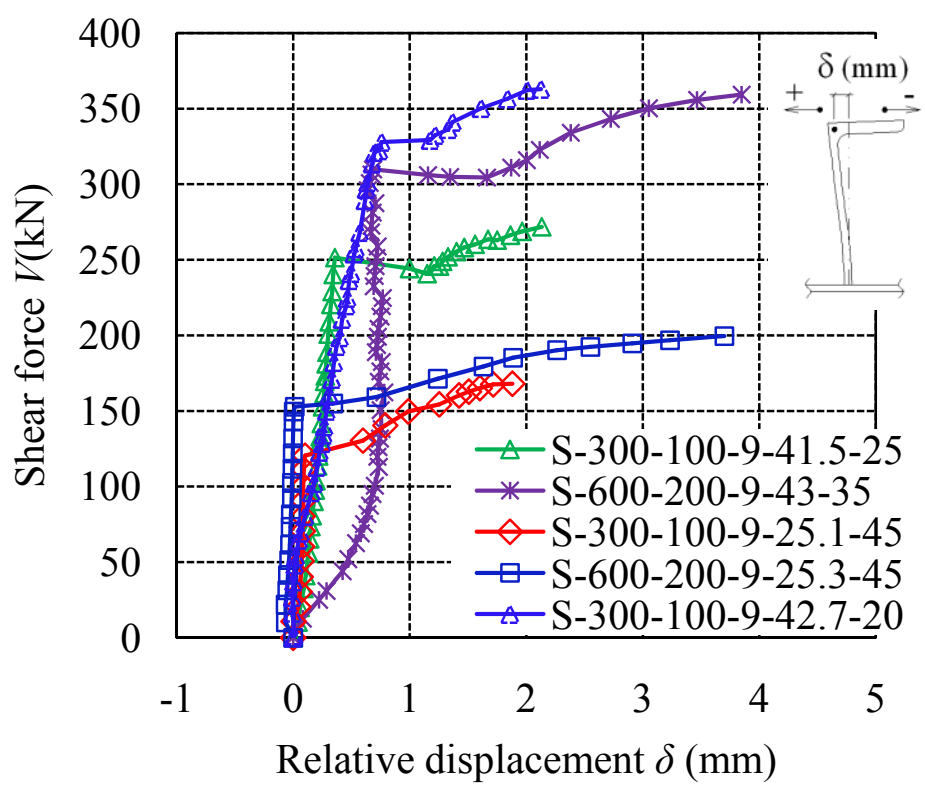

Figure IV.2. $20 \boldsymbol{V}-\boldsymbol{\delta}$ relationships of $1^{\text {st }}$ and $2^{\text {nd }}$ test series shear connectors.

Even though shear force-relative displacement relationships of L-shape shear connectors were clearly understood from the experimental results, the formula to predict the enveloped curve of the relationships also plays a vital role in the design. Therefore, the following sub-chapter discussed the formulation for the enveloped curve of shear force-relative displacement relationships of the shear connectors.

\section{IV.2.9 Formulation for Shear Force-Relative Displacement Relationships $\left(\theta \leq \mathbf{4 5}^{\circ}\right)$}

The formula for shear force-relative displacement relationship of L-shape shear connector proposed in previous subchapter by means of the results from $1^{\text {st }}$ test series specimens and FEM analyses for the case that strut angle $\theta$ approximately $45^{\circ}$ and splitting crack in front of the shear connector controlled the final failure modes, Eq.IV.5. The formula was given as followings:

$$
\frac{V}{V_{\mathrm{u}}}=\left(1-e^{-180 \frac{\delta}{h_{\mathrm{sc}}}}\right)^{0.6}
$$

Additionally, Eq.IV.5 was proposed for the case after the occurrence of crack from the head of the shear connector until failure of the shear connector where the shapes of the curves were clearly observed. The calculated results by means of Eq.IV.5 were compared with those obtained 


\section{CHAPTER V}

\section{CONCLUSIONS}

Based on the experimental results, analyses, and discussions in the previous chapter, the followings conclusions can be obtained.

1. L-shape shear connectors subjected to strut compressive force in steel-concrete composite structures were found to have two different failure modes, split failure mode and concrete crush/shear failure mode. Meanwhile, the failure criterion of L-shape shear connector was determined by the failure criterion of concrete element in front of the shear connector.

2. The strut angle and the thickness to height ratio of the shear connector $t_{1, \mathrm{sc}} / h_{\mathrm{sc}}$ were found to control the final failure mode of the shear connector.

3. There existed a critical strut angle $\theta_{\mathrm{o}}$ representing the border between split failure mode and concrete crush/shear failure mode of L-shape shear connector subjected to strut compressive force. Accordingly, an equation to predict the critical strut angle $\theta_{\mathrm{o}}$ was developed and proposed. The equation was found to be a function of the thickness to height ratio of the shear connector which is expressed as followings:

$$
\theta_{\mathrm{o}}=-210\left(\frac{t_{1, \mathrm{sc}}}{h_{\mathrm{sc}}}\right)+41
$$

Split failure and concrete crush/shear failure would occur when the strut angle $\theta>\theta_{\mathrm{o}}$ and $\theta \leq \theta_{0}$, respectively.

4. The equation to predict the ultimate shear capacity $V_{\mathrm{u}}$ of L-shape shear connector subjected to strut compressive force in steel-concrete composite structures was developed and proposed for two cases of failure modes, split failure mode and concrete crush/shear failure mode. The equation was a function of the concrete strength, the width and the height of the shear connector, the strut angle, and a constant $k$; while the equation of constant $k$ was a function of thickness to height ratio of the shear connector. The selection of constant $k$ depends on the strut angle $\theta$ used comparing to the critical strut angle $\theta_{\mathrm{o}}$. The equations are expressed as followings: 


$$
\begin{aligned}
& V_{\mathrm{u}}=k \times f_{t} \times b_{\mathrm{sc}} \times h_{\mathrm{sc}} \times \cos \theta \\
& k=63 \times\left(\frac{t_{1, \mathrm{sc}}}{h_{\mathrm{sc}}}\right)+1.60 \quad\left(\text { for } \theta>\theta_{o}\right) \\
& k=81 \times\left(\frac{t_{1, s c}}{h_{s c}}\right)+1.50 \quad\left(\text { for } \theta \leq \theta_{o}\right)
\end{aligned}
$$

The applicable ranges of the proposed equations are in the interval of strut angle $\left(20^{\circ} \leq\right.$ $\left.\theta \leq 45^{\circ}\right)$.

5. When the relationship between shear force $V$ and relative displacement $\delta$ represented by the relationships between $V / V_{\mathrm{u}}$ and $\delta / h_{\mathrm{sc}}$, a unique enveloped curve of the relationships was observed regardless of the size of the shear connector, the concrete strength, and the strut angle for the case after the occurrence of crack from the head of the shear connector until failure of the shear connector.

6. An equation to predict the enveloped curved of the relationships between $V / V_{\mathrm{u}}$ and $\delta / h_{\mathrm{sc}}$ of L-shape shear connector subjected to strut compressive force in steel-concrete composite structure was developed and proposed as followings:

$$
\frac{V}{V_{\mathrm{u}}}=\left(1-e^{-180 \frac{\delta}{h_{\mathrm{sc}}}}\right)^{0.6}
$$

The enveloped curved was proposed for the case after the occurrence of crack from the head of the shear connector until failure of the shear connector.

7. The ultimate relative displacements $\delta_{\mathrm{u}}$ of L-shape shear connectors were found approximately 0.02 times the height of the shear connector regardless of the concrete strength and the strut angle.

The equation to predict the enveloped curve of the shear force-relative displacement relationship of the shear connector was proposed only after the occurrence of crack from the head of the shear connector. However, by means of this equation, the ultimate state of partial interaction mechanism of the shear connector which is important for the design can be understood. Additionally, the performances and the formulations for L-shape shear connector found in this study were found only for the shear connector whose direction is opposite of the direction of shear force. Therefore, further study should be taken into account the effects of the direction of the shear connector. 


\section{REFERENCES}

1) JSCE, (2006). "Guideline for performance verification of steel-concrete hybrid structures." Hybrid Structure Series 2, Japan Society of Civil Engineers.

2) Japanese Society of Civil Engineer (2009). "Standard specifications for hybrid structure", JSCE. (in Japanese)

3) JSCE Research Subcommittee on Steel-Concrete Sandwich Structures (1992). "Design code for steel-concrete sandwich structures - Draft”, Concrete Library of JSCE, No. 20, 1-21.

4) Sakai, F., Yabe, J., Ohgaki, K., Hashimoto, Y. and Tomoda, T. (1995). “A study on three dimensional characteristics of composite bridges with two plate girders. Journal of Structure Engineering, JSCE, Vol.41A.

5) Sakai, F., Yabe, J., Ohgaki, K. and Hashimoto, Y. (1997). "A study on positioning of cross beam in composite two-plate-girder bridges", Bridge and Foundation, Vol.31, No.3, 31-38.

6) Kiyomiya, O. and Yokota, H. (1986). "Strength of shear connector by shape steel in composite member with steel and concrete", Proc. of Symposium on Research and Application of Composite Constructions, JSCE, 113-118.

7) Kimura, H., Kojima, K., and Kiyomiya, O. (1993). "Influence of Test Methods to Ultimate Strength of Shaped Steel Shear connector", Proc. of The 48th Annual Conference of The Japan Society of Civil Engineers, V, 20-21. (in Japanese).

8) Chin, C. K. and Ueda, T. (1989). "Experimental study on plate shear connector for composite construction", Proc. of The Second East Asia-Pacific Conference on Structural Engineering and Construction, Vol.1, 651-656.

9) Chuah, C.L., Shima, H., and Virach, R. (1991). "Load-displacement relationship of plate shear connector in steel-concrete composite structure.” Proc. of JSCE, No. 433/V-15, $223-$ 229.

10) Ueda, T. and Chin, C.K. (1989). "Strength of steel plate shear connector." Proc. Of Second Symposium on Research and Application of Composite Constructions, JSCE, 149-156. (in Japanese)

11) Makabe, T., Malek, N., Mutsuyoshi, H. and Machida, A. (1992). "Experimental Study on Mechanical Properties of Steel and Concrete Sandwich Beam", J. of Structural Div., JCI, Vol.14, 729-733.

12) Saidi, T., Furuuchi, H., and Ueda, T. (1998). "Relationship between transferred shear force and relative displacement of shear connector in steel-concrete sandwich beam." Journal of 
Structural Engineering, JSCE, 44 (A), 1537-1545.

13) Saidi, T., Furuuchi, H. and Ueda, T. (1999). "Effect of shape and location of shear connector on its transferred shear force and relative displacement relationship in steel-concrete sandwich beam.” Journal of Structural Engineering, JSCE, 45 (A), 1451-1459.

14) Saidi, T., Furuuchi, H., and Ueda, T. (2008). "The transfer shear force-relative displacement relationship of the shear connector in steel-concrete sandwich beam and its model." Doboku Gakkai Ronbunshuu, E, JSCE, Vol.64, No.1, 122-141.

15) Ollgaard, J., Slutter, R. and Fisher, J. (1971). "Shear strength of stud connectors in lightweight and normal-weight concrete", AISC Engineering Journal, 55-64.

16) Shima, H. and Watanabe, S. (2009). "Formulation for Load-Slip Relationships of Headed Stud Connector, Proc. Of fib2009, 22-24, London.

17) Ros, S. and Shima, H. (2009): "New beam type test method for load-slip relationship of Lshape shear connector," Proc. of $8^{\text {th }}$ Symposium on Research and Application of Hybrid and Composite Structures JSCE, Tokyo, Japan.

18) Ros, S. and Shima, H. (2009): "Finite Element Analyses for Performance of L-shape Shear Connector Subjected to Strut Compressive Force in Beam Type Specimen” AIJ Shikoku Chapter Architectural Research Meeting, No.10, Kochi.

19) Ros, S. and Shima, H. (2010). "Behaviors of L-shape shear connector subjected to strut compressive force in beam type test specimens." Proceeding of the Japan Concrete Institute, JCI, Vol.32, No.2, 1195-1200.

20) Ros, S. and Shima, H. (2010). "Shear force-horizontal relative displacement relationship of L-shape shear connector subjected to strut compressive force in steel-concrete composite structures.” Doboku Gakkai Ronbunshuu A, JSCE, Vol. 66, No.4, 767-782.

21) Ros, S. and Shima, H. (2010): "Formulation for maximum shear force of L-shape shear connector subjected to strut compressive force at splitting crack occurrence in steel-concrete composite structures," The Twelfth East Asia-Pacific Conference on Structural Engineering and Construction, EASEC-12.

22) Ros, S. and Shima, H. (2011). "Effect of strut angle on the behavior of L-shape shear connector subjected to strut compressive force in steel-concrete composite structures." Journal of Structural Engineering, JSCE, Vol. 57A, 987-995.

23) Ros, S. and Shima, H. (2010). "Formulation for shear force-relative displacement relationship of L-shape shear connector in steel-concrete composite structures." Journal of Advanced Concrete Technology, ACT. (Accepted May-2011) 
24) Ros, S. and Shima, H. (2011). "Shear force-relative displacement relationship of L-shape shear connector.” Annual Join Convention, JCI, Vol.33, No.2, 1219-1224.

25) JSCE Committee on Revision of the Standard Specification for Concrete Structure: Standard Specification for concrete Structures-2002, "Material and Construction", JSCE Guideline for Concrete, No.6, pp.64, November 2005.

26) Okamura, H. and Maekawa, K. "Nonlinear Analysis and Constitutive Models of Reinforced Concrete", January 1997. (in Japanese) 


\section{APPENDIX III.1}

Stress-strain relationships of the steels used in the experiments

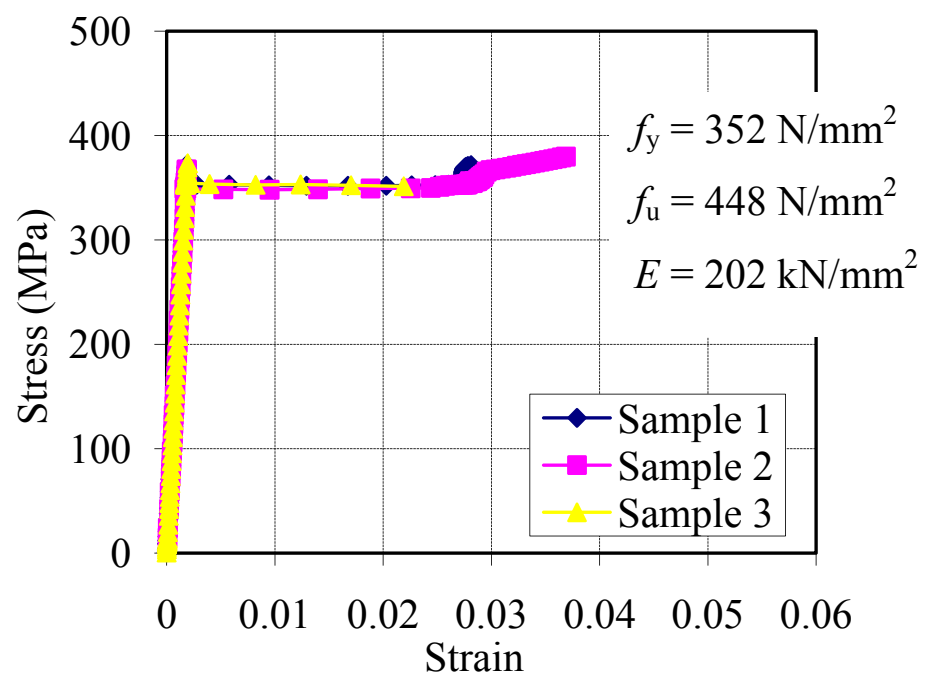

Fig.A.III.1 Stress-strain relationship of L-shape shear connector SS400

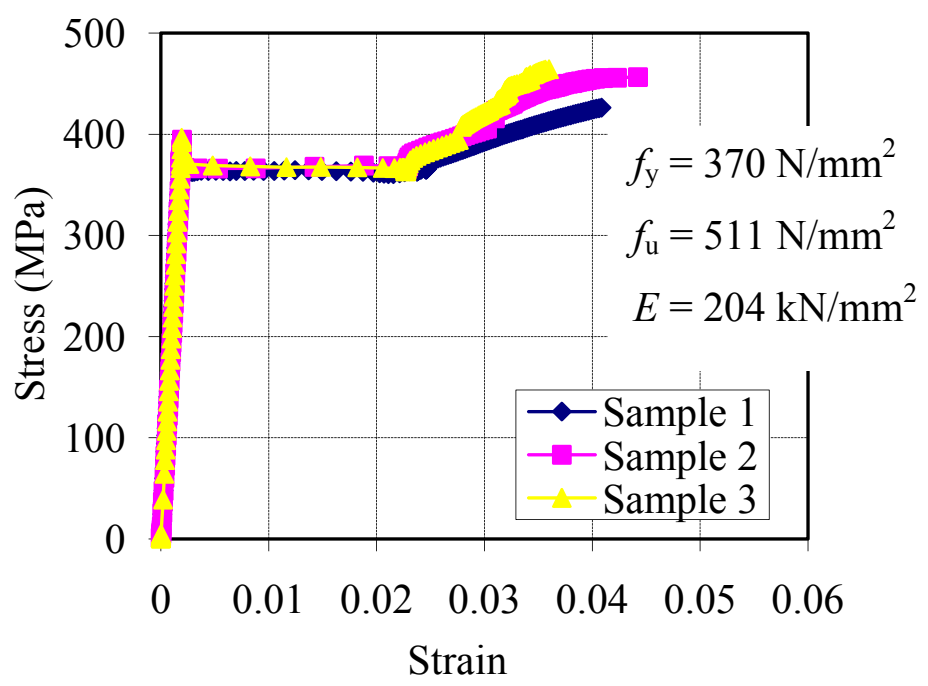

Fig.A.III.2 Stress-strain relationship of steel skin plate SM490 


\section{APPEXDIX III.2}

The activities of concrete work, form work and experimental set-up
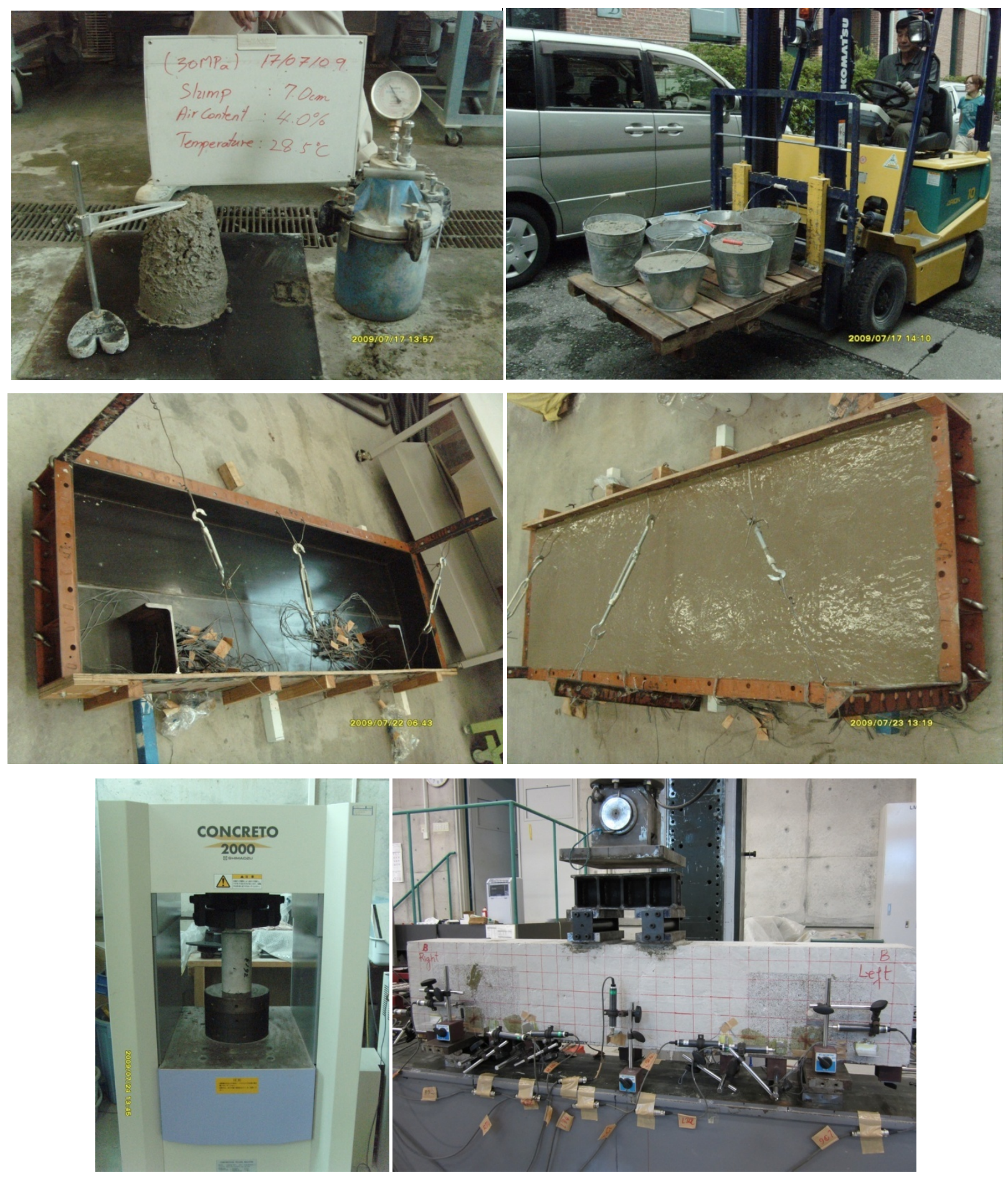

Fig.A.III.3 Concrete work, form work, and experimental set-up 


\section{APPENDIX IV.1}

Conditions of $1^{\text {st }}$ series specimens at failure

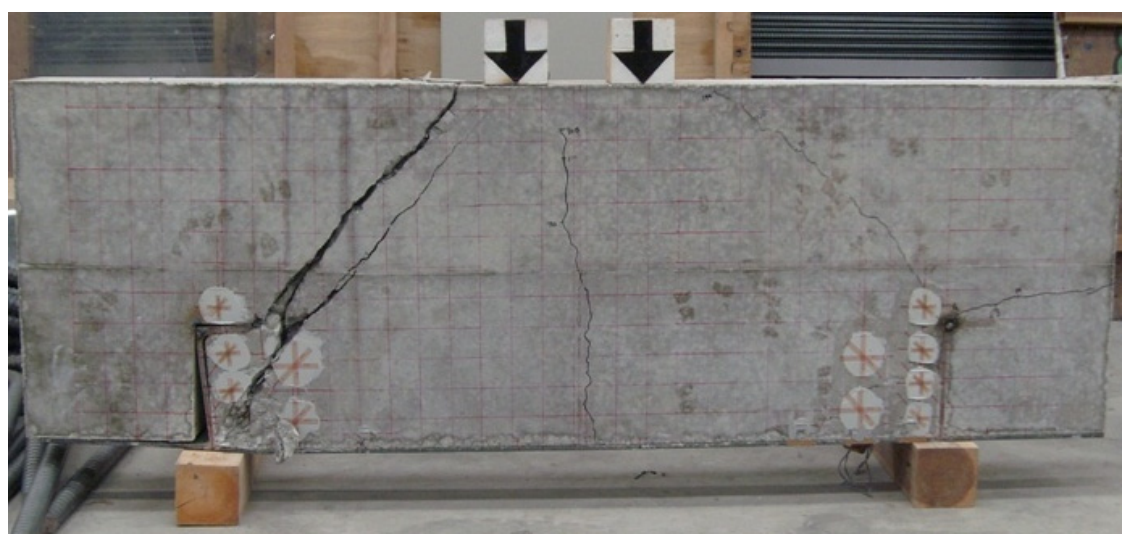

Fig.A.IV.1 Specimen S-600-200-9-38-45 at failure

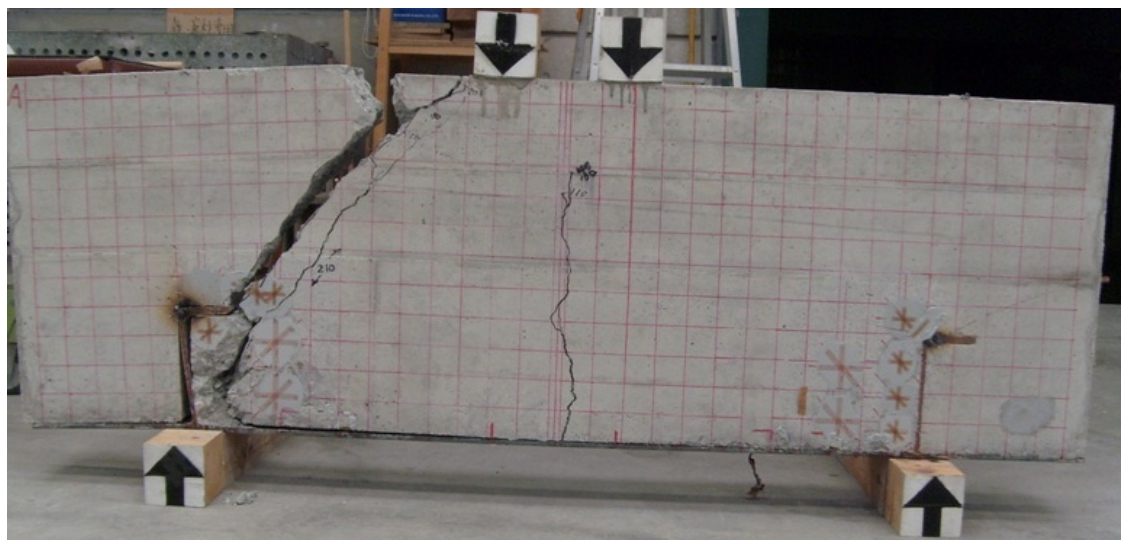

Fig.A.IV.2 Specimen S-600-200-9-25.3-45 at failure

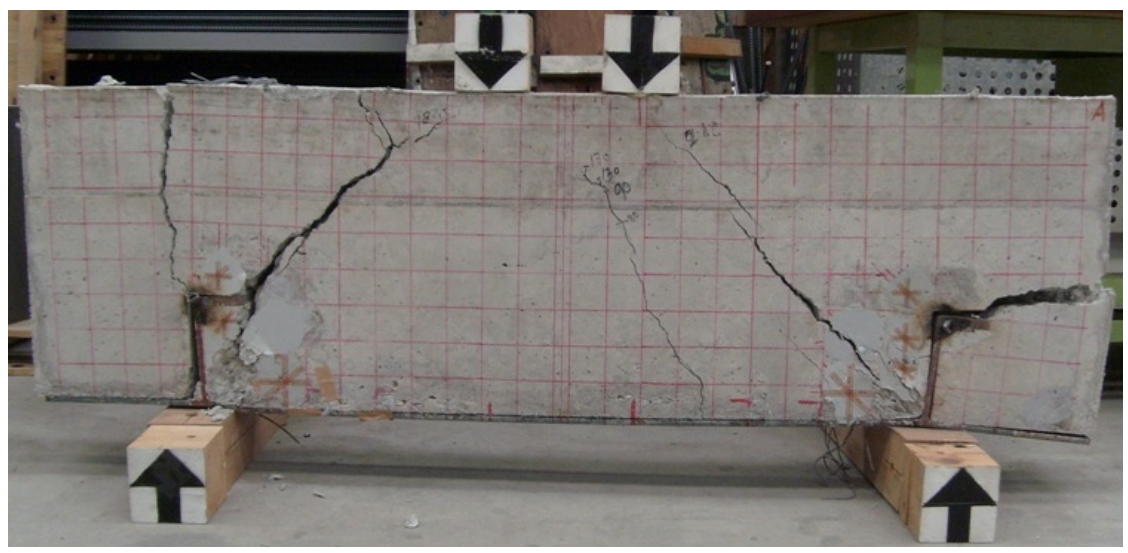

Fig.A.IV.3 Specimen S-450-150-9-23.6-45 at failure 


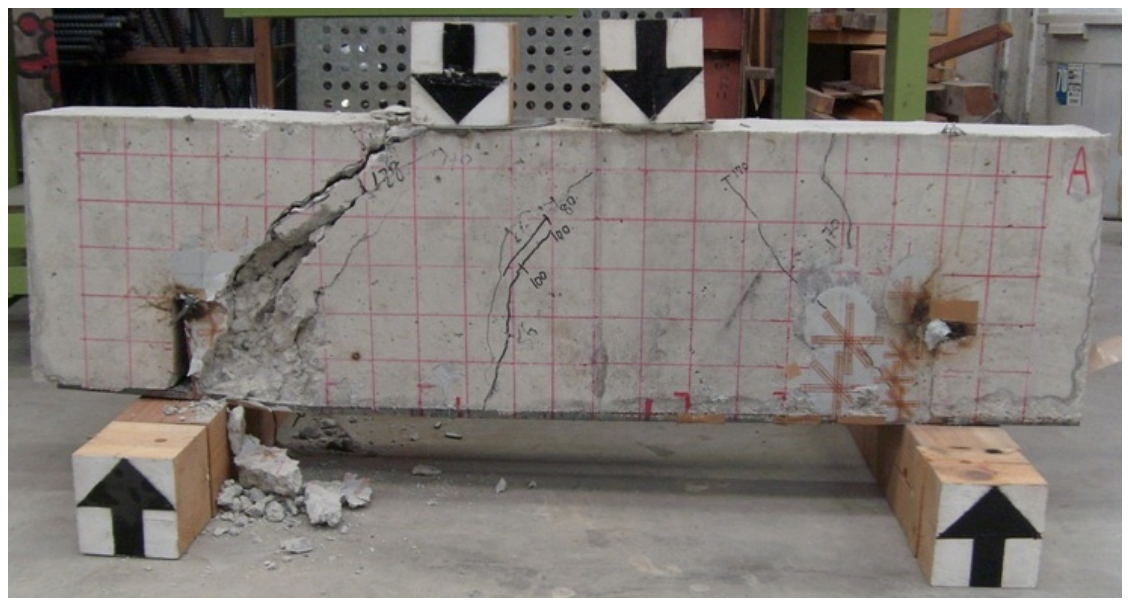

Fig.A.IV.4 Specimen S-300-100-9-25.1-45 at failure

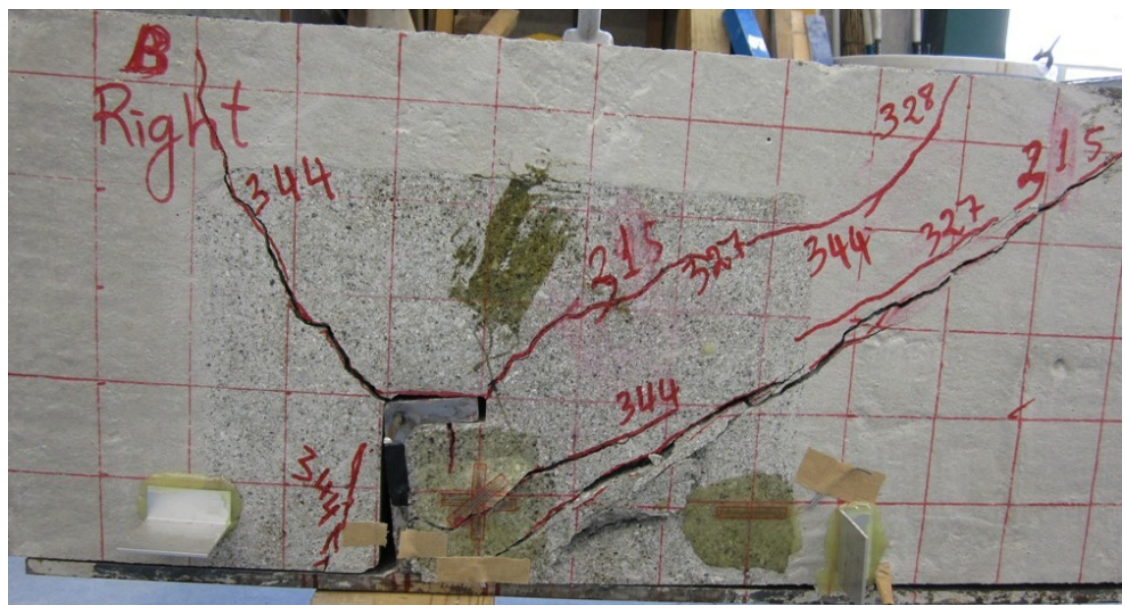

Fig.A.IV.5 Specimen S-300-100-9-41.5-25 at failure

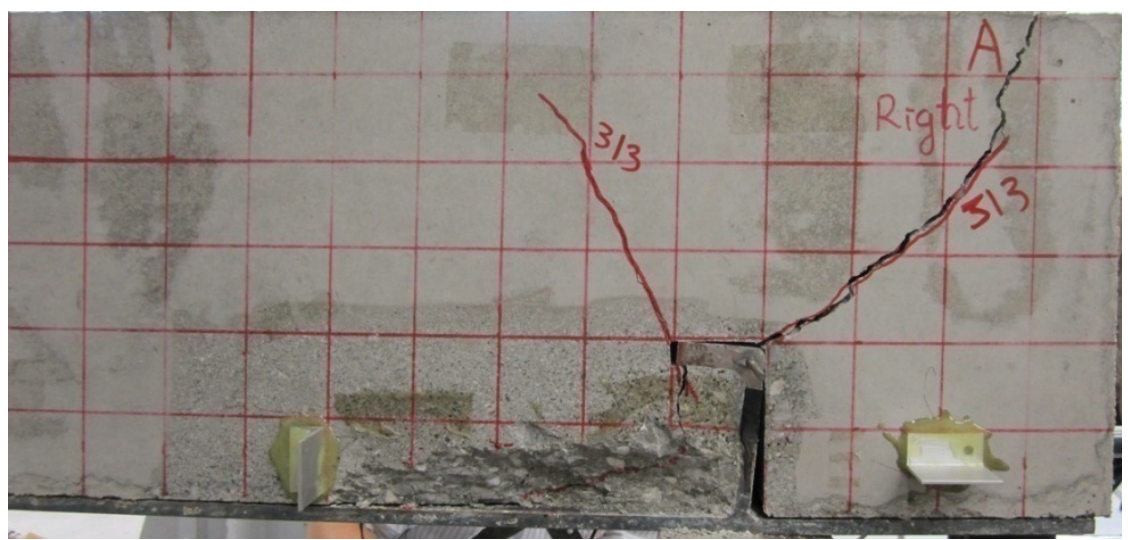

Fig.A.IV.6 Specimen S-300-100-9-42.7-20 at failure 


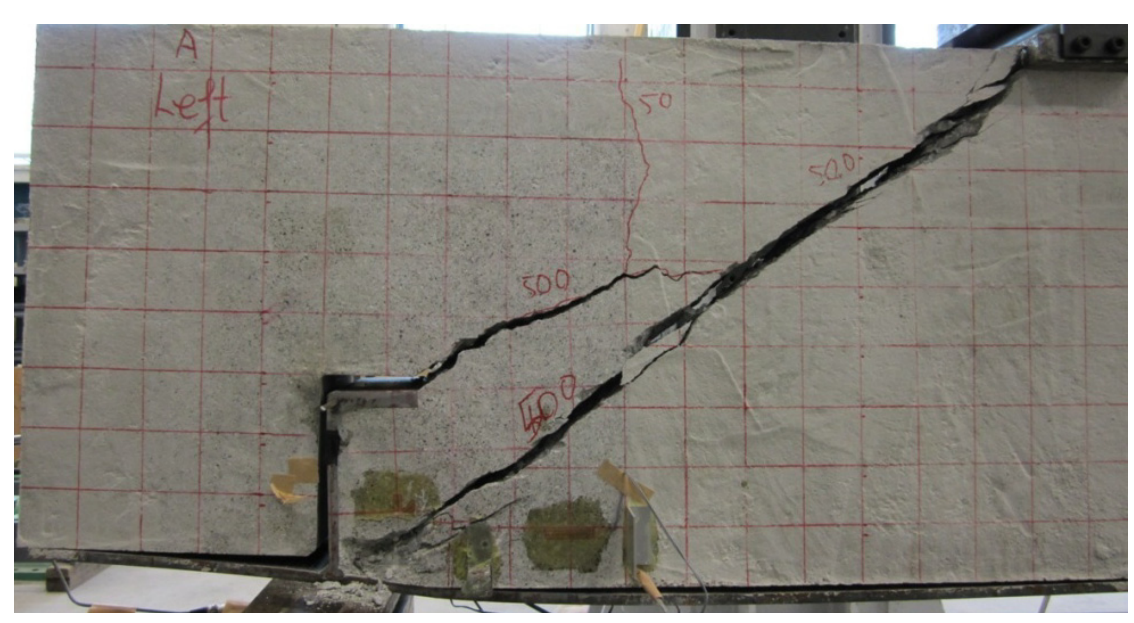

Fig.A.IV.7 Specimen S-450-150-9-43-30 at failure

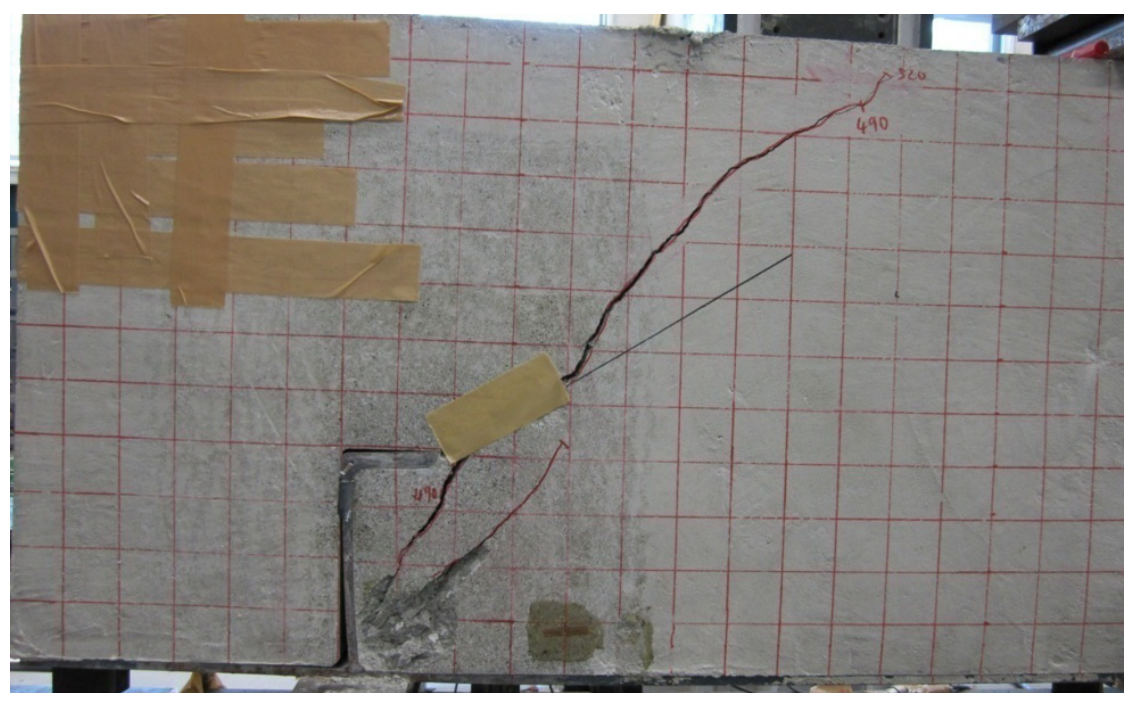

Fig.A.IV.8 Specimen S-600-200-9-43-35 at failure 


\section{APPENDIX IV.2}

Linear relationships between load $\mathrm{P}(\mathrm{kN})$ and tensile strain in the skin plate show that the steel plate was still in elastic range. The lists of strain data are given in Table A.IV.1 and A.IV.2.

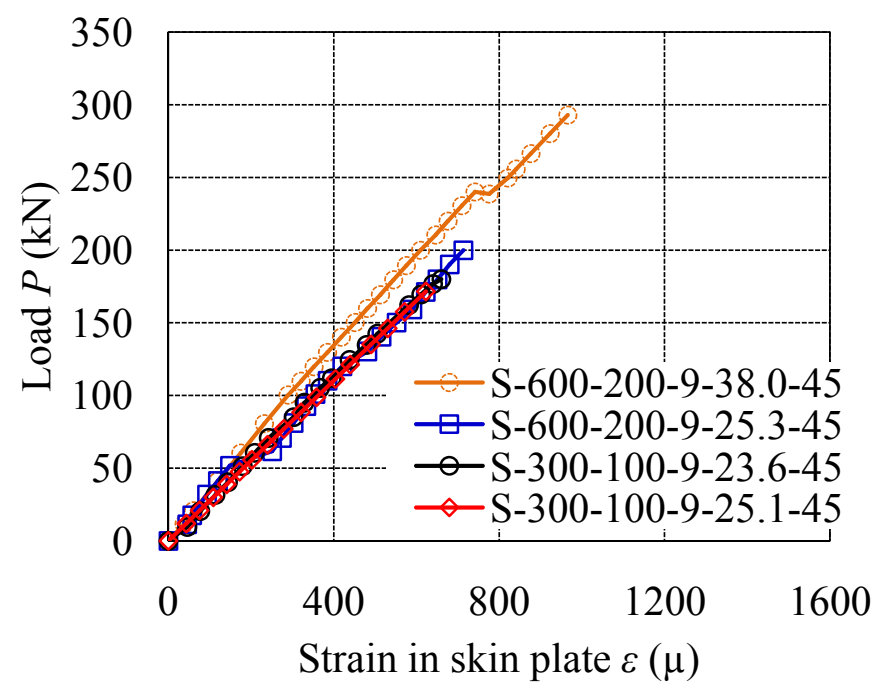

Fig.A.IV.9 Load-strain in skin plate relationship of $1^{\text {st }}$ test series specimens

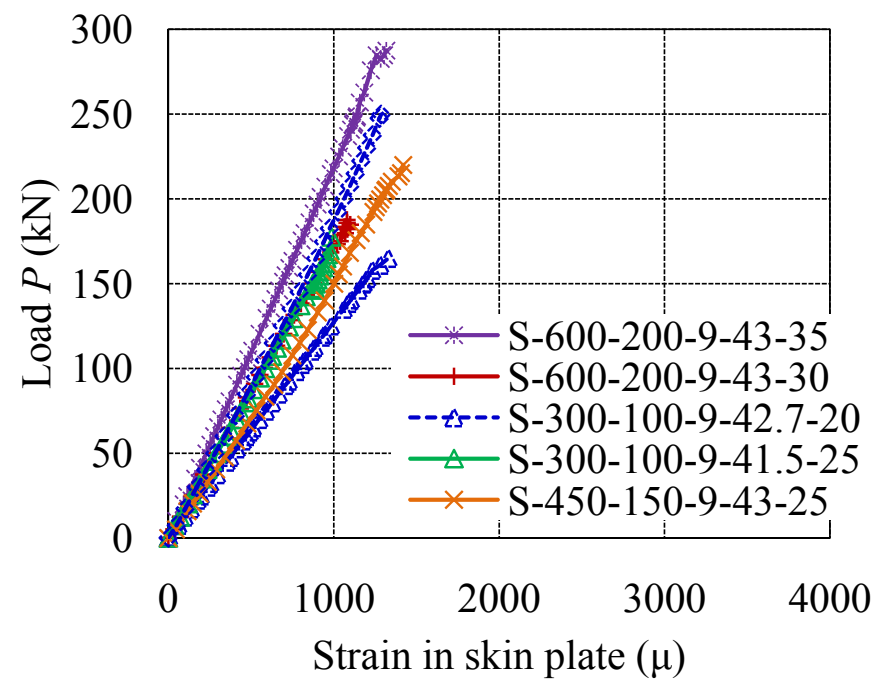

Fig.A.IV.10 Load-strain in skin plate relationship of $2^{\text {st }}$ test series specimens 
Table A.IV.1 Load-average strain in steel plate data $1^{\text {st }}$ test series specimens

\begin{tabular}{|c|c|c|c|c|c|c|c|}
\hline \multicolumn{2}{|c|}{ S-600-200-9-38-45 } & \multicolumn{2}{|c|}{ S-600-200-9-25.3-45 } & \multicolumn{2}{|c|}{ S-300-100-9-23.6-45 } & \multicolumn{2}{|c|}{ S-300-100-9-25.1-45 } \\
\hline $\begin{array}{l}\text { Load } \\
\mathrm{P}(\mathrm{kN})\end{array}$ & $\begin{array}{c}\text { Strain } \\
(\mu)\end{array}$ & $\begin{array}{c}\text { Load } \\
\mathrm{P}(\mathrm{kN})\end{array}$ & $\begin{array}{l}\text { Strain } \\
(\mu)\end{array}$ & $\begin{array}{c}\text { Load } \\
\mathrm{P}(\mathrm{kN})\end{array}$ & $\begin{array}{l}\text { Strain } \\
(\mu)\end{array}$ & $\begin{array}{l}\text { Load } \\
\mathrm{P}(\mathrm{kN})\end{array}$ & $\begin{array}{l}\text { Strain } \\
(\mu)\end{array}$ \\
\hline 0 & 0.000 & 0 & 0 & 0 & 0 & 0 & 0 \\
\hline 12 & 37.736 & 12 & 45 & 10 & 46 & 12 & 43 \\
\hline 21 & 61.321 & 18 & 58 & 20 & 77 & 21 & 76 \\
\hline 41 & 118.868 & 32 & 93 & 32 & 114 & 30 & 109 \\
\hline 60 & 175.000 & 41 & 120 & 40 & 144 & 39 & 141 \\
\hline 81 & 232.547 & 52 & 149 & 51 & 180 & 48 & 173 \\
\hline 100 & 290.095 & 62 & 251 & 61 & 209 & 56 & 202 \\
\hline 110 & 321.226 & 71 & 275 & 71 & 242 & 66 & 240 \\
\hline 120 & 352.359 & 81 & 303 & 85 & 303 & 77 & 279 \\
\hline 130 & 385.377 & 93 & 334 & 95 & 329 & 88 & 321 \\
\hline 140 & 418.396 & 101 & 356 & 105 & 367 & 99 & 358 \\
\hline 150 & 451.415 & 110 & 385 & 112 & 395 & 111 & 404 \\
\hline 160 & 482.076 & 120 & 421 & 125 & 439 & 121 & 440 \\
\hline 169 & 513.208 & 130 & 481 & 135 & 479 & 135 & 491 \\
\hline 180 & 544.811 & 140 & 516 & 142 & 506 & 146 & 531 \\
\hline 189 & 575.472 & 150 & 552 & 162 & 582 & 157 & 572 \\
\hline 200 & 609.906 & 159 & 590 & 170 & 611 & 172 & 623 \\
\hline 210 & 646.699 & 171 & 622 & 177 & 640 & & \\
\hline 220 & 676.415 & 180 & 651 & 180 & 660 & & \\
\hline 231 & 710.378 & 190 & 680 & & & & \\
\hline 240 & 741.982 & 200 & 714 & & & & \\
\hline 239 & 775.944 & & & & & & \\
\hline 250 & 821.699 & & & & & & \\
\hline 256 & 841.038 & & & & & & \\
\hline 266 & 876.887 & & & & & & \\
\hline 280 & 923.113 & & & & & & \\
\hline 293 & 966.039 & & & & & & \\
\hline
\end{tabular}


Table A.IV.2 Load-average strain in steel plate data $2^{\text {nd }}$ test series specimens

\begin{tabular}{|c|c|c|c|c|c|}
\hline \multicolumn{2}{|c|}{ S-600-200-9-43-35 } & \multicolumn{2}{|c|}{ S-300-100-9-42.7-20 } & \multicolumn{2}{|c|}{ S-300-100-9-41.5-25 } \\
\hline $\begin{array}{c}\text { Load } \\
\mathrm{P}(\mathrm{kN})\end{array}$ & $\begin{array}{l}\text { Strain } \\
(\mu)\end{array}$ & $\begin{array}{c}\text { Load } \\
\mathrm{P}(\mathrm{kN})\end{array}$ & $\begin{array}{c}\text { Strain } \\
(\mu)\end{array}$ & $\begin{array}{c}\text { Load } \\
\mathrm{P}(\mathrm{kN})\end{array}$ & $\begin{array}{c}\text { Strain } \\
(\mu)\end{array}$ \\
\hline 0 & 0.764 & 0 & 0.000 & 0 & 0.00 \\
\hline 10 & 46.618 & 1 & 5.240 & 7 & 37.50 \\
\hline 20 & 91.707 & 8 & 60.264 & 12 & 72.64 \\
\hline 25 & 113.869 & 13 & 98.257 & 20 & 118.16 \\
\hline 35 & 161.250 & 17 & 136.249 & 26 & 149.06 \\
\hline 42 & 190.291 & 23 & 176.862 & 35 & 204.01 \\
\hline 50 & 229.266 & 25 & 196.513 & 41 & 237.50 \\
\hline 55 & 252.957 & 30 & 237.126 & 45 & 266.75 \\
\hline 60 & 275.883 & 32 & 254.158 & 50 & 293.16 \\
\hline 66 & 300.338 & 38 & 294.771 & 55 & 327.59 \\
\hline 70 & 320.208 & 45 & 352.415 & 60 & 354.72 \\
\hline 76 & 348.484 & 48 & 374.686 & 64 & 377.12 \\
\hline 81 & 369.118 & 53 & 413.989 & 70 & 412.50 \\
\hline 90 & 414.207 & 57 & 450.672 & 74 & 436.79 \\
\hline 96 & 439.427 & 60 & 471.633 & 80 & 469.34 \\
\hline 101 & 462.353 & 63 & 492.595 & 82 & 482.78 \\
\hline 105 & 482.985 & 65 & 512.246 & 88 & 514.62 \\
\hline 111 & 506.679 & 70 & 550.238 & 95 & 554.48 \\
\hline 121 & 552.530 & 75 & 589.541 & 100 & 586.56 \\
\hline 130 & 595.329 & 80 & 627.534 & 105 & 615.57 \\
\hline 135 & 620.545 & 85 & 668.146 & 107 & 628.54 \\
\hline 141 & 646.530 & 90 & 707.449 & 112 & 658.02 \\
\hline 146 & 669.458 & 93 & 728.411 & 117 & 685.85 \\
\hline 151 & 693.147 & 98 & 772.954 & 125 & 729.25 \\
\hline 155 & 709.961 & 103 & 805.705 & 130 & 758.73 \\
\hline 159 & 730.592 & 105 & 824.045 & 137 & 800.71 \\
\hline 164 & 749.702 & 110 & 867.280 & 142 & 831.37 \\
\hline 170 & 779.506 & 113 & 884.316 & 150 & 872.41 \\
\hline 176 & 804.726 & 119 & 931.479 & 157 & 912.97 \\
\hline 180 & 824.592 & 120 & 944.578 & 147 & 886.79 \\
\hline 186 & 852.869 & 125 & 983.876 & 146 & 874.29 \\
\hline 192 & 878.089 & 135 & 1061.174 & 150 & 892.69 \\
\hline 197 & 901.779 & 139 & 1088.685 & 150 & 892.45 \\
\hline 201 & 921.649 & 141 & 1104.408 & 152 & 904.01 \\
\hline 207 & 949.161 & 146 & 1150.259 & 155 & 914.86 \\
\hline
\end{tabular}




\begin{tabular}{|l|l|l|l|l|l|}
\hline 215 & 983.553 & 150 & 1177.770 & 158 & 927.36 \\
\hline 218 & 999.601 & 150 & 1181.699 & 160 & 937.27 \\
\hline 225 & 1031.697 & 153 & 1202.664 & 162 & 945.05 \\
\hline 230 & 1054.625 & 158 & 1233.292 & 165 & 957.08 \\
\hline 237 & 1085.955 & 161 & 1282.154 & 165 & 955.19 \\
\hline 241 & 1103.534 & 165 & 1331.015 & 167 & 966.75 \\
\hline 245 & 1123.405 & & & 170 & 976.18 \\
\hline 248 & 1136.395 & & & 178 & 987.03 \\
\hline 245 & 1122.639 & & & & \\
\hline 244 & 1118.056 & & & & \\
\hline 244 & 1116.525 & & & & \\
\hline 249 & 1140.218 & & & & \\
\hline 257 & 1158.357 & & & & \\
\hline 263 & 1183.917 & & & & \\
\hline 276 & 1225.223 & & & & \\
\hline 285 & 1258.383 & & & & \\
\hline 283 & 1284.219 & & & & \\
\hline 285 & 1304.524 & & & & \\
\hline 288 & 1317.840 & & & & \\
\hline
\end{tabular}


Table A.IV.3 Load-average strain in steel plate data $2^{\text {nd }}$ test series specimens

\begin{tabular}{|c|c|c|c|c|c|}
\hline \multicolumn{2}{|c|}{ S-600-200-9-43-30 } & \multicolumn{2}{|c|}{ S-450-150-9-43-25 } & \multicolumn{2}{|c|}{ S-450-150-9-43-30 } \\
\hline Load & Strain & Load & Strain & Load & Strain \\
\hline $\mathrm{P}(\mathrm{kN})$ & $(\mu)$ & $\mathrm{P}(\mathrm{kN})$ & $(\mu)$ & $\mathrm{P}(\mathrm{kN})$ & $(\mu)$ \\
\hline 0 & 0.000 & 0 & 0 & 0 & 0.000 \\
\hline 5 & 33.019 & 5 & 46 & 8 & 49.764 \\
\hline 13 & 75.000 & 16 & 117 & 17 & 102.830 \\
\hline 25 & 143.396 & 20 & 149 & 30 & 171.934 \\
\hline 38 & 215.095 & 26 & 190 & 40 & 228.066 \\
\hline 50 & 285.378 & 33 & 238 & 50 & 282.312 \\
\hline 65 & 374.528 & 41 & 289 & 60 & 339.859 \\
\hline 76 & 434.434 & 48 & 342 & 72 & 406.840 \\
\hline 83 & 473.113 & 58 & 410 & 85 & 474.292 \\
\hline 91 & 522.170 & 68 & 478 & 95 & 527.830 \\
\hline 96 & 552.830 & 75 & 533 & 105 & 580.896 \\
\hline 100 & 580.189 & 83 & 588 & 115 & 636.793 \\
\hline 107 & 614.623 & 90 & 640 & 125 & 690.094 \\
\hline 113 & 653.774 & 98 & 689 & 135 & 743.632 \\
\hline 120 & 696.699 & 108 & 750 & 145 & 792.689 \\
\hline 129 & 742.453 & 115 & 797 & 155 & 843.161 \\
\hline 132 & 759.906 & 123 & 844 & 165 & 892.453 \\
\hline 138 & 801.415 & 133 & 903 & 175 & 939.859 \\
\hline 143 & 834.434 & 140 & 946 & 183 & 975.472 \\
\hline 150 & 876.415 & 150 & 1003 & 192 & 1025.470 \\
\hline 157 & 914.151 & 156 & 1031 & 200 & 1063.443 \\
\hline 164 & 955.189 & 160 & 1055 & 208 & 1099.055 \\
\hline 168 & 981.605 & 168 & 1097 & 215 & 1131.135 \\
\hline 173 & 1020.754 & 176 & 1138 & 222 & 1165.565 \\
\hline 175 & 1038.209 & 180 & 1163 & 230 & 1200.470 \\
\hline 180 & 1069.339 & 185 & 1195 & 238 & 1234.668 \\
\hline 182 & 1083.018 & 192 & 1239 & 248 & 1276.418 \\
\hline 185 & 1100.470 & 195 & 1254 & 250 & 1286.793 \\
\hline 188 & 1080.188 & 197 & 1267 & & \\
\hline 186 & 1081.605 & 200 & 1282 & & \\
\hline 183 & 1062.262 & 202 & 1298 & & \\
\hline 183 & 1069.813 & 205 & 1313 & & \\
\hline \multirow[t]{6}{*}{179} & 1043.395 & 206 & 1318 & & \\
\hline & & 208 & 1334 & & \\
\hline & & 210 & 1350 & & \\
\hline & & 213 & 1391 & & \\
\hline & & 215 & 1406 & & \\
\hline & & 220 & 1420 & & \\
\hline
\end{tabular}




\section{APPENDIX IV.3}

Bound link element was the universal joints may be defined in the joint plane between different material elements, such as a RC element and a soil element. By introducing universal joints, the shear slip and gap opening can be considered between two material boundary planes.

Contact stiffness $K_{n}\left(\mathrm{kN} / \mathrm{mm}^{2} / \mathrm{mm}\right)$ represents the resistance property to gap closure in a normal direction to a joint plane. This value is defined as a property per unit length. A large value for $K_{n}$ for gap closure is theoretically better and it is set to $10\left(\mathrm{kN} / \mathrm{mm}^{2} / \mathrm{mm}\right)$ in basic mode to prevent overlapping. The stiffness is effective for gap closure and would reduce for gap opening, generally it should be set to 0.0 for opening.

Note that the contact closure stiffness never controls the structural behavior. So do not be nervous with this value. However if a large value is entered, there may be a danger of a rounding error or a divergence. If the stiffness can be presumed, for instance in an experimental specimen etc., you can use an optional value in advanced mode.

\section{Shear Stiffness}

Universal joints may be defined in the joint plane between different material elements, such as a $\mathrm{RC}$ element and a soil element. By introducing universal joints, the shear slip and gap opening can be considered between the two material boundary planes Shear stiffness $K_{s}(\mathrm{kN} / \mathrm{mm} 2 / \mathrm{mm})$ represents the resistance property to slip along the joint plane, this value is defined as a property per unit length. The stiffness is effective when the joint is closed, and it would decrease when the joint is open. Generally it should be set to 0.0 for opening and the value of Ks for closing recommended as $0.1(\mathrm{kN} / \mathrm{mm} 2 / \mathrm{mm})$ through the numerical verifications in the past in basic mode.

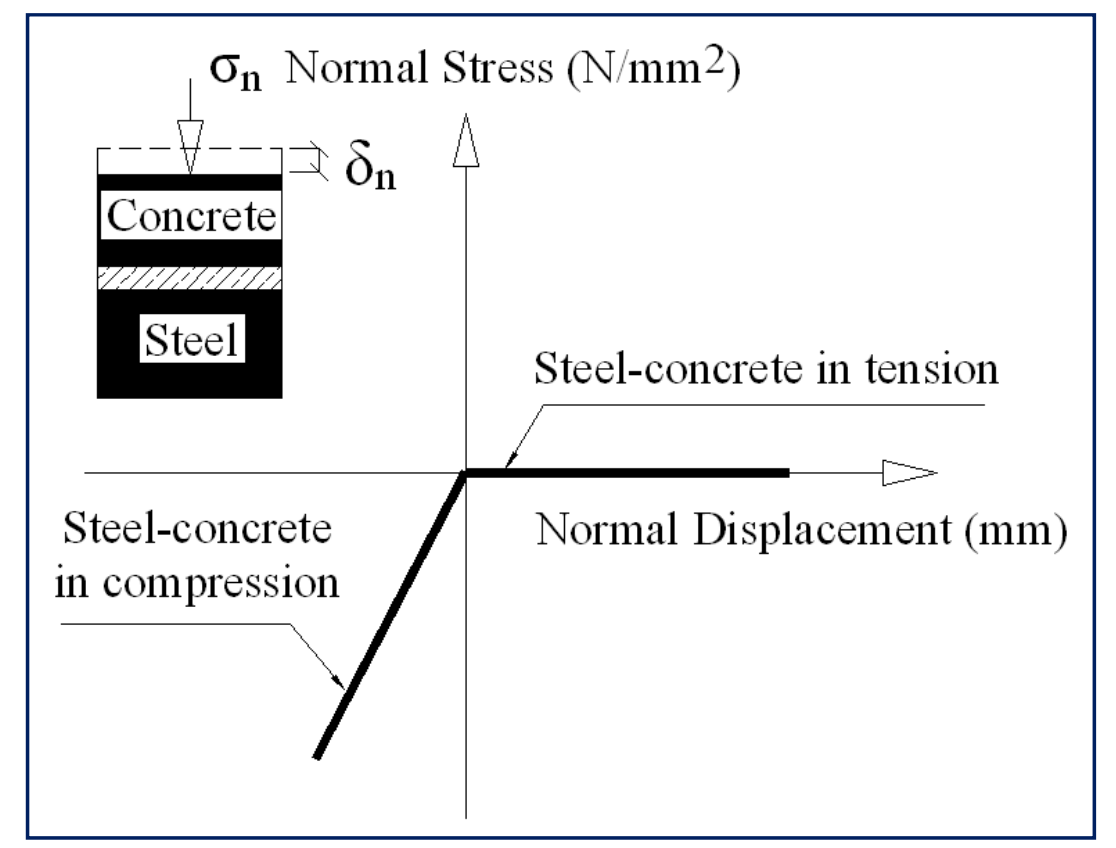

Fig.A.IV.11 Function of bond link element 


\section{APPENDIX IV.4}

Table. A.IV.4 Shear Force-Slip Data 1st Test Series Specimens

\begin{tabular}{|c|c|c|c|c|c|c|c|}
\hline \multicolumn{2}{|c|}{ S-600-200-9-38-45 } & \multicolumn{2}{|c|}{ S-600-200-9-25.3-45 } & \multicolumn{2}{|c|}{ S-300-100-9-23.6-45 } & \multicolumn{2}{|c|}{ S-300-100-9-25.1-45 } \\
\hline Shear Force & Slip & Shear Force & Slip & Shear Force & Slip & Shear Force & Slip \\
\hline $\mathrm{V}(\mathrm{kN})$ & $(\mathrm{mm})$ & $\mathrm{V}(\mathrm{kN})$ & $(\mathrm{mm})$ & $\mathrm{V}(\mathrm{kN})$ & $(\mathrm{mm})$ & $\mathrm{V}(\mathrm{kN})$ & $(\mathrm{mm})$ \\
\hline 0 & 0.000 & 0 & 0.000 & 0 & 0.000 & 0 & 0 \\
\hline 10 & 0.003 & 12 & 0.005 & 10 & 0.001 & 11 & 0.008 \\
\hline 17 & 0.009 & 18 & 0.005 & 20 & 0.007 & 21 & 0.017 \\
\hline 33 & 0.026 & 32 & 0.009 & 32 & 0.014 & 31 & 0.027 \\
\hline 48 & 0.044 & 41 & 0.013 & 40 & 0.020 & 41 & 0.038 \\
\hline 64 & 0.061 & 52 & 0.019 & 51 & 0.027 & 51 & 0.048 \\
\hline 80 & 0.077 & 62 & 0.029 & 61 & 0.033 & 60 & 0.058 \\
\hline 88 & 0.086 & 71 & 0.037 & 71 & 0.040 & 70 & 0.075 \\
\hline 97 & 0.099 & 81 & 0.048 & 83 & 0.051 & 80 & 0.094 \\
\hline 106 & 0.112 & 93 & 0.060 & 90 & 0.058 & 91 & 0.123 \\
\hline 115 & 0.126 & 101 & 0.068 & 100 & 0.070 & 100 & 0.144 \\
\hline 124 & 0.143 & 110 & 0.080 & 110 & 0.079 & 111 & 0.18 \\
\hline 133 & 0.156 & 120 & 0.098 & 120 & 0.092 & 120 & 0.198 \\
\hline 141 & 0.173 & 130 & 0.125 & 130 & 0.102 & 128 & 0.25 \\
\hline 150 & 0.186 & 140 & 0.151 & 140 & 0.152 & 140 & 0.25 \\
\hline 158 & 0.202 & 143 & 0.161 & 150 & 0.170 & 150 & 0.25 \\
\hline 168 & 0.218 & 145 & 0.170 & 160 & 0.196 & 160 & 0.271 \\
\hline 178 & 0.242 & 150 & 0.174 & 170 & 0.214 & 170 & 0.267 \\
\hline 186 & 0.259 & 159 & 0.185 & 177 & 0.211 & & \\
\hline 196 & 0.280 & 171 & 0.192 & 180 & 0.206 & & \\
\hline 204 & 0.298 & 179 & 0.200 & & & & \\
\hline 214 & 0.322 & 185 & 0.206 & & & & \\
\hline 226 & 0.351 & 200 & 0.212 & & & & \\
\hline 232 & 0.360 & & & & & & \\
\hline 241 & 0.377 & & & & & & \\
\hline 254 & 0.399 & & & & & & \\
\hline 266 & 0.431 & & & & & & \\
\hline
\end{tabular}


Table A.IV.5 Shear Force-Relative Displacement Data of $1^{\text {st }}$ Test Series Specimens

\begin{tabular}{|c|c|c|c|}
\hline \multicolumn{2}{|c|}{ S-600-200-9-25.3-45 } & \multicolumn{2}{|c|}{ S-300-100-9-25.1-45 } \\
\hline $\begin{array}{l}\text { Shear Force } \\
\qquad \mathrm{V}(\mathrm{kN})\end{array}$ & $\begin{array}{c}\text { Relative Displacement } \\
\qquad \delta(\mathrm{mm})\end{array}$ & $\begin{array}{c}\text { Shear Force } \\
\qquad \mathrm{V}(\mathrm{kN})\end{array}$ & $\begin{array}{c}\text { Relative Displacement } \\
\delta(\mathrm{mm})\end{array}$ \\
\hline 0 & 0.000 & 0 & 0 \\
\hline 10 & -0.065 & 11 & 0.003 \\
\hline 22 & -0.067 & 20 & 0.044 \\
\hline 31 & -0.053 & 30 & 0.056 \\
\hline 42 & -0.045 & 40 & 0.064 \\
\hline 51 & -0.037 & 51 & 0.072 \\
\hline 62 & -0.030 & 60 & 0.076 \\
\hline 73 & -0.024 & 70 & 0.082 \\
\hline 82 & -0.020 & 80 & 0.081 \\
\hline 92 & -0.014 & 91 & 0.087 \\
\hline 102 & -0.011 & 100 & 0.085 \\
\hline 112 & -0.008 & 111 & 0.091 \\
\hline 122 & -0.004 & 120 & 0.102 \\
\hline 132 & -0.003 & 130 & 0.598 \\
\hline 143 & 0.001 & 140 & 0.789 \\
\hline 150 & 0.005 & 150 & 0.987 \\
\hline 153 & 0.012 & 154 & 1.252 \\
\hline 155 & 0.342 & 160 & 1.423 \\
\hline 159 & 0.713 & 163 & 1.507 \\
\hline 171 & 1.241 & 165 & 1.601 \\
\hline 179 & 1.631 & 168 & 1.716 \\
\hline 185 & 1.885 & 170 & 1.88 \\
\hline 190 & 2.263 & & \\
\hline 192 & 2.549 & & \\
\hline 195 & 2.911 & & \\
\hline 197 & 3.232 & & \\
\hline 200 & 3.699 & & \\
\hline
\end{tabular}


Table A.IV.6 Shear Force-Slip Data $2^{\text {st }}$ Test Series Specimens

\begin{tabular}{|c|c|c|c|c|c|}
\hline \multicolumn{2}{|c|}{ S-600-200-9-43-35 } & \multicolumn{2}{|c|}{ S-300-100-9-42.7-20 } & \multicolumn{2}{|c|}{ S-300-100-9-41.5-25 } \\
\hline $\begin{array}{l}\text { Shear Force } \\
\qquad \mathrm{V}(\mathrm{kN})\end{array}$ & $\begin{array}{l}\text { Slip } \\
(\mathrm{mm})\end{array}$ & $\begin{array}{c}\text { Shear Force } \\
\quad \mathrm{V}(\mathrm{kN})\end{array}$ & $\begin{array}{l}\text { Slip } \\
(\mathrm{mm})\end{array}$ & $\begin{array}{c}\text { Shear Force } \\
\mathrm{V}(\mathrm{kN})\end{array}$ & $\begin{array}{l}\text { Slip } \\
(\mathrm{mm})\end{array}$ \\
\hline 0 & -0.001 & 0 & 0.000 & 0 & 0.000 \\
\hline 13 & 0.015 & 1 & 0.023 & 10 & 0.026 \\
\hline 25 & 0.034 & 16 & 0.037 & 20 & 0.035 \\
\hline 31 & 0.045 & 27 & 0.048 & 33 & 0.051 \\
\hline 44 & 0.068 & 37 & 0.061 & 41 & 0.062 \\
\hline 52 & 0.081 & 48 & 0.076 & 56 & 0.086 \\
\hline 63 & 0.101 & 54 & 0.086 & 65 & 0.100 \\
\hline 69 & 0.109 & 65 & 0.103 & 73 & 0.112 \\
\hline 75 & 0.121 & 69 & 0.112 & 81 & 0.123 \\
\hline 82 & 0.132 & 80 & 0.128 & 90 & 0.137 \\
\hline 87 & 0.143 & 96 & 0.154 & 98 & 0.149 \\
\hline 95 & 0.153 & 102 & 0.166 & 104 & 0.158 \\
\hline 101 & 0.167 & 113 & 0.184 & 114 & 0.174 \\
\hline 113 & 0.191 & 123 & 0.202 & 120 & 0.186 \\
\hline 120 & 0.203 & 129 & 0.219 & 129 & 0.200 \\
\hline 126 & 0.215 & 134 & 0.229 & 133 & 0.207 \\
\hline 132 & 0.227 & 140 & 0.238 & 142 & 0.222 \\
\hline 138 & 0.241 & 150 & 0.258 & 153 & 0.241 \\
\hline 151 & 0.266 & 161 & 0.283 & 162 & 0.259 \\
\hline 162 & 0.291 & 171 & 0.307 & 170 & 0.273 \\
\hline 169 & 0.309 & 182 & 0.330 & 173 & 0.280 \\
\hline 176 & 0.321 & 193 & 0.355 & 181 & 0.295 \\
\hline 183 & 0.335 & 199 & 0.382 & 189 & 0.310 \\
\hline 189 & 0.355 & 211 & 0.409 & 201 & 0.338 \\
\hline 194 & 0.365 & 220 & 0.450 & 209 & 0.355 \\
\hline 199 & 0.375 & 225 & 0.462 & 221 & 0.386 \\
\hline 204 & 0.389 & 237 & 0.488 & 229 & 0.410 \\
\hline 213 & 0.412 & 241 & 0.509 & 240 & 0.435 \\
\hline 219 & 0.428 & 254 & 0.550 & 251 & 0.470 \\
\hline 225 & 0.445 & 258 & 0.564 & 244 & 0.338 \\
\hline 233 & 0.468 & 268 & 0.617 & 241 & 0.335 \\
\hline 239 & 0.483 & 289 & 0.701 & 246 & 0.338 \\
\hline 246 & 0.495 & 297 & 0.726 & 246 & 0.339 \\
\hline
\end{tabular}




\begin{tabular}{|l|l|l|l|l|l|}
\hline 251 & 0.509 & 301 & 0.749 & 249 & 0.341 \\
\hline 259 & 0.530 & 314 & 0.822 & 252 & 0.345 \\
\hline 268 & 0.585 & 321 & 0.859 & 255 & 0.351 \\
\hline 273 & 0.591 & 322 & 0.920 & 258 & 0.355 \\
\hline 281 & 0.620 & 328 & 0.956 & 260 & 0.360 \\
\hline 288 & 0.649 & 329 & 1.198 & 264 & 0.368 \\
\hline 296 & 0.711 & 333 & 1.237 & 263 & 0.373 \\
\hline 301 & 0.730 & 336 & 1.554 & 266 & 0.376 \\
\hline 306 & 0.749 & 341 & 1.600 & 269 & 0.376 \\
\hline 310 & 0.762 & 350 & 1.745 & 272 & 0.372 \\
\hline 306 & 0.750 & 357 & 1.870 & & \\
\hline 305 & 0.751 & 360 & 1.967 & & \\
\hline 304 & 0.751 & 363 & 2.035 & & \\
\hline 311 & 0.747 & 362 & 2.1495 & & \\
\hline 316 & 0.797 & & & & \\
\hline 323 & 0.837 & & & & \\
\hline 334 & 0.943 & & & & \\
\hline 342 & 1.061 & & & & \\
\hline 350 & 1.136 & & & & \\
\hline 357 & 1.161 & & & & \\
\hline 362 & 1.167 & & & & \\
\hline
\end{tabular}


Table A.IV.7 Shear Force-Slip Data $2^{\text {st }}$ Test Series Specimens

\begin{tabular}{|c|c|c|c|c|c|}
\hline \multicolumn{2}{|c|}{ S-600-200-9-43-30 } & \multicolumn{2}{|c|}{ S-450-150-9-43-25 } & \multicolumn{2}{|c|}{ S-450-150-9-43-30 } \\
\hline $\begin{array}{c}\text { Shear Force } \\
\mathrm{V}(\mathrm{kN})\end{array}$ & $\begin{array}{l}\text { Slip } \\
(\mathrm{mm})\end{array}$ & $\begin{array}{c}\text { Shear Force } \\
\mathrm{V}(\mathrm{kN})\end{array}$ & $\begin{array}{l}\text { Slip } \\
(\mathrm{mm})\end{array}$ & $\begin{array}{c}\text { Shear Force } \\
\mathrm{V}(\mathrm{kN})\end{array}$ & $\begin{array}{l}\text { Slip } \\
(\mathrm{mm})\end{array}$ \\
\hline 0 & 0.000 & 0 & 0.000 & 0 & 0.000 \\
\hline 9 & 0.010 & 13 & 0.050 & 14 & 0.032 \\
\hline 21 & 0.014 & 32 & 0.060 & 28 & 0.045 \\
\hline 39 & 0.045 & 41 & 0.067 & 47 & 0.066 \\
\hline 59 & 0.081 & 52 & 0.079 & 63 & 0.089 \\
\hline 79 & 0.122 & 66 & 0.094 & 78 & 0.117 \\
\hline 103 & 0.171 & 80 & 0.115 & 94 & 0.146 \\
\hline 120 & 0.209 & 94 & 0.135 & 112 & 0.176 \\
\hline 130 & 0.232 & 113 & 0.163 & 131 & 0.212 \\
\hline 144 & 0.264 & 132 & 0.196 & 145 & 0.243 \\
\hline 152 & 0.286 & 147 & 0.221 & 160 & 0.272 \\
\hline 160 & 0.306 & 162 & 0.249 & 175 & 0.310 \\
\hline 169 & 0.330 & 176 & 0.277 & 190 & 0.341 \\
\hline 180 & 0.369 & 190 & 0.313 & 205 & 0.387 \\
\hline 192 & 0.405 & 207 & 0.360 & 218 & 0.419 \\
\hline 204 & 0.447 & 219 & 0.402 & 232 & 0.471 \\
\hline 209 & 0.480 & 232 & 0.439 & 246 & 0.508 \\
\hline 221 & 0.521 & 249 & 0.508 & 259 & 0.550 \\
\hline 230 & 0.559 & 260 & 0.545 & 269 & 0.614 \\
\hline 241 & 0.619 & 276 & 0.616 & 282 & 0.659 \\
\hline 252 & 0.693 & 284 & 0.667 & 293 & 0.694 \\
\hline 263 & 0.768 & 291 & 0.698 & 303 & 0.735 \\
\hline 270 & 0.835 & 302 & 0.771 & 312 & 0.820 \\
\hline 281 & 0.983 & 314 & 0.837 & 321 & 0.859 \\
\hline 286 & 1.194 & 320 & 0.882 & 331 & 0.908 \\
\hline 294 & 1.310 & 329 & 0.986 & 340 & 0.965 \\
\hline 298 & 1.411 & 341 & 1.070 & 352 & 1.093 \\
\hline 303 & 1.611 & 345 & 1.139 & 354 & 1.108 \\
\hline 297 & 1.841 & 349 & 1.177 & & \\
\hline 298 & 2.045 & 353 & 1.203 & & \\
\hline 293 & 2.212 & 357 & 1.260 & & \\
\hline 295 & 2.450 & 362 & 1.315 & & \\
\hline \multirow[t]{6}{*}{287} & 2.648 & 363 & 1.390 & & \\
\hline & & 367 & 1.484 & & \\
\hline & & 372 & 1.585 & & \\
\hline & & 383 & 1.963 & & \\
\hline & & 387 & 2.015 & & \\
\hline & & 391 & 2.080 & & \\
\hline
\end{tabular}


Table A.IV.8 Shear Force-Relative Displacement Data $2^{\text {st }}$ Test Series Specimens

\begin{tabular}{|c|c|c|c|c|c|}
\hline \multicolumn{2}{|c|}{ S-600-200-9-43-35 } & \multicolumn{2}{|c|}{ S-300-100-9-42.7-20 } & \multicolumn{2}{|c|}{ S-300-100-9-41.5-25 } \\
\hline Shear Force & R.D & Shear Force & R.D & Shear Force & R.D \\
\hline $\mathrm{V}(\mathrm{kN})$ & $\delta(\mathrm{mm})$ & $\mathrm{V}(\mathrm{kN})$ & $\delta(\mathrm{mm})$ & $\mathrm{V}(\mathrm{kN})$ & $\delta(\mathrm{mm})$ \\
\hline 0 & 0.000 & 0 & 0.000 & 0 & 0.000 \\
\hline 13 & 0.081 & 1 & 0.008 & 10 & 0.041 \\
\hline 25 & 0.221 & 16 & -0.007 & 20 & 0.059 \\
\hline 31 & 0.286 & 27 & -0.007 & 33 & 0.090 \\
\hline 44 & 0.423 & 37 & 0.002 & 41 & 0.106 \\
\hline 52 & 0.471 & 48 & 0.013 & 56 & 0.130 \\
\hline 63 & 0.537 & 54 & 0.021 & 65 & 0.141 \\
\hline 69 & 0.578 & 65 & 0.048 & 73 & 0.151 \\
\hline 75 & 0.608 & 69 & 0.064 & 81 & 0.162 \\
\hline 82 & 0.635 & 80 & 0.101 & 90 & 0.178 \\
\hline 87 & 0.657 & 96 & 0.157 & 98 & 0.188 \\
\hline 95 & 0.678 & 102 & 0.179 & 104 & 0.195 \\
\hline 101 & 0.701 & 113 & 0.205 & 114 & 0.208 \\
\hline 113 & 0.735 & 123 & 0.227 & 120 & 0.218 \\
\hline 120 & 0.722 & 129 & 0.249 & 129 & 0.228 \\
\hline 126 & 0.731 & 134 & 0.259 & 133 & 0.232 \\
\hline 132 & 0.743 & 140 & 0.267 & 142 & 0.240 \\
\hline 138 & 0.757 & 150 & 0.285 & 153 & 0.251 \\
\hline 151 & 0.751 & 161 & 0.309 & 162 & 0.263 \\
\hline 162 & 0.780 & 171 & 0.332 & 170 & 0.270 \\
\hline 169 & 0.735 & 182 & 0.349 & 173 & 0.274 \\
\hline 176 & 0.746 & 193 & 0.371 & 181 & 0.281 \\
\hline 183 & 0.759 & 199 & 0.399 & 189 & 0.289 \\
\hline 189 & 0.710 & 211 & 0.419 & 201 & 0.300 \\
\hline 194 & 0.718 & 220 & 0.455 & 209 & 0.308 \\
\hline 199 & 0.725 & 225 & 0.464 & 221 & 0.323 \\
\hline 204 & 0.733 & 237 & 0.480 & 229 & 0.334 \\
\hline 213 & 0.749 & 241 & 0.497 & 240 & 0.343 \\
\hline 219 & 0.759 & 254 & 0.524 & 251 & 0.357 \\
\hline 225 & 0.769 & 258 & 0.535 & 244 & 0.997 \\
\hline 233 & 0.689 & 268 & 0.571 & 241 & 1.149 \\
\hline 239 & 0.699 & 289 & 0.616 & 246 & 1.210 \\
\hline 246 & 0.706 & 297 & 0.627 & 246 & 1.255 \\
\hline
\end{tabular}




\begin{tabular}{|c|c|c|c|c|c|}
\hline 251 & 0.712 & 301 & 0.639 & 249 & 1.282 \\
\hline 259 & 0.723 & 314 & 0.679 & 252 & 1.327 \\
\hline 268 & 0.667 & 321 & 0.699 & 255 & 1.401 \\
\hline 273 & 0.670 & 322 & 0.738 & 258 & 1.467 \\
\hline 281 & 0.681 & 328 & 0.757 & 260 & 1.560 \\
\hline 288 & 0.703 & 329 & 1.176 & 264 & 1.671 \\
\hline 296 & 0.640 & 333 & 1.218 & 263 & 1.750 \\
\hline 301 & 0.655 & 336 & 1.330 & 266 & 1.864 \\
\hline 306 & 0.672 & 341 & 1.368 & 269 & 1.965 \\
\hline 310 & 0.685 & 350 & 1.613 & 272 & 2.133 \\
\hline 306 & 1.157 & 357 & 1.839 & & \\
\hline 305 & 1.346 & 362 & 2.007 & & \\
\hline 304 & 1.663 & 363 & 2.126 & & \\
\hline 311 & 1.870 & & & & \\
\hline 316 & 2.004 & & & & \\
\hline 323 & 2.115 & & & & \\
\hline 334 & 2.381 & & & & \\
\hline 342 & 2.724 & & & & \\
\hline 350 & 3.051 & & & & \\
\hline 357 & 3.464 & & & & \\
\hline 362 & 3.847 & & & & \\
\hline
\end{tabular}


Table A.IV.9 Shear Force-Relative Displacement Data (FEM Analyses $\theta=45^{\circ}$ )

\begin{tabular}{|c|c|c|c|c|c|}
\hline \multicolumn{2}{|c|}{ F-300-100-9-25.3 } & \multicolumn{2}{|c|}{$\mathrm{S}-450-150-9-25.3$} & \multicolumn{2}{|c|}{ S-600-200-9-25.3 } \\
\hline Shear Force & R.D & Shear Force & R.D & Shear Force & R.D \\
\hline $\mathrm{V}(\mathrm{kN})$ & $\delta(\mathrm{mm})$ & $\mathrm{V}(\mathrm{kN})$ & $\delta(\mathrm{mm})$ & $\mathrm{V}(\mathrm{kN})$ & $\delta(\mathrm{mm})$ \\
\hline 0 & 0.000 & 0 & 0.001 & 0 & 0.000 \\
\hline 10 & 0.022 & 15 & 0.052 & 10 & 0.002 \\
\hline 20 & 0.046 & 30 & 0.081 & 20 & 0.004 \\
\hline 30 & 0.070 & 45 & 0.125 & 30 & 0.006 \\
\hline 40 & 0.096 & 60 & 0.178 & 40 & 0.007 \\
\hline 50 & 0.124 & 75 & 0.241 & 50 & 0.009 \\
\hline 60 & 0.153 & 90 & 0.314 & 60 & 0.010 \\
\hline 70 & 0.189 & 105 & 0.415 & 70 & 0.047 \\
\hline 80 & 0.233 & 120 & 0.612 & 80 & 0.112 \\
\hline 90 & 0.305 & 135 & 0.860 & 90 & 0.153 \\
\hline 100 & 0.417 & 150 & 1.160 & 100 & 0.180 \\
\hline 110 & 0.573 & 165 & 1.780 & 110 & 0.209 \\
\hline 120 & 0.780 & 180 & 2.210 & 120 & 0.253 \\
\hline 130 & 1.037 & & & 130 & 0.333 \\
\hline 140 & 1.237 & & & 140 & 0.493 \\
\hline 150 & 1.444 & & & 150 & 0.756 \\
\hline 160 & 1.618 & & & 160 & 1.570 \\
\hline \multirow[t]{4}{*}{170} & 1.785 & & & 170 & 2.120 \\
\hline & & & & 180 & 2.420 \\
\hline & & & & 190 & 3.040 \\
\hline & & & & 200 & 3.400 \\
\hline
\end{tabular}


Table A.IV.10 Shear Force-Relative Displacement Data (FEM Analyses $\theta=45^{\circ}$ )

\begin{tabular}{|c|c|c|c|c|c|}
\hline \multicolumn{2}{|c|}{ S-600-200-9-30 } & \multicolumn{2}{|c|}{ F-600-200-9-38 } & \multicolumn{2}{|c|}{ F-300-100-4.5-25.3 } \\
\hline Shear Force & R.D & Shear Force & R.D & Shear Force & R.D \\
\hline $\mathrm{V}(\mathrm{kN})$ & $\delta(\mathrm{mm})$ & $\mathrm{V}(\mathrm{kN})$ & $\delta(\mathrm{mm})$ & $\mathrm{V}(\mathrm{kN})$ & $\delta(\mathrm{mm})$ \\
\hline 0 & 0.001 & 0 & 0.000 & 0 & 0.000 \\
\hline 15 & 0.048 & 18 & 0.054 & 10 & 0.037 \\
\hline 29 & 0.096 & 35 & 0.118 & 20 & 0.075 \\
\hline 44 & 0.132 & 53 & 0.156 & 30 & 0.114 \\
\hline 58 & 0.179 & 70 & 0.223 & 40 & 0.157 \\
\hline 73 & 0.232 & 88 & 0.288 & 50 & 0.209 \\
\hline 87 & 0.302 & 105 & 0.359 & 60 & 0.278 \\
\hline 102 & 0.369 & 123 & 0.444 & 70 & 0.417 \\
\hline 116 & 0.466 & 140 & 0.572 & 80 & 0.603 \\
\hline 131 & 0.605 & 158 & 0.759 & 90 & 0.862 \\
\hline 145 & 0.793 & 175 & 1.090 & 100 & 1.210 \\
\hline 160 & 1.070 & 193 & 1.380 & 110 & 1.530 \\
\hline 174 & 1.360 & 210 & 1.750 & & \\
\hline 189 & 1.810 & 228 & 2.200 & & \\
\hline 203 & 2.100 & 245 & 2.820 & & \\
\hline 218 & 2.630 & 263 & 3.270 & & \\
\hline 232 & 3.130 & & & & \\
\hline
\end{tabular}


Table A.IV.10 Shear Force-Relative Displacement Data (FEM Analyses $\theta=45^{\circ}$ )

\begin{tabular}{|c|c|c|c|c|c|}
\hline \multicolumn{2}{|c|}{ F-600-200-7-25.3 } & \multicolumn{2}{|c|}{ F-600-200-4.5-25.3 } & \multicolumn{2}{|c|}{ F-900-300-13.5-25.3 } \\
\hline Shear Force & R.D & Shear Force & R.D & Shear Force & R.D \\
\hline $\mathrm{V}(\mathrm{kN})$ & $\delta(\mathrm{mm})$ & $\mathrm{V}(\mathrm{kN})$ & $\delta(\mathrm{mm})$ & $\mathrm{V}(\mathrm{kN})$ & $\delta(\mathrm{mm})$ \\
\hline 0 & 0.001 & 0 & 0.001 & 0 & 0.000 \\
\hline 15 & 0.053 & 11 & 0.047 & 16 & 0.034 \\
\hline 30 & 0.114 & 22 & 0.095 & 32 & 0.072 \\
\hline 45 & 0.174 & 33 & 0.144 & 48 & 0.109 \\
\hline 60 & 0.246 & 44 & 0.199 & 64 & 0.150 \\
\hline 75 & 0.332 & 55 & 0.261 & 80 & 0.190 \\
\hline 90 & 0.449 & 66 & 0.331 & 96 & 0.233 \\
\hline 105 & 0.659 & 77 & 0.422 & 112 & 0.270 \\
\hline 120 & 0.986 & 88 & 0.583 & 128 & 0.332 \\
\hline 135 & 1.430 & 99 & 0.858 & 144 & 0.374 \\
\hline 150 & 1.970 & 110 & 1.250 & 160 & 0.481 \\
\hline 165 & 2.580 & 121 & 1.710 & 176 & 0.569 \\
\hline 180 & 3.450 & 132 & 2.260 & 192 & 0.834 \\
\hline & & 143 & 3.090 & 208 & 0.982 \\
\hline & & & & 224 & 1.380 \\
\hline & & & & 240 & 1.730 \\
\hline & & & & 256 & 2.490 \\
\hline & & & & 272 & 2.910 \\
\hline & & & & 288 & 3.900 \\
\hline & & & & 304 & 4.380 \\
\hline
\end{tabular}


Table A.IV.11 Shear Force-Relative Displacement Data (FEM Analyses $\theta=45^{\circ}$ )

\begin{tabular}{|c|c|c|c|c|c|}
\hline \multicolumn{2}{|c|}{ F-450-150-5-30 } & \multicolumn{2}{|c|}{ F-600-200-5-30 } & \multicolumn{2}{|c|}{ F-300-100-5-30 } \\
\hline $\begin{array}{c}\text { Shear Force } \\
\text { V }(\mathrm{kN})\end{array}$ & $\begin{array}{c}\text { R.D } \\
\delta(\mathrm{mm})\end{array}$ & $\begin{array}{c}\text { Shear Force } \\
\mathrm{V}(\mathrm{kN})\end{array}$ & $\begin{array}{c}\text { R.D } \\
\delta(\mathrm{mm})\end{array}$ & $\begin{array}{c}\text { Shear Force } \\
\mathrm{V}(\mathrm{kN})\end{array}$ & $\begin{array}{c}\text { R.D } \\
\delta(\mathrm{mm})\end{array}$ \\
\hline 0 & 0.000 & 0 & 0.001 & 0 & 0.000 \\
\hline 5 & 0.016 & 5 & 0.019 & 5 & 0.014 \\
\hline 10 & 0.033 & 10 & 0.037 & 10 & 0.026 \\
\hline 16 & 0.050 & 16 & 0.055 & 16 & 0.039 \\
\hline 21 & 0.067 & 21 & 0.073 & 21 & 0.053 \\
\hline 26 & 0.084 & 26 & 0.091 & 26 & 0.067 \\
\hline 31 & 0.101 & 31 & 0.110 & 31 & 0.081 \\
\hline 36 & 0.119 & 36 & 0.128 & 36 & 0.096 \\
\hline 42 & 0.137 & 42 & 0.148 & 42 & 0.112 \\
\hline 47 & 0.156 & 47 & 0.168 & 47 & 0.130 \\
\hline 52 & 0.176 & 52 & 0.190 & 52 & 0.150 \\
\hline 57 & 0.196 & 57 & 0.213 & 57 & 0.172 \\
\hline 62 & 0.219 & 62 & 0.237 & 62 & 0.199 \\
\hline 68 & 0.244 & 68 & 0.262 & 68 & 0.235 \\
\hline 73 & 0.273 & 73 & 0.292 & 73 & 0.285 \\
\hline 78 & 0.306 & 78 & 0.319 & 78 & 0.352 \\
\hline 83 & 0.342 & 83 & 0.348 & 83 & 0.456 \\
\hline 88 & 0.394 & 88 & 0.380 & 88 & 0.579 \\
\hline 94 & 0.473 & 94 & 0.416 & 94 & 0.747 \\
\hline 99 & 0.580 & 99 & 0.462 & 99 & 0.912 \\
\hline 104 & 0.703 & 104 & 0.5411 & 104 & 1.090 \\
\hline 109 & 0.888 & 109 & 0.6684 & 109 & 1.260 \\
\hline 114 & 1.080 & 114 & 0.8204 & 114 & 1.430 \\
\hline 120 & 1.280 & 120 & 0.9834 & 120 & 1.640 \\
\hline 125 & 1.530 & 125 & 1.1614 & & \\
\hline 130 & 1.750 & 130 & 1.424 & & \\
\hline 135 & 2.000 & 135 & 1.467 & & \\
\hline \multirow[t]{5}{*}{140} & 2.340 & 140 & 1.673 & & \\
\hline & & 146 & 1.882 & & \\
\hline & & 151 & 2.096 & & \\
\hline & & 156 & 2.725 & & \\
\hline & & 161 & 3.163 & & \\
\hline
\end{tabular}


Table A.IV.12 Shear Force-Relative Displacement Data (FEM Analyses $\theta=45^{\circ}$ )

\begin{tabular}{|c|c|c|c|c|c|}
\hline \multicolumn{2}{|c|}{ F-900-300-9-25.3 } & \multicolumn{2}{|c|}{ F-1200-400-9-30 } & \multicolumn{2}{|c|}{ F-750-250-9-30 } \\
\hline Shear Force & R.D & Shear Force & R.D & Shear Force & R.D \\
\hline $\mathrm{V}(\mathrm{kN})$ & $\delta(\mathrm{mm})$ & $\mathrm{V}(\mathrm{kN})$ & $\delta(\mathrm{mm})$ & $\mathrm{V}(\mathrm{kN})$ & $\delta(\mathrm{mm})$ \\
\hline 0 & 0.000 & 0 & 0.000 & 0 & 0.000 \\
\hline 15 & 0.047 & 16 & 0.059 & 10 & 0.001 \\
\hline 31 & 0.091 & 31 & 0.090 & 20 & 0.030 \\
\hline 46 & 0.138 & 47 & 0.121 & 30 & 0.047 \\
\hline 62 & 0.189 & 63 & 0.154 & 40 & 0.071 \\
\hline 77 & 0.243 & 79 & 0.188 & 50 & 0.095 \\
\hline 92 & 0.301 & 94 & 0.226 & 60 & 0.120 \\
\hline 108 & 0.369 & 110 & 0.258 & 70 & 0.146 \\
\hline 123 & 0.487 & 126 & 0.304 & 80 & 0.173 \\
\hline 139 & 0.667 & 141 & 0.347 & 90 & 0.201 \\
\hline 154 & 1.050 & 157 & 0.418 & 100 & 0.232 \\
\hline 169 & 1.420 & 173 & 0.490 & 110 & 0.275 \\
\hline 185 & 1.880 & 188 & 0.600 & 120 & 0.316 \\
\hline 200 & 2.670 & 204 & 0.776 & 130 & 0.372 \\
\hline 216 & 3.440 & 220 & 1.130 & 140 & 0.432 \\
\hline 231 & 4.200 & 236 & 1.610 & 150 & 0.513 \\
\hline & & 251 & 2.270 & 160 & 0.691 \\
\hline & & 267 & 2.960 & 170 & 0.926 \\
\hline & & 283 & 4.000 & 180 & 1.170 \\
\hline & & 298 & 5.200 & 190 & 1.440 \\
\hline & & & & 200 & 1.770 \\
\hline & & & & 210 & 2.130 \\
\hline & & & & 220 & 2.600 \\
\hline & & & & 230 & 3.200 \\
\hline & & & & 240 & 3.700 \\
\hline
\end{tabular}


Table A.IV.10 Shear Force-Relative Displacement Data (FEM Analyses $\theta=45^{\circ}$ )

\begin{tabular}{|c|c|c|c|c|c|}
\hline \multicolumn{2}{|c|}{ S-600-200-9-30 } & \multicolumn{2}{|c|}{ F-600-200-9-38 } & \multicolumn{2}{|c|}{ F-300-100-4.5-25.3 } \\
\hline Shear Force & R.D & Shear Force & R.D & Shear Force & R.D \\
\hline $\mathrm{V}(\mathrm{kN})$ & $\delta(\mathrm{mm})$ & $\mathrm{V}(\mathrm{kN})$ & $\delta(\mathrm{mm})$ & $\mathrm{V}(\mathrm{kN})$ & $\delta(\mathrm{mm})$ \\
\hline 0 & 0.001 & 0 & 0.000 & 0 & 0.000 \\
\hline 15 & 0.048 & 18 & 0.054 & 10 & 0.037 \\
\hline 29 & 0.096 & 35 & 0.118 & 20 & 0.075 \\
\hline 44 & 0.132 & 53 & 0.156 & 30 & 0.114 \\
\hline 58 & 0.179 & 70 & 0.223 & 40 & 0.157 \\
\hline 73 & 0.232 & 88 & 0.288 & 50 & 0.209 \\
\hline 87 & 0.302 & 105 & 0.359 & 60 & 0.278 \\
\hline 102 & 0.369 & 123 & 0.444 & 70 & 0.417 \\
\hline 116 & 0.466 & 140 & 0.572 & 80 & 0.603 \\
\hline 131 & 0.605 & 158 & 0.759 & 90 & 0.862 \\
\hline 145 & 0.793 & 175 & 1.090 & 100 & 1.210 \\
\hline 160 & 1.070 & 193 & 1.380 & 110 & 1.530 \\
\hline 174 & 1.360 & 210 & 1.750 & & \\
\hline 189 & 1.810 & 228 & 2.200 & & \\
\hline 203 & 2.100 & 245 & 2.820 & & \\
\hline 218 & 2.630 & 263 & 3.270 & & \\
\hline 232 & 3.130 & & & & \\
\hline
\end{tabular}


Table A.IV.10 Shear Force-Relative Displacement Data (FEM Analyses $\theta=45^{\circ}$ )

\begin{tabular}{|c|c|c|c|c|c|}
\hline \multicolumn{2}{|c|}{ F-600-200-7-25.3 } & \multicolumn{2}{|c|}{ F-600-200-4.5-25.3 } & \multicolumn{2}{|c|}{ F-900-300-13.5-25.3 } \\
\hline Shear Force & R.D & Shear Force & R.D & Shear Force & R.D \\
\hline $\mathrm{V}(\mathrm{kN})$ & $\delta(\mathrm{mm})$ & $\mathrm{V}(\mathrm{kN})$ & $\delta(\mathrm{mm})$ & $\mathrm{V}(\mathrm{kN})$ & $\delta(\mathrm{mm})$ \\
\hline 0 & 0.001 & 0 & 0.001 & 0 & 0.000 \\
\hline 15 & 0.053 & 11 & 0.047 & 16 & 0.034 \\
\hline 30 & 0.114 & 22 & 0.095 & 32 & 0.072 \\
\hline 45 & 0.174 & 33 & 0.144 & 48 & 0.109 \\
\hline 60 & 0.246 & 44 & 0.199 & 64 & 0.150 \\
\hline 75 & 0.332 & 55 & 0.261 & 80 & 0.190 \\
\hline 90 & 0.449 & 66 & 0.331 & 96 & 0.233 \\
\hline 105 & 0.659 & 77 & 0.422 & 112 & 0.270 \\
\hline 120 & 0.986 & 88 & 0.583 & 128 & 0.332 \\
\hline 135 & 1.430 & 99 & 0.858 & 144 & 0.374 \\
\hline 150 & 1.970 & 110 & 1.250 & 160 & 0.481 \\
\hline 165 & 2.580 & 121 & 1.710 & 176 & 0.569 \\
\hline 180 & 3.450 & 132 & 2.260 & 192 & 0.834 \\
\hline & & 143 & 3.090 & 208 & 0.982 \\
\hline & & & & 224 & 1.380 \\
\hline & & & & 240 & 1.730 \\
\hline & & & & 256 & 2.490 \\
\hline & & & & 272 & 2.910 \\
\hline & & & & 288 & 3.900 \\
\hline & & & & 304 & 4.380 \\
\hline
\end{tabular}


Table A.IV.11 Shear Force-Relative Displacement Data (FEM Analyses $\theta=45^{\circ}$ )

\begin{tabular}{|c|c|c|c|c|c|}
\hline \multicolumn{2}{|c|}{ F-450-150-5-30 } & \multicolumn{2}{|c|}{ F-600-200-5-30 } & \multicolumn{2}{|c|}{ F-300-100-5-30 } \\
\hline Shear Force & R.D & Shear Force & R.D & Shear Force & R.D \\
\hline $\mathrm{V}(\mathrm{kN})$ & $\delta(\mathrm{mm})$ & $\mathrm{V}(\mathrm{kN})$ & $\delta(\mathrm{mm})$ & $\mathrm{V}(\mathrm{kN})$ & $\delta(\mathrm{mm})$ \\
\hline 0 & 0.000 & 0 & 0.001 & 0 & 0.000 \\
\hline 5 & 0.016 & 5 & 0.019 & 5 & 0.014 \\
\hline 10 & 0.033 & 10 & 0.037 & 10 & 0.026 \\
\hline 16 & 0.050 & 16 & 0.055 & 16 & 0.039 \\
\hline 21 & 0.067 & 21 & 0.073 & 21 & 0.053 \\
\hline 26 & 0.084 & 26 & 0.091 & 26 & 0.067 \\
\hline 31 & 0.101 & 31 & 0.110 & 31 & 0.081 \\
\hline 36 & 0.119 & 36 & 0.128 & 36 & 0.096 \\
\hline 42 & 0.137 & 42 & 0.148 & 42 & 0.112 \\
\hline 47 & 0.156 & 47 & 0.168 & 47 & 0.130 \\
\hline 52 & 0.176 & 52 & 0.190 & 52 & 0.150 \\
\hline 57 & 0.196 & 57 & 0.213 & 57 & 0.172 \\
\hline 62 & 0.219 & 62 & 0.237 & 62 & 0.199 \\
\hline 68 & 0.244 & 68 & 0.262 & 68 & 0.235 \\
\hline 73 & 0.273 & 73 & 0.292 & 73 & 0.285 \\
\hline 78 & 0.306 & 78 & 0.319 & 78 & 0.352 \\
\hline 83 & 0.342 & 83 & 0.348 & 83 & 0.456 \\
\hline 88 & 0.394 & 88 & 0.380 & 88 & 0.579 \\
\hline 94 & 0.473 & 94 & 0.416 & 94 & 0.747 \\
\hline 99 & 0.580 & 99 & 0.462 & 99 & 0.912 \\
\hline 104 & 0.703 & 104 & 0.5411 & 104 & 1.090 \\
\hline 109 & 0.888 & 109 & 0.6684 & 109 & 1.260 \\
\hline 114 & 1.080 & 114 & 0.8204 & 114 & 1.430 \\
\hline 120 & 1.280 & 120 & 0.9834 & 120 & 1.640 \\
\hline 125 & 1.530 & 125 & 1.1614 & & \\
\hline 130 & 1.750 & 130 & 1.424 & & \\
\hline 135 & 2.000 & 135 & 1.467 & & \\
\hline 140 & 2.340 & 140 & 1.673 & & \\
\hline & & 146 & 1.882 & & \\
\hline & & 151 & 2.096 & & \\
\hline & & 156 & 2.725 & & \\
\hline & & 161 & 3.163 & & \\
\hline
\end{tabular}


Table A.IV.12 Shear Force-Relative Displacement Data (FEM Analyses $\theta=45^{\circ}$ )

\begin{tabular}{|c|c|c|c|c|c|}
\hline \multicolumn{2}{|c|}{ F-900-300-9-25.3 } & \multicolumn{2}{|c|}{ F-1200-400-9-30 } & \multicolumn{2}{|c|}{ F-750-250-9-30 } \\
\hline Shear Force & R.D & Shear Force & R.D & Shear Force & R.D \\
\hline $\mathrm{V}(\mathrm{kN})$ & $\delta(\mathrm{mm})$ & $\mathrm{V}(\mathrm{kN})$ & $\delta(\mathrm{mm})$ & $\mathrm{V}(\mathrm{kN})$ & $\delta(\mathrm{mm})$ \\
\hline 0 & 0.000 & 0 & 0.000 & 0 & 0.000 \\
\hline 15 & 0.047 & 16 & 0.059 & 10 & 0.001 \\
\hline 31 & 0.091 & 31 & 0.090 & 20 & 0.030 \\
\hline 46 & 0.138 & 47 & 0.121 & 30 & 0.047 \\
\hline 62 & 0.189 & 63 & 0.154 & 40 & 0.071 \\
\hline 77 & 0.243 & 79 & 0.188 & 50 & 0.095 \\
\hline 92 & 0.301 & 94 & 0.226 & 60 & 0.120 \\
\hline 108 & 0.369 & 110 & 0.258 & 70 & 0.146 \\
\hline 123 & 0.487 & 126 & 0.304 & 80 & 0.173 \\
\hline 139 & 0.667 & 141 & 0.347 & 90 & 0.201 \\
\hline 154 & 1.050 & 157 & 0.418 & 100 & 0.232 \\
\hline 169 & 1.420 & 173 & 0.490 & 110 & 0.275 \\
\hline 185 & 1.880 & 188 & 0.600 & 120 & 0.316 \\
\hline 200 & 2.670 & 204 & 0.776 & 130 & 0.372 \\
\hline 216 & 3.440 & 220 & 1.130 & 140 & 0.432 \\
\hline 231 & 4.200 & 236 & 1.610 & 150 & 0.513 \\
\hline & & 251 & 2.270 & 160 & 0.691 \\
\hline & & 267 & 2.960 & 170 & 0.926 \\
\hline & & 283 & 4.000 & 180 & 1.170 \\
\hline & & 298 & 5.200 & 190 & 1.440 \\
\hline & & & & 200 & 1.770 \\
\hline & & & & 210 & 2.130 \\
\hline & & & & 220 & 2.600 \\
\hline & & & & 230 & 3.200 \\
\hline & & & & 240 & 3.700 \\
\hline
\end{tabular}

